University of Louisville

ThinkIR: The University of Louisville's Institutional Repository

Electronic Theses and Dissertations

8-2017

\title{
BDNF-TRKB signaling regulates adult taste bud innervation.
}

Tao Tang

University of Louisville

Follow this and additional works at: https://ir.library.louisville.edu/etd

Part of the Medicine and Health Sciences Commons

\section{Recommended Citation}

Tang, Tao, "BDNF-TRKB signaling regulates adult taste bud innervation." (2017). Electronic Theses and Dissertations. Paper 2762.

https://doi.org/10.18297/etd/2762

This Doctoral Dissertation is brought to you for free and open access by ThinkIR: The University of Louisville's Institutional Repository. It has been accepted for inclusion in Electronic Theses and Dissertations by an authorized administrator of ThinkIR: The University of Louisville's Institutional Repository. This title appears here courtesy of the author, who has retained all other copyrights. For more information, please contact thinkir@louisville.edu. 


\title{
BDNF-TRKB SIGNALING REGULATES ADULT TASTE BUD INNERVATION
}

By

\author{
Tao Tang \\ B.S., East china university of Technology, 2010 \\ M.S., University of Louisville, 2015 \\ A Dissertation \\ Submitted to the Faculty of the \\ School of Medicine of the University of Louisville \\ In Partial Fulfillment of the Requirements \\ For the degree of
}

Doctor of Philosophy in Anatomical Sciences and Neurobiology

\author{
Department of Anatomical Sciences and Neurobiology \\ University of Louisville \\ Louisville, Kentucky
}

August 2017 

BDNF-TRKB SIGNALING REGULATES ADULT TASTE BUD INNERVATION

\author{
By \\ Tao Tang \\ B.S., East china university of Technology, 2010 \\ M.S., University of Louisville, 2015 \\ A Dissertation Approved on
}

April 12, 2017

by the following Dissertation Committee:

Robin Krimm, Ph.D.; Dissertation Director

Jeffrey Petruska, Ph.D.

Jun Cai, Ph.D.

Martha Bickford, Ph.D.

Robert Lundy, Ph.D 


\title{
DEDICATION
}

This dissertation is dedicated to my parents

\author{
Mr. Junhua Tang, Mrs. Chunlian Qiu \\ and my wife \\ Jiaan Yan \\ for their tremendous love and support.
}




\section{ACKNOWLEDGEMENTS}

I would like to express my sincere gratitude to my mentor, Dr. Robin Krimm, for her excellent guidance and patience. I would also like to thank the other committee members, Dr's. Martha Bickford, Robert Lundy, Jeffrey Petruska and Jun Cai, for their guidance and support over the past four years.

I would also like to thanks Dr. Tao Huang, Liqun Ma, Lisa Christina Ohman for their help on my research projects. Additional thanks to my fellow labmates and friends: Dr. Lingbin Meng, Biggs Bradley, Jennifer Rios-Pilier, and many others outside the lab and department, for their support and friendship.

Finally, I would like to thank my family for supporting me spiritually throughout my life. Especially for my grandfather supporting, who I was grew up until I came to USA to pursue my Ph.D study. 
ABSTRACT

BDNF-TRKB SIGNALING REGULATES ADULT TASTE BUD INNERVATION Tao Tang

March $27^{\text {th }} 2017$

Taste receptor cells transduce stimuli transmitting information to gustatory neurons that carry it to the brain. They turn-over continuously in adulthood, and must be constantly reinnervated, making the maintenance of innervation to taste buds an active process mediated by many factors, including brain-derived neurotrophic factor (BDNF). Taste bud innervation (40\%) is lost when Bdnf is removed during adulthood, but it is unclear why remaining fibers were not lost. We found that some gustatory nerve fibers remained because they lack the TrkB receptor $55 \%$ of TrkB-labeled fibers were lost and fibers without TrkB remained following adult Bdnf gene recombination.

It is unclear if BDNF has a direct function on the nerve fibers or could influence innervation indirectly by binding to taste bud cells, nor has it been determined which receptors mediate BDNF's effects. BDNF functions through two receptors-TrkB and p75; furthermore TrkB has a truncated (TrkBT1) and full length form. Rt-PCR and immunohistochemistry determined that the full length TrkB receptor is expressed in the geniculate ganglion, but not in the taste buds, and both taste buds and the geniculate ganglion express TrkBT1 and p75. Furthermore, TrkBT1 was expressed in multiple types of taste bud cells. Finally, BDNF regu- 
lates TrkBT1 expression in the taste bud. We conclude that BDNF signaling via the full length TrkB receptor can only occur at nerve fibers, but BDNF could influence innervation indirectly via TrkBT1 or p75 expressed in taste receptors.

Next we sought to determine whether BDNF functions through the full length TrkB receptor with a timing consistent with BDNF regulation of innervation during receptor cell turnover. A chemical genetic approach to block TrkBsignaling was combined with genetic labeling of subset of TrkB+ fibers to examine branching patterns in the taste bud. After blocking TrkB signaling for 2 weeks fewer taste buds are innervated by labeled TrkB-positive fibers and there was less labeled TrkB+ innervation in taste buds. Blocking TrkB signaling reduced the numbers of branches, and some higher order branches also become shorter. We conclude that BDNF functions through TrkB, encouraging fiber growth and branching with a timing consistent with TrkB-regulation of innervation to new taste receptor cells during renewal. 


\section{TABLE OF CONTENTS}

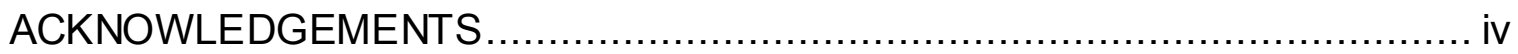

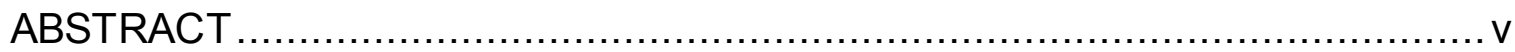

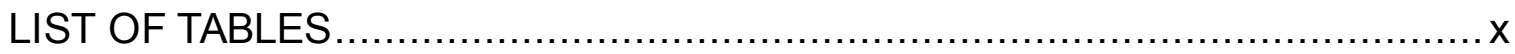

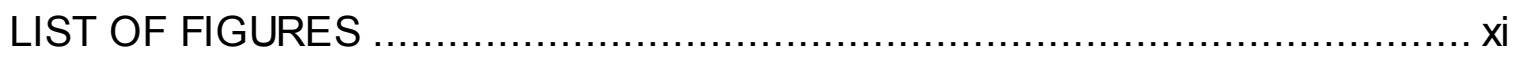

CHAPTERS

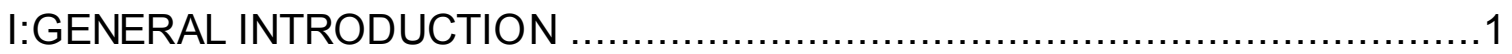

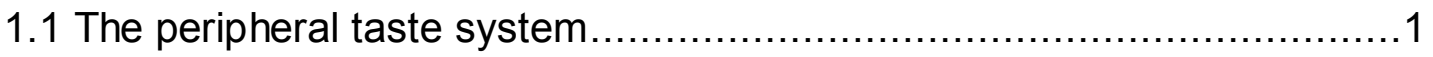

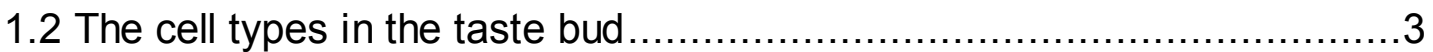

1.3 The role of neurotrophins in taste system development .......................

1.4 The expression and role of neurotrophins in the adult taste system ......10

1.5 The receptors for BDNF and their functions. ................................11

1.6 Neurotrophin (BDNF) regulation of axon/dendritic branching ...............15

II: TASTE BUD-DERIVED BDNF MAINTAINS INNERVATION OF A SUBSET OF TRKB-EXPRESSING GUSTATORY NERVE FIBERS

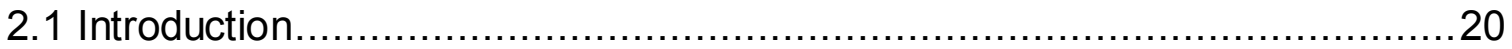

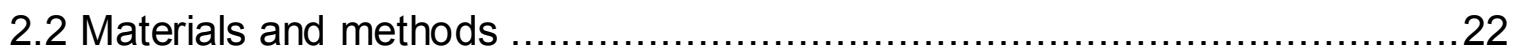

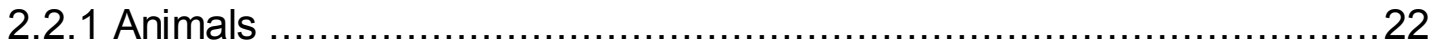

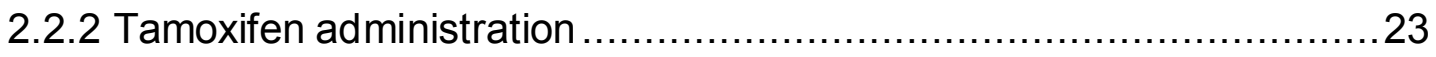

2.2.3 Laser capture microdissection, RNA extraction, and cDNA amplification

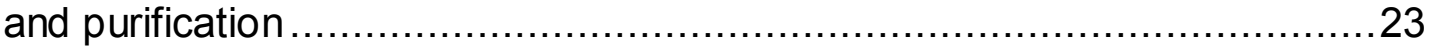

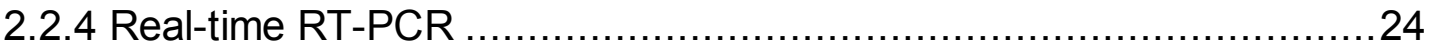

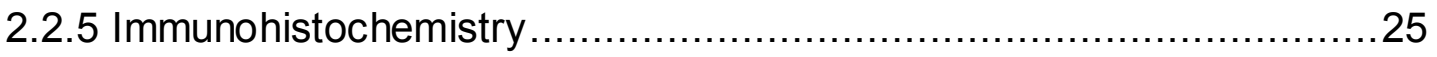

2.2.6 Quantification of taste bud innervation and volume ........................26

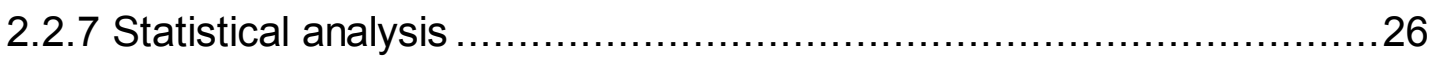

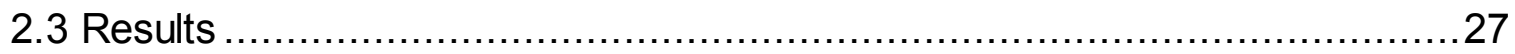

2.3.1 Taste bud innervation can be divided into TrkB-positive and TrkB-

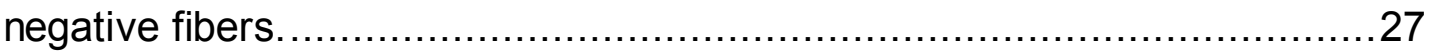

2.3.3 BDNF regulates TrkB-positive but not TrkB-negative innervation within taste buds. 
2.3.4 BDNF removal reduced expression of the $\mathrm{Y}$ subunit of the $\mathrm{ENaC}$

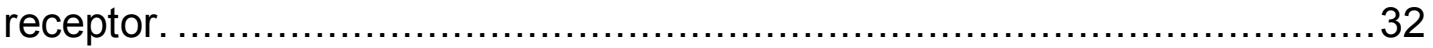

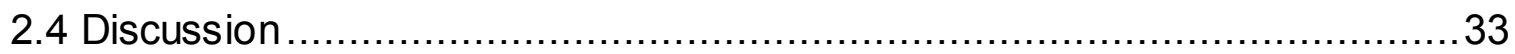

III: FULL LENGTH TRKB RECEPTOR IS EXPRESSED IN THE GENICULATE GANGLION NEURONS, WHILE NOT IN TASET BUDS

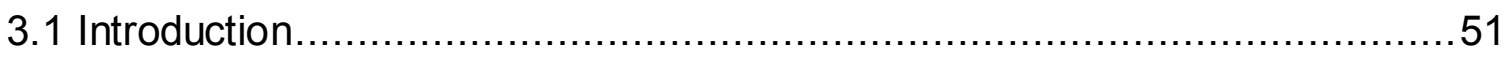

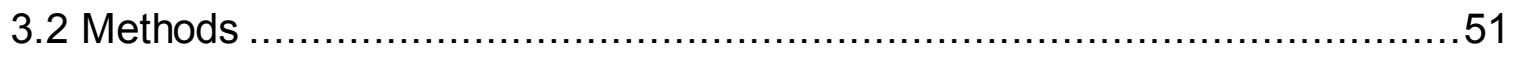

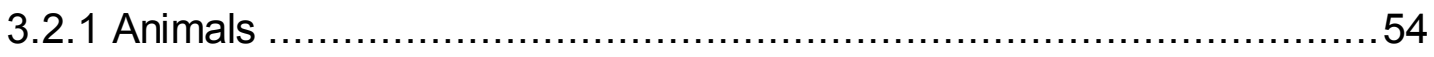

3.2.2 Laser capture microdissection, RNA extraction, cDNA amplification and

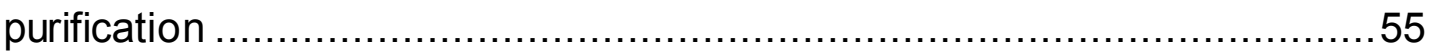

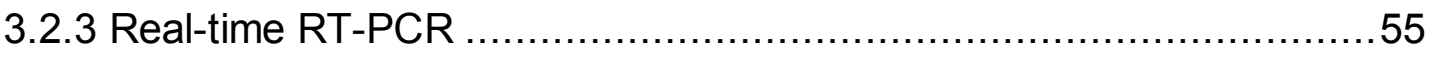

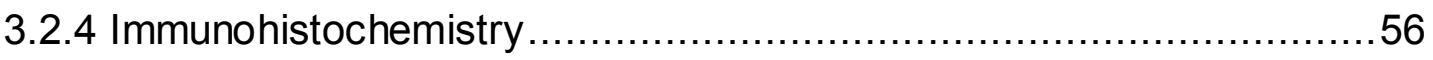

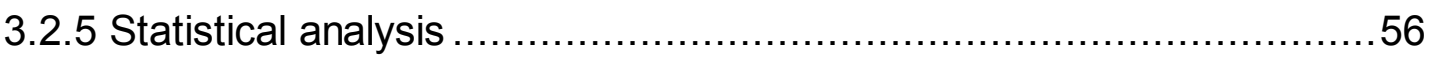

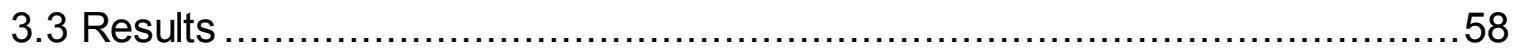

3.3.1 Both taste buds and geniculate ganglion expressed the TrkB and p75

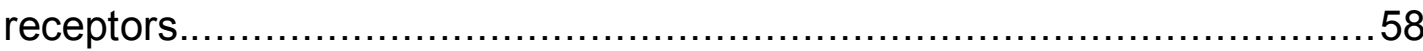

3.3.2 Both the full length TrkB and TrkBT1 receptors are expressed in geniculate ganglia, while only the TrkBT1 receptor is expressed in taste buds.

3.3.3 The TrkBT1 receptor is expressed in multiple types of taste bud cells. 61

3.3.4 BDNF regulates the expression of the TrkBT1 receptor, but not the full length TrkB receptor in the circumvallate taste buds.............................62

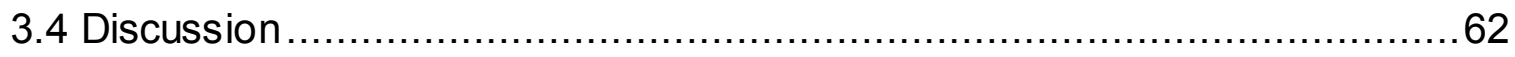
IV:BLOCKING TRKB-SIGNALING DECREASES BRANCHES WITHIIN THE TASTE BUD WITHIN TWO WEEKS

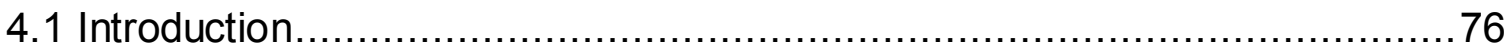

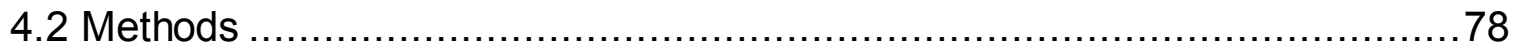

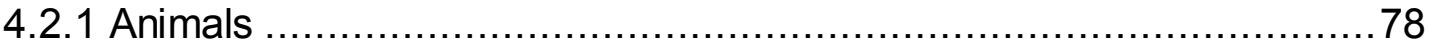

4.2.2 Tamoxifen and 1NM-PP1 administration ....................................79

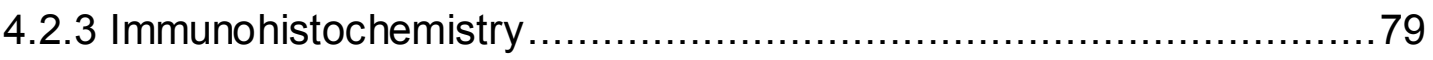

4.2.4 Quantification of the number of taste buds innervated by labeled TrkB-

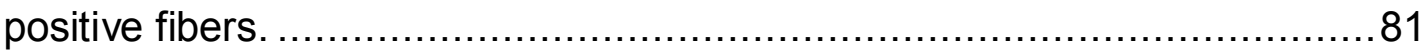

4.2.5 Quantification of TrkB-positive fiber branching within the taste bud. ...81

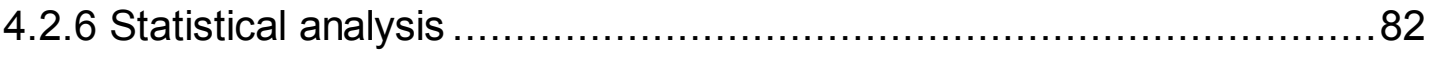

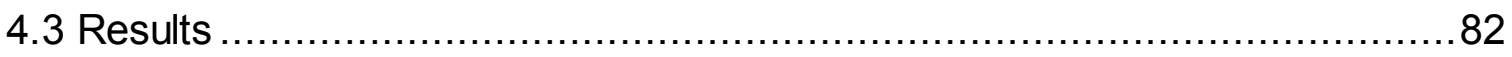


4.3.1 Fewer taste buds are innervated by labeled TrkB-positive fibers when

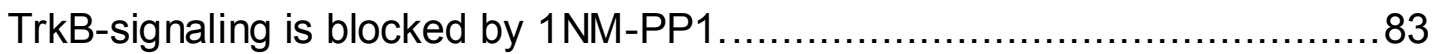

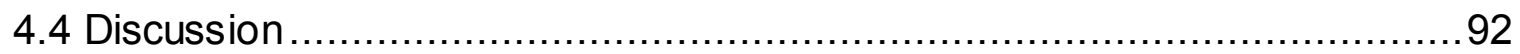

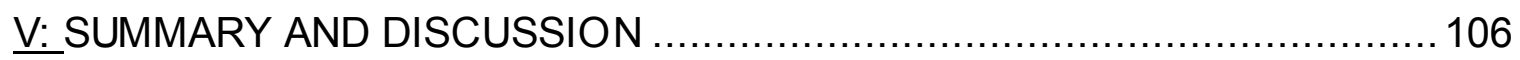

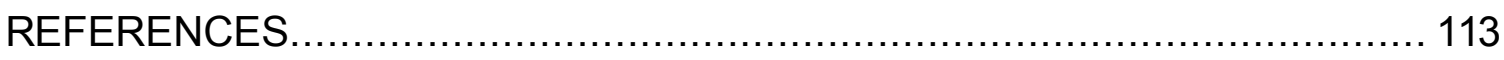

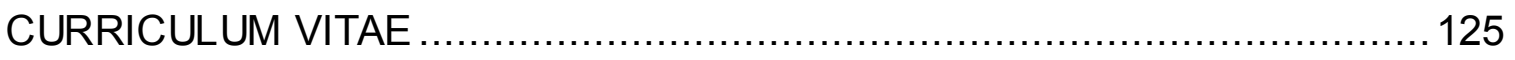




\section{LIST OF TABLES}

\section{TABLE}

PAGE

1. Sequences of primer pairs and probes used for real-time RT-PCR ..........38

2. Sequences of primer pairs and probes used for real-time RT-PCR ..........67 


\section{LIST OF FIGURES}

1. Not all P2X3-positive fibers are labeled with TrkB in fungiform taste buds.

2. Bdnf gene expression in taste buds is reduced by inducible K14-CreERmediated gene recombination in lingual epithelial cells after 3 weeks of tamoxifen administration

3. Fungiform taste buds appear to lose both P2X3-positive and TrkB-positive innervation when Bdnf is inducibly removed from the adult lingual epithelium.

4. The total amount of innervation to taste buds is reduced due to a loss of TrkBpositive taste fibers. .46

5. Inducibly removing Bdnf from the epithelium reduced expression of the $Y$ subunit of the ENaC channel but did not affect expression of $\alpha$ and $\beta$ subunits.

6. The TrkB and $p 75$ receptors are expressed in the geniculate ganglion and taste buds.

69

Figure 7. Geniculate ganglia express both full length TrkB and TrkBT1 receptors, while taste buds only expressed the TrkBT1 receptor. 
Figure 8. The TrkBT1 receptor is expressed in both Car4- and PLCß2-positive taste bud cells.

Figure 9. BDNF regulates the expression of TrkBT1, but not the full length receptor in the circumvallate taste buds. .74

Figure 10. Fungiform taste buds appear to have less TrkB-positive or no TrkBpositive innervation when TrkB signaling is blocked by 1NM-PP1.

Figure 11. TrkB-positive innervation to the taste bud decreases when TrkB signaling is blocked. .99

Figure 12. Quantification of TrkB-positive fiber branching within taste buds. 101

Figure 13. Innervation is lost in the taste bud with reduction of TrkB-signaling due to a loss of fiber branches. 102

Figure 14. The longest secondary and tertiary branches were lost disproportionately when TrkB-signaling is blocked. 104

Figure 15. A model illustrating how we think BDNF-TrkB signaling functions in the adult taste system. 


\section{CHAPTER I}

\section{GENERAL INTRODUCTION}

\subsection{The peripheral taste system}

There are five basic senses in vertebrate animals: taste, sight, smell, touch and hearing. Taste includes five basic taste qualities: sweet, umami, bitter, sour and salty, which are detected by taste buds. In mammals, taste buds are located in the specialized structures on the tongue, called papillae. Taste buds are also located in the nasoincisive papilla and eminences on the soft palate. There are three types of papillae on the tongue which are located in different regions of the tongue surface. Fungiform papillae are located at the anterior twothirds of the tongue, foliate papillae are placed on the lateral margins of the tongue, circumvallate papillae are situated on the posterior part of the tongue (Hill, 2004; Krimm, 2007). Taste buds in the different types of papillae are innervated by distinct nerves. Taste buds in the fungiform papillae are innervated by the chorda tympani nerve, whose cell bodies are located in the geniculate ganglion. Taste buds in the incisive papilla and soft palate are innervated by the greater superficial petrosal nerve, which also originated from the geniculate ganglion; The geniculate ganglion also provides somatosensory innervation to the skin of the external ear (Krimm, 2007). Taste buds in the circumvallate and foliate papillae are innervated by glossopharyngeal nerve, which has cell bodies 
located in the petrosal ganglion. The petrosal ganglion also contains other chemoreceptors such as baroreceptor neurons, which innervate the cardiac outflow tract to monitor blood pressure. Both geniculate and petrosal ganglia transmit taste information to the nucleus of the solitary tract (NST). Taste information is passed from the parabrachial nucleus (in rodents) into the thalamus, then the thalamus relays the information to the primary gustatory cortex in the insula (Carleton et al., 2010).

Taste stimuli are detected by taste cells, which release neurotransmitters that transmit the taste information to nerve fibers. It have been shown that several neurotransmitters were found in the taste buds, including acetylcholine, Adenosine triphosphate (ATP), glutamate, serotonin (5-HT), $\mathrm{Y}$-aminobutyric acid (GABA) (Nagahama and Kurihara, 1985; Nagai et al., 1998; Huang et al., 2007; Murata et al., 2010; Starostik et al., 2010). ATP is a key neurotransmitter in the taste system. Most geniculate neurons (98.4\%) express one type receptor of ATP (P2X3) and more than half of geniculate neurons express another receptor of ATP (P2X2) (Ishida et al., 2009). Taste cells release ATP to activate P2X2 and P2X3 receptors on gustatory nerve fibers when taste cells received the taste stimuli (Finger et al., 2005). Double knockout of the P2X2 and P2X3 receptors eliminate taste responses from gustatory nerve fibers, but the responses to the temperature, menthol and touch remain (Finger et al., 2005). A recent study reported that $5-\mathrm{HT}$ released from type III cells also activates gustatory nerve fibers through 5- $\mathrm{HT}_{3}$ receptors (Larson et al., 2015). Specifically, taste nerve responses to acids and other taste stimuli are significant reduced when $5-\mathrm{HT}_{3}$ receptors are 
blocked or following genetic deletion of $5-\mathrm{HT}_{3}$ receptors. Therefore, both ATP and 5-HT are important neurotransmitters connecting the taste cells to gustatory nerve fibers (Finger et al., 2005; Huang et al., 2007; Ishida et al., 2009; Murata et al., 2010; Larson et al., 2015).

Taste bud cells have a plastic feature. Taste bud cells have a limited lifespan and continuously turn over throughout the animal's life (Beidler and Smallman, 1965; Perea-Martinez et al., 2013). The functional connections between the cells and nerve fibers are lost when a taste cell dies. When new taste bud cells enter the taste buds, they must be innervated by nerve fibers and form new connections with gustatory neurons. Thus, there is an active process for maintaining innervation between taste buds and nerve fibers in adulthood. This process may retain many features of a developing system. However, it is unclear what the mechanism/s for the maintenance of innervation is, and which factors regulate the constant reinnervation of new taste cells by nerve fibers. It's possible that neurotrophins may be involved in adult innervation of the taste bud, since neurotrophins have this role during the development.

1.2 The cell types in the taste bud

Taste buds are an onion-shaped end organ which contain 50-100 taste cells, depends on the species (Finger, 2005). Taste cells can be categorized into different cell types based on their function, ultrastructure or light microscope markers (Farbman, 1965; Murray et al., 1969; Kinnamon et al., 1985). Using ultrastructural criteria, taste cells are classified into various types, including undif- 
ferentiated peripheral cells, type I ("dark") cells, type II ("light") (receptor) cells, type III cells, type IV (basal) cells and intermediate cells.

Type I (dark) cells are slender cells with moderately expanded nuclear regions based primarily on the electron-density of the cytoplasm (Murray and Murray, 1967; Delay et al., 1986; Nelson and Finger, 1993; Pumplin et al., 1997). No synaptic connections associated with type I cells have been observed. Type I cells are also called "support cells", because Type I cells are thought to have a glial like supportive function in taste buds, and may function to clear neurotransmitters and ensheath other taste cells (Pumplin et al., 1997). They can be detected by the expression of a glial glutamate/aspartate transporter (GLAST) and nucleoside triphosphate diphosphohydrolase 2 (NTPDase 2) (Bartel et al., 2006).

Type II (light) (receptor) taste cells have a characteristic large, round nucleus and electron-lucent cytoplasm (Pumplin et al., 1997). At the molecular level, a subset of Type II cells show immunoreactivity for the phospholipase C- $\beta 2$ (PLC $\beta 2$ ), a principal G protein-coupled receptors (GPCRs) effector, involved in intracellular signaling for transducing sweet, bitter or umami (Hoon et al., 1999; Miyoshi et al., 2001; Finger et al., 2005). It can be divided into multiple subtypes based on the stimuli they transduce (sweet, umami and bitter). These taste cells express the G-protein coupled receptors (TAS1R and TAS2R family) and share a common intracellular signal transduction pathway. Sweet taste is mediated by T1R2 and T1R3 (Li et al., 2002; Zhao et al., 2003), umami taste is detected by T1R1 and T1R3 (Li et al., 2002; Zhao et al., 2003), bitter taste is regulated by T2Rs family of receptors (Adler et al., 2000). After sweet, bitter, or umami stimuli 
bind to G-protein couple receptors, phospholipase C- $\beta 2$ (PLC $\beta 2)$ is activated, $\mathrm{Ca} 2+$ is released from endoplasmic reticulum, and $\mathrm{Ca} 2+$ stores activate the TRPM5 channel. Activation of this pathway depolarizes the membrane resulting in ATP release by CALHM1 ion channel (Taruno et al., 2013a). Sweet, amino acid and low- and midrange concentrations of bitter reception are abolished in PLCß2 knockout mice (Zhang et al., 2003). But PLC $\beta 2$ knockout mice significantly avoid licking higher concentrations of bitter compounds, which suggest that higher concentrations of bitter taste mediated by a PLC $\beta 2$-independent taste transduction pathway (Dotson et al., 2005). However, Type II cells do not form synapses onto nerve fibers (Clapp et al., 2004). It has been shown that Type II cells secrete ATP as a neurotransmitter onto sensory afferent fibers via voltagegated CALHM1-associated ion channels in their surface membrane (Taruno et al., 2013b; Ma et al., 2017)

Type III cells have a slender shape with a moderately electron-lucent cytoplasm. Type III cells are the only cell type forming synaptic contacts onto nerve processes in rodent taste buds (Takeda and Hoshino, 1975; Takeda, 1976). Type III cells do not secrete ATP, but release serotonin, norepinephrine, and GABA (Huang et al., 2007; Huang et al., 2008a; Dvoryanchikov et al., 2011; Huang et al., 2011). Type III cells do not express G-protein coupled receptors, but they do show the immunoreactivity for carbonic anhydrase 4 (Car4) (Chandrashekar et al., 2009), neuronal cell adhesion molecule (NCAM) (Nelson and Finger, 1993), presynaptic plasma membrane synaptosomal-associated protein 25 (SNAP25) (Yang et al., 2000), serotonin (5-HT) and voltage-gated calci- 
um channels (Medler et al., 2003). Type III cells exhibit responsiveness to sour taste stimuli (Huang et al., 2008b). Sour taste is mediated in part by two transient receptor potential (TRP) ion channel members, polycystic-kidney-disease 1L3 and 2L1 (Huang et al., 2006; Ishimaru et al., 2006), and at least one unidentified mechanism, since only $25 \%-45 \%$ of sour taste responses are reduced in PKD2L1 and PKD1L3 gene double knockout mice (Horio et al., 2011).

Type IV cells are located in the basolateral region of taste buds. These cells are small, irregular, and similar to peripheral cells in morphology. These cells are considered to be the precursor cells for other taste cell types in taste buds (Beidler and Smallman, 1965; Conger and Wells, 1969; Farbman, 1980). These populations are believed to provide new taste bud cells during the continuous process of taste bud cell renewal. Type IV cells include the stem and progenitor cells. Taste bud cells are thought to be derived from a common K14+ population of bipotential progenitor cells located outside the taste bud (Okubo et al., 2009). However, a recent study shows that some taste bud cells are derived from connective tissue cells which do not express K14 (Boggs et al., 2016).

In addition to taste qualities, sweet, umami, bitter, and sour, salt taste is also detected by taste cells. Salt taste transduction also occurs through multiple known and unknown mechanisms including an ion channel, the epithelial sodium channel (ENaC) (Chandrashekar et al., 2010), which includes three subunit- $\alpha, \beta$ and $\mathrm{V}$, which taste receptor cells express this channel is unclear (Kretz et al., 1999; Chandrashekar et al., 2010). A recent study shows that Angiotensin II modulates salt taste sensitivity, and it's receptor, angiotensin II type 1 receptor 
(AT1) are coexpressed with aENaC and type I cell marker GLAST in the taste bud (Shigemura et al., 2013). These finding suggests that some of type I cells may respond to salt stimuli.

1.3 The role of neurotrophins in taste system development

During geniculate ganglion development, neurons are produced and added quickly (Altman and Bayer, 1982), then neuron cell number is decreased from E12.5 to E14.5 in mice (Patel and Krimm, 2010). Thus, like most regions of the nervous system, the geniculate ganglion overproduces neurons first and then reduces the number by cell death (Carr et al., 2005). Once taste neurons of geniculate ganglion are differentiated, they project axons from geniculate neurons to the tongue surface by a restricted pathway (Mbiene and Mistretta, 1997). By E14.5, chorda tympani nerves reach the tongue epithelium and form a nerve ending in the developing taste buds (Lopez and Krimm, 2006b). Many molecular cues likely regulate axon guidance of these neurons but only a few, such as Semin3A (Vilbig et al., 2004), have been identified.

Among the many factors which play an important role during the taste neuron development are the neurotrophins. Neurotrophins regulate multiple developmental processes including neuron survival, differentiation, dendritic pruning and patterning of innervation (Huang and Reichardt, 2001). There are four members of the neurotrophin family in mammals, nerve growth factor (NGF), brain-derived neurotrophic factor (BDNF), neurotrophin-3 (NT-3), and neurotrophin-4 (NT-4) (Huang and Reichardt, 2001). The neurotrophins bind to two types of receptors, the p75 neurotrophin receptor and Trk receptors, which are tyrosine 
kinases receptors. Specifically, all four neurotrophin ligands bind to p75 receptors, and NGF binds TrkA; BDNF and NT-4 bind TrkB; and NT-3 mainly binds TrkC (Huang and Reichardt, 2001).

In the taste system, most of studies focus on BDNF and NT-4. The development of the geniculate ganglion and the formation of peripheral connections are highly regulated by BDNF and NT-4 and its receptors (Fritzsch et al., 1997; Zhang et al., 1997; Krimm et al., 2001; Lopez and Krimm, 2006b; Ma et al., 2009; Patel et al., 2010; Patel and Krimm, 2010; Fei and Krimm, 2013; Fei et al., 2014; Huang and Krimm, 2014). BDNF and NT-4 play a critical role in regulating the number of geniculate neurons during development (Patel and Krimm, 2010, 2012). Specifically, geniculate neurons are increased during development when mice overexpress BDNF or NT-4 (Lopez and Krimm, 2006b). Geniculate neurons are lost by about $50 \%$ during the development when Bdnf or Ntf4 are removed in mice (Patel et al., 2010; Patel and Krimm, 2010), but double mutants of Bdnf and Ntf4 lose about 90\% geniculate neurons from E13.5- E18.5 (Patel et al., 2010). $\mathrm{TrkB}^{-/}$mice lose approximately $95 \%$ of their geniculate neurons during development (Fritzsch et al., 1997; Fei and Krimm, 2013). In addition, embryonic $p 75^{1-}$ mice lose geniculate ganglion neurons beginning on E14.5 (Fei et al., 2014). Taken together, these findings suggest that neurotrophins and their receptors are important for the development of geniculate neurons.

In addition to regulation of neuronal survival, neurotrophins also mediate target innervation, axon elongation and synapse formation in many sensory systems (McCarty and Feinstein, 1998; Righi et al., 2000; Sommerfeld et al., 2000). 
In the taste system, BDNF regulates taste nerve outgrowth and guidance to the final target during the development in vitro (Hoshino et al., 2010). In vivo, overexpressing BDNF in non-taste epithelium results in non-taste filiform papillae becoming innervated by taste fibers, which indicate that BDNF is attracts the chorda tympani nerve to incorrect locations in the tongue (Lopez and Krimm, 2006b). Gustatory axons also fail to correctly innervate fungiform papillae after BDNF removal during the development, which means that BDNF is necessary for normal targeting (Ma et al., 2009). In addition, embryonic $p 75^{-1}$ mice show reduced geniculate ganglion axon branching and a lack of innervation in the mid-region of the tongue (Fei et al., 2014). In summary, BDNF is important for gustatory nerve outgrowth and guidance to the taste bud during development.

During taste bud development, fungiform placodes (future fungiform papillae) form on the tongue surface at E13.5 in mice and they are not yet innervated (Patel and Krimm, 2012). By E14.5, the chorda tympani reaches the fungiform papillae and penetrates the epithelium to form a nerve ending in the taste bud (Lopez and Krimm, 2006a). Gustatory nerve innervation is necessary for maintaining fungiform papillae and taste buds during the development (Farbman and Mbiene, 1991; Sollars and Bernstein, 2000; Lopez and Krimm, 2006a). For example, both fungiform papillae and taste buds are completely and permanently lost when the chorda tympani nerve is cut at an early stage (Sollars, 2005). The maintenance of gustatory innervation to fungiform papillae and taste buds is dependent on neurotrophins and its receptors during the development (Nosrat et al., 1997; Patel et al., 2010; Fei and Krimm, 2013). Specifically, both $B d n f^{/} / N_{t f} 4^{-/}$, 
$\mathrm{TrkB}^{-/}$and $p 75^{-\alpha}$ mice had a significant reduction in the taste innervation within taste buds at P0 (Fei and Krimm, 2013; Fei et al., 2014). In conclusion, during development neurons require trophic factors from their target and fungiform papillae and taste buds depend on taste innervation for their survival.

During development, taste bud number and size are decreased in mice when neurotrophins or their receptors are removed (Nosrat et al., 1997; Patel et al., 2010; Fei and Krimm, 2013; Fei et al., 2014). Specifically, more than half of the fungiform taste buds are lost and $60 \%$ of taste bud volume is reduced in $B d n f^{/-}$mice (Nosrat et al., 1997; Mistretta et al., 1999; Patel et al., 2010). In $p 75^{/-}$ mice, $42 \%$ of taste buds are lost at P0 and $35 \%$ at P10 (Fei et al., 2014). In Bdnf ${ }^{1-} / \mathrm{NtfH}^{-/}$and $\mathrm{TrkB}^{-/}$mice, both taste bud number and size are reduced at PO (Fei and Krimm, 2013). In addition, taste buds are more sensitive to BDNF than NT-4 deletion during development. Loss of BDNF (Bdnf/- mice) causes more malformed taste buds and greater reduction in taste bud number compared with loss of NT4 (Ntf $4^{-}$mice; (Patel et al., 2010). This finding indicates that BDNF is required for innervation to reach and successfully innervate taste buds. Therefore, unlike geniculate ganglion neurons which are equally dependent on BDNF and NT-4, taste buds in are more dependent on BDNF than NT-4.

1.4 The expression and role of neurotrophins in the adult taste system

Neurotrophic factors are expressed in many adult systems, including the somatosensory (Bergman et al., 2000), visual (Hirsch et al., 2000), auditory (Popper et al., 1999), and motor systems (Sartini et al., 2013). Neurotrophin factors are also expressed in the adult taste system (Huang and Krimm, 2010). For 
example, BDNF is not only expressed in taste buds and geniculate ganglia during the development (Nosrat and Olson, 1995; Nosrat et al., 1996; Huang and Krimm, 2010), but continues to be expressed in the adult geniculate ganglion, fungiform, foliate, and circumvallate taste buds (Biffo et al., 1995; Alderson et al., 2000; Yacoubian and Lo, 2000; Yee et al., 2003; Huang et al., 2015). In adult taste buds, BDNF is co-expressed with the synaptic protein, SNAP-25 and Car4+ (Yee et al., 2003; Huang et al., 2015). BDNF's major receptor, TrkB, is also expressed in the geniculate ganglion and taste bud cells of adult mice (Alderson et al., 2000; Yacoubian and Lo, 2000; Matsumoto et al., 2001). So it is possible that BDNF may continue to regulate taste bud innervation in the adult taste system. Indeed, taste bud innervation is lost when the Bdnf gene is removed from adult mice (Meng et al., 2015). Specifically, $40 \%$ of taste innervation and $30 \%$ of taste bud volume are reduced when the Bdnf gene is inducibly removed from all tissues in adulthood (Meng et al., 2015). When the Bdnf gene is specifically removed from the taste bud and lingual epithelium in adult mice, taste bud innervation is reduced, but there is no effect on the taste bud volume (Meng et al., 2015). However, there is also innervation remaining in the taste buds after BDNF removal. These findings indicate that BDNF plays an important role in maintaining taste innervation in the adult taste system.

1.5 The receptors for BDNF ligand and their functions.

BDNF accomplishes its diverse functions by binding two receptors - the high affinity tyrosine kinase receptor, TrkB, and the low affinity pan-neurotrophic receptor p75 (Klein et al., 1991; Chao, 2003; Huang and Reichardt, 2003; 
Kharebava et al., 2008; Nguyen et al., 2009). The TrkB receptor has multiple isoforms; a full length TrkB and the truncated TrkB receptors (Klein et al., 1990; Baxter et al., 1997; Stoilov et al., 2002; Luberg et al., 2010). Both full length TrkB and truncated TrkB receptors share the same extracellular domain (ECD) and transmembrane domain (TMD) (Rose et al., 2003; Ohira et al., 2005); however the full length TrkB receptor contains a complex intracellular domain with a tyrosine rich catalytic region and binding sites for Shc and PLCY (McCarty and Feinstein, 1998; Huang and Reichardt, 2001). While truncated TrkB receptor has a short intracellular domain containing serine residue and the SNT (sucassociated neurotrophic factor induced tyrosine phosphorylation target) activation sequence KFG (lysine-phenylalanine-glycine) (Baxter et al., 1997), but lacks the Shc, tyrosine kinase, and PLCy regions (Luberg et al., 2010). There are three different truncated TrkB receptors in human and rat gene, including TrkBT1, TrkBT2 and TrkBT4 (TrkB-T-ShC) (Stoilov et al., 2002; Ohira et al., 2005). TrkBT1 and TrkBT2 have very short intracellular tails; however, TrkBT4 has a much longer intracellular domain than the other two truncated domains, which contains a putative internalization sequence (Rose et al., 2003). The primary truncated TrkB receptor in mice is the TrkBT1 receptor (Klein et al., 1989; Dorsey et al., 2006; Carim-Todd et al., 2009), such that no other mouse truncated sequences have been published. In addition the most abundantly expressed TrkB isoforms in the brain of all animals are the full length TrkB and TrkBT1 receptors (Klein et al., 1989; Stoilov et al., 2002; Luberg et al., 2010). 
BDNF binds to three types of TrkB dimers, which are full length TrkB homodimer, TrkBT1 homodimer and full length TrkB-TrkBT1 heterodimer (Friedman, 2000). When BDNF binds to the full length TrkB homodimer, it can activate intracellular signaling pathways through three different binding sites, which are PLCY, $\mathrm{PI} 3 \mathrm{~K}$, and Erk/MAPK pathways. BDNF-full length TrkB signaling through PLCY pathway can induces neuronal survival and enhanced neuronal transmission (Huang and Reichardt, 2001). Specifically, activated PLCY catalyzes the phosphatidylinositides (PIs) convert to IP3 and DAG. DAG can activate PKCs to induce cell survival and enhance synaptic plasticity (Minichiello, 2009; Numakawa et al., 2010). IP3 regulates synaptic plasticity and enhances neurotransmission (Minichiello, 2009; Numakawa et al., 2010). The PI3K signaling pathway regulates neurite outgrowth and neuron survival. Specifically, full length TrkB interacts with Shc to form a protein complex with GRB2, GAB1 and SOS to stimulate Ras (Huang and Reichardt, 2001). Ras activates PI3K to mediate neuronal survival via Akt signaling (Minichiello, 2009), and induce axonal growth with GSK3 $\beta$ (Yoshimura et al., 2005). PI3K/Akt/mTOR pathways regulate dendritic growth (Kumar et al., 2005). The full length TrkB receptor also activates Erk/MAPK signaling to regulate neuronal survival through CREB activation of transcription factors (Numakawa et al., 2010). Erk/MAPK-induced phosphorylation of elF4E and subsequent CAMKIla activity mediates protein synthesis (Takei et al., 2001). The intracellular signaling pathways through the full length TrkB homodimer are complex, because there crosstalk between the PLCy, PI3K, and Erk/MAPK pathways to regulate the diverse functions BDNF-TrkB signaling on neurons. 
The most characterized function of TrkBT1 is dominant negative inhibition of full length TrkB-signaling. TrkBT1 binds to and forms heterodimers with the full length TrkB receptor, TrkB heterodimerization inhibits full length TrkB receptor autophosphorylation and subsequent activation of PI3K, PLCY, and MAPK signaling pathways (Numakawa et al., 2010). Specifically, upregulation of TrkBT1 stimulates heterodimerization with full length TrkB, resulting in decreased autophosphorylation and inhibition of BDNF-mediated cell survival (Steinbeck and Methner, 2005). TrkBT1 also binds, internalizes and sequesters BDNF to neurons (Biffo et al., 1995; Fryer et al., 1997; Alderson et al., 2000). In addition to binding to the full length TrkB receptor, TrkBT1 also binds to BDNF independently. It has been shown that TrkBT1 binds to BDNF independently to induce neurite outgrowth by an unknown mechanism (Yacoubian and Lo, 2000). Although TrkBT1 intracellular signaling pathway in neurons has not been identified, there is some evidence for intracellular signaling downstream of TrkBT1 in astrocytes (Rose et al., 2003; Ohira et al., 2005; Ohira et al., 2006; Cheng et al., 2007). Specifically, BDNF binds to TrkBT1 to induce G-protein and PKC activation, leading to cortical neural stem cells to adopt glial cell phenotypes (Cheng et al., 2007). G-protein also activates PLCy pathways to regulate calcium release from the endoplasmic reticulum, which result in the rearrangement of the actin cytoskeleton (Rose et al., 2003). TrkBT1 also binds to RhoGDI1, which is a RhoGTPAse inhibitor. When RhoGDI1 is bound to TrkBT1, RhoGTPAse can activate ROCK, MAPK, and PAK pathways to induce cytoskeletal changes and potential cytoskeletal stability (Ohira et al., 2005; Ohira et al., 2006). 
BDNF also binds to the low-affinity neurotrophin receptor p75, which is a member of the tumor necrosis factor receptor superfamily (Frade and Barde, 1998). The cytoplasmic domain of the p75 receptor contains a "death" domain structurally similar to those in other members of this receptor family (Liepinsh et al., 1997). The p75 receptor can directly induce neuronal death through apoptosis (Frade and Barde, 1998; Friedman, 2000). Ligand engagement of p75 has been shown to promote survival of some cells and apoptosis of others (Bamji et al., 1998; Casademunt et al., 1999). P75-mediated signaling also affects axonal outgrowth both in vivo and in vitro (Lee et al., 1994; Walsh et al., 1999; Yamashita et al., 1999; Bentley and Lee, 2000). The p75 receptor can also cause axon degeneration by binding to neurotrophins in both developmental sympathetic neurons and adult septal cholinergic neurons (Singh et al., 2008; Park et al., 2010).

1.6 Neurotrophin (BDNF) regulation of axon/dendritic branching

Axon branching is a complex morphological process. Many factors known to be important for axon growth and guidance have emerged as key regulators of axon branching. The extrinsic factors implicated in axon branching including slits, semaphorins, and ephrins; neurotrophins such as BDNF; the secreted glycoprotein Wnt; the extracellular matrix protein anosmin-1 (Cohen-Cory and Fraser, 1995; Yates et al., 2001; Krylova et al., 2002; MacColl et al., 2002; Ma and Tessier-Lavigne, 2007). In this study, we focus the role of neurotrophins (BDNF) in the control of axon branching. 
In vitro, BDNF has been shown to regulate axon branching in different types of neurons. Specifically, 6 hours of exposure to BDNF significantly increased dendritic length in E19 rat cortical neurons in culture (Takemoto-Kimura et al., 2007), however, at P7 BDNF treatment for 5 hours did not increase total dendritic length and number of branch points, but did increase the number of primary dendrites (Dijkhuizen and Ghosh, 2005). Activation of BDNF signaling increased the number of primary axonal branches in E18 mice cortical neurons (Jeanneteau et al., 2010). Together these studies demonstrate that BDNF promotes distinct characteristics of both axon and dendritic branching at different ages of cortical neuron development. Exogenous addition of BDNF in vitro to E17-19 hippocampal neurons for 2 and 3 days significantly increased the number of branching points, but not the number of primary dendrites or total dendrite length (Cheung et al., 2007; Lazo et al., 2013; Yan et al., 2016). Most rat P0 cerebral cortex neurons exhibit a significant increase in the number of dendrite branches and total dendritic length after BDNF-treatment in culture (Galati et al., 2016). Overexpression of epitope tagged BDNF in individual ferret layer $2 / 3$ pyramidal neurons increased the number of short, unbranched basal dendrites, while reducing the higher order branching of the original basal dendritic in cortical slice at P25-P28 (Horch et al., 1999). Mice P4 corticospinal motor neurons exhibited elaborate branching and arborization, but not increased axon outgrowth when grown in the presence of BDNF in culture (Ozdinler and Macklis, 2006). Taken together, these results indicate that BDNF can promote different aspects of axon and dendritic branching in different ages, neurons, and animals in vitro. 
BDNF also has been shown to mediate dendritic branching in vivo during development. For example, during visual system development, exogenous BDNF injected into the developing Xenopus retina at stage 38 reduced the number of primary dendrites and dendritic branch tips, total dendritic arbor length, while BDNF functional-blocking antibodies into the developing Xenopus retina increased primary dendrites, dendritic branch tips and total dendritic arbor length (Lom and Cohen-Cory, 1999). Increasing BDNF levels in the optic tectum of live developing Xenopus tadpoles at stage 45 significantly increases the total branch number of retinal ganglion cell axons within 4 hours of treatment (Alsina et al., 2001). Conversely, decreasing endogenous BDNF levels significantly decrease the total branch number of retinal ganglion cell axon (Hu et al., 2005). Those studies suggest that BDNF have the opposite roles in regulation of axon vs dendritic branching in Xenopus retinal ganglion cells at different developing ages. Transgenic overexpression of BDNF increases the number of dendritic branches in mice in $\mathrm{ON}$ retinal ganglion cells during postnatal development (P13), whereas decreased TrkB expression decreases them at P28 (Liu et al., 2007). TrkB ${ }^{-/-}$mice reveal a significant reduced number of axonal branches in mouse (P10-16) hippocampus neurons during postnatal development (Martinez et al., 1998). Taken together, these studies indicate that either BDNF or TrkB play an essential role on the dendritic branching during development, but the function is different across neurons and across ages in the same neurons.

In addition to its developmental role, BDNF also participates in the regulation of dendritic branching in the adult brain. For example, conditional deletion of 
BDNF by Cre-mediated recombination during embryogenesis in mice did not affect the initially developed dendrite structure of visual cortical layer $2 / 3$ neurons at P14, but significantly reduced both the number of primary dendrites and branch points per primary dendrite, and distal dendritic branching at P35 (Gorski et al., 2003). Transgenic mice expressing dominant negative TrkB-EGFP (which inhibits TrkB signaling) showed a reduction in the density of mushroom and stubby spines, and an increase in long and thin spines of primary visual cortex neurons. But this inhibition only decreases the density of stubby spines, not the others in CA1 pyramidal neurons (Chakravarthy et al., 2006). Conditional deletion BDNF or TrkB signaling in adult-born granule cells (GCs) significantly reduced total dendrite length and total number of branch points, but overexpressing BDNF significantly increased them (Bergami et al., 2008; Wang et al., 2015). The striatum of postnatal forebrain-restricted BDNF mutant mice display fewer dendritic spines and thinner dendrites in striatum and medium spiny neurons in adulthood (Baquet et al., 2004). Collectively, in comparison to developmental studies, BDNF and the TrkB receptor exhibit similar roles on the regulation of axon branching across different systems, which is more frequently to promote the branching than inhibit it.

However, it is still unknown whether either BDNF or TrkB regulates dendritic/axon branching in the taste system. Here, I plan to study how blocking TrkB signaling will affect axon branching in adult geniculate ganglion cells. Removal of BDNF in adulthood results in a reduction of innervation to the taste bud (Meng et al., 2015). In other systems, deletion of BDNF or TrkB signaling causes a loss in 
the total dendrite length and total number of branch points. Therefore, I speculate that TrkB-signaling may regulate innervation to the taste bud by influencing branching. 


\section{CHAPTER II}

\section{TASTE BUD-DERIVED BDNF MAINTAINS INNERVATION OF A SUBSET OF TRKB-EXPRESSING GUSTATORY NERVE FIBERS}

\subsection{Introduction}

In the tongue, clusters of taste receptor cells organized into taste buds respond to chemicals in food. Taste buds are innervated by neurons of the geniculate ganglion, which carry taste information to the brain. Taste receptor cells have a limited lifespan and continuously turnover (Beidler and Smallman, 1965; PereaMartinez et al., 2013). As taste receptor cells die, functional connections between taste receptor cells and nerve fibers are lost. When new taste receptor cells enter taste buds, they must become innervated by nerve fibers and form new connections with gustatory neurons. Thus, the maintenance of innervation within taste buds is an active process that likely depends on many molecular mechanisms.

Clues as to the nature of these mechanisms could come from similar developmental processes. In particular, brain-derived neurotrophic factor (BDNF) directs the innervation of newly formed taste buds during development (Ringstedt et al., 1999; Krimm et al., 2001; Lopez and Krimm, 2006b; Ma et al., 2009). As BDNF is also expressed in adult taste buds (Yee et al., 2003; Huang et al., 2015), it could continue to maintain taste bud innervation throughout the taste cell's lifespan. In 
deed, taste bud innervation is lost when the Bdnf gene is removed from adult animals (Meng et al., 2015). Interestingly, however, considerable innervation to taste buds remains after BDNF removal.

One possible explanation for this remaining innervation is that there are different "types" of gustatory neurons that vary in their BDNF dependence due to differences in receptor expression. By binding to TrkB receptors, BDNF initiates multiple signaling pathways that regulate neuronal survival, synaptic plasticity, and differentiation (Minichiello, 2009; Waterhouse and Xu, 2009; Numakawa et al., 2010). If not all nerve fibers express TrkB receptors, BDNF removal may only affect neurons that express this receptor. Consistent with this idea, only some geniculate ganglion neurons express TrkB receptors (Cho and Farbman, 1999; Farbman et al., 2004b; Farbman et al., 2004a; Yamout et al., 2005; Fei and Krimm, 2013). A second possible explanation is that BDNF was not completely removed from all taste receptors cells in this earlier study.

The goal of the current study was to distinguish between these two possibilities. First, we aimed to verify efficient $B d n f$ removal from taste buds and to determine whether TrkB is expressed in a subset of innervating taste fibers in adult mice. Next, we examined whether TrkB-positive fibers are impacted by Bdnf removal from the epithelium and taste buds. We also sought to determine whether taste bud-derived BDNF plays a role in maintaining taste bud size or taste receptor expression, either of which could influence taste function. We found that Bdnf expression was efficiently eliminated from taste buds. Furthermore, BDNF supported a large subset of TrkB-expressing nerve fibers and not TrkB-negative 
nerve fibers. Lastly, BDNF maintained expression of $\mathrm{y}$ subunit of $\mathrm{ENaC}$ in taste buds. Thus, BDNF maintains taste bud innervation in adulthood of a particular subset of nerve fibers and regulates factors required for taste transduction.

\subsection{Materials and methods}

\subsubsection{Animals}

Inducible Bdnf mutants were produced by breeding mice with floxed Bdnf alleles (Bdnfox/+ ; Jackson Laboratory, 002267) with mice with an inducible Cremediated recombination system driven by a K14 promoter (K14-CreER; \#005107, Jackson Laboratory). Gene recombination under control of the K14 promoter results in successful gene recombination in cells that differentiate into taste buds (Vasioukhin et al., 1999; Okubo et al., 2009). These mice were bred with heterozygous $\mathrm{Bdnf}^{+/}$knock-out mice (\#002266, Jackson Laboratory) and mice in which a green fluorescent protein (GFP) cassette was inserted into the first coding exon of Ntrk2 $\left(T r k B^{\mathrm{GFP} /+}\right)$ to visualize the cells in which TrkB is expressed (Li et al., 2011). Thus, mice used for anatomical analysis lacked a functional Bdnf gene in one allele, Bdnf could be inducibly removed from the other allele and GFP is expressed in TrkB-positive neurons (K14-CreER:Bdnflox/$\left.: T r k B^{\mathrm{GFP} /+}\right)$. Three control genotypes were used for different purposes of comparison. $B d n f^{\text {fox/+ }}:$ TrkB $B^{\mathrm{GFP} /+}$ mice (with tamoxifen) were used to exclude any effects of tamoxifen administration, and $K 14-C r e E R: B d n f^{\mathrm{dox} /+}: T r k B^{\mathrm{GFP} /+}$ mice (without tamoxifen) were used to exclude the possibility of gene recombination in the absence of tamoxifen; both genotypes were expected to produce wild-type levels of BDNF. Bdnf $f^{\text {ox/- }}: \operatorname{Trk} B^{\mathrm{GFP} /+}$ mice (with tamoxifen) were used to control for any ef- 
fects of heterozygous Bdnf knock out. In addition, we bred K14-CreER and K14Cre mice with mice expressing tdTomato (\#007914, Jackson Laboratory) to visualize the effectiveness of tamoxifen-induced gene recombination. To measure Bdnf gene expression by real-time reverse transcription polymerase chain reaction (RT-PCR), the same genotypes without $\operatorname{Trk} B^{\mathrm{GFP} /+}$ were used.

\subsubsection{Tamoxifen administration}

Mice received tamoxifen (T5648, Sigma-Aldrich, St. Louis, MO; mixed in peanut oil, $188 \mathrm{ng} / \mathrm{g}$ body weight) once per day for 3 weeks by oral gavage. This dose was previously used for effective inducible gene recombination in adult mice (Ruzankina et al., 2007; McGraw et al., 2011; Meng et al., 2015). Tamoxifen administrations were initiated in all mice around 60 days of age. Mice were euthanized 10 weeks after the final tamoxifen administration.

2.2.3 Laser capture microdissection, RNA extraction, and cDNA amplification and purification

Mice were euthanized by an overdose of $2.5 \%$ tribromoethanol (Avertin) i.p., (T48402, Sigma-Aldrich, St. Louis, MO; mixed in tert-amyl alcohol, then diluted in 1/40 PBS,). Taste buds were isolated using laser capture microdissection (LCM) as previously described (Huang and Krimm, 2010). The anterior part of the tongue was removed, rinsed with $0.1 \mathrm{M}$ PBS solution $(\mathrm{pH} 7.4)$, and cut in half under a microscope. Each half was placed into a disposable embedding mold, covered with OCT, and frozen immediately and stored at $-80^{\circ} \mathrm{C}$ for future use. Identified taste buds were captured onto CapSure Macro LCM Caps (Molecular 
Devices, Sunnyvale, CA). For each mouse, all captured samples were stored for RNA isolation.

Total RNA was extracted from taste buds using an RNeasy micro kit according to the manufacturer's instructions (\#74004, Qiagen, Germantown, MD).

DNase I treatment was applied to eliminate traces of DNA during the procedure. Following isolation, RNA quality was analyzed using a Bioanalyzer 2100 (Agilent Technologies, Santa Clara, CA) and estimated by the RNA Integrity Number (RIN) and $28 \mathrm{~S} / 18 \mathrm{~S}$ ratio. Only RNA samples with a $260 / 280$ ratio $\geq 1.80$ and RIN $\geq 8.0$ were used. Taste bud cDNA was synthesized from total RNA using random primers (Invitrogen, Carlsbad, CA).

\subsubsection{Real-time RT-PCR}

Real-time RT-PCR was performed using ABI PRISM/7900HT Sequence detection systems (Applied Biosystems, Waltham, MA, USA) with TaqMan Universal PCR kits (\#4304437, Applied Biosystems) and oligonucleotide primer/probe sets, which were designed from sequences available in the GenBank Database using Beacon Designer software (Premier Biosoft International, Atlanta, GA). When possible, primers were chosen to span an intron to avoid genomic DNA contamination (Table 1). TaqMan probes were labeled at the $5^{\prime}$ end with a fluorescent dye (fluorescein) and at the 3' end with a quencher dye (carboxytetramethylrhodamine). Real-time RT-PCR reactions were conducted using $10 \mu \mathrm{l}$ $1 \times$ Master Mix, 720/200 nm primer/probe sets (TaqMan PCR kit), and the same amount of target cDNA. For normalization of cDNA loading, all samples were run in parallel with $18 \mathrm{~S}$ ribosomal RNA, mouse glyceraldehyde 3 phosphate dehy- 
drogenase (GAPDH), and cytokeratin 8 (K8). Each assay was carried out in triplicate. Amplification of cDNA was performed for 40 cycles of $95^{\circ} \mathrm{C}$ for $15 \mathrm{~s}$ and $60^{\circ} \mathrm{C}$ for $1 \mathrm{~min}$.

\subsubsection{Immunohistochemistry}

Mice were euthanized by an overdose $(1 \mathrm{ml})$ of $2.5 \%$ of Avertin, transcardially perfused with 4\% paraformaldehyde (PFA), and post-fixed in 4\% PFA for 2 hours or immersion-fixed in 4\% PFA overnight. The anterior part of the tongue was dissected and post-fixed overnight in 4\% PFA. The tissue was transferred to $30 \%$ sucrose at $4^{\circ} \mathrm{C}$ overnight, frozen in OCT, and stored at $-80^{\circ} \mathrm{C}$ until sectioned on a cryostat. To visualize whole taste buds and their innervation, tongues were sectioned at $70 \mu \mathrm{m}$, and the sections were collected in $0.1 \mathrm{M}$ phosphate-buffered saline (PBS) and rinsed four times in PBS. Cryostat sections were blocked with $3 \%$ normal donkey serum in $0.1 \mathrm{M}$ PBS containing $0.5 \%$ Triton $\mathrm{X}-100$. The tissue was incubated with the following primary antibodies for 5 days at $4^{\circ} \mathrm{C}$ : rat anti-K8 in PBS (1:50; Developmental Studies Hybridoma Bank, AB Registry ID: AB_531826, cat\#: Troma-1-s, lowa City, IA), goat anti-GFP (1:400; Novus, AB Registry ID: AB_10128178, cat\#: NB100-1700, Littleton, CO), or rabbit anti-P2X3 (1:500; Millipore, AB Registry ID: AB_11212062, cat\#: AB58950, Billerica, MA). After incubation in primary antibodies and four rinses in PBS, sections were incubated in the following secondary antibodies for 2 days: anti-rat Alexa Fluor 555 (1:500; Jackson ImmunoResearch Laboratories, West Grove, PA), anti-goat Alexa Fluor 488 (1:500; Jackson ImmunoResearch Laboratories), or anti-rabbit Alexa Fluor 647 (1:500; Jackson ImmunoResearch Laboratories). The tissue was 
then washed four times in 0.1M PBS, mounted onto slides, and cover-slipped using aqueous mounting medium (Fluoromount-G, SouthernBiotech, Birmingham, $A L)$.

\subsubsection{Quantification of taste bud innervation and volume}

Taste buds from the tip of the tongue were imaged using a confocal microscope (Olympus, model no. FV1200BX61). During both image capture and analysis, the experimenter was blind to mouse genotype. Optical images were captured every $1 \mu \mathrm{m}$ with a $60 \times$ oil immersion lens at a zoom level of 3.5 from the front one-third of the fungiform field (i.e., tongue tip). For each image, all three channels were taken separately using single-wavelength excitation and merged to produce a composite image. Imaris software (Bitplane, http://www.bitplane.com/contact) was used to rotate taste buds and determine whether the whole taste bud was captured. Innervation density in the first six whole taste buds imaged per mouse tongue was determined. For each optical section, taste buds were outlined using K8 labeling to define the perimeter. Next, the total taste bud volume, the volume occupied by the 647 label (representative of P2X3-labeled nerve fibers), and the volume occupied by the 488 label (representative of TrkB-labeled nerve fibers) were measured separately using the masking feature in Imaris.

\subsubsection{Statistical analysis}

Results are expressed as mean \pm standard error of the mean (SEM). For real-time RT-PCR results, the comparative $2^{-\Delta \Delta C T}$ method was used to quantify target gene expression (Livak and Schmittgen, 2001). The Shapiro-Wilk test was 
used to assess whether data were normally distributed. One-way analysis of variance (ANOVA) was used to test for differences between genotypes in mRNA levels, taste bud volume, and nerve fiber innervation. Two-way ANOVA was used to test for differences between genotypes in P2X3- and TrkB-labeled fibers. After significant overall ANOVAs, Student-Newman-Keuls post-hoc tests were used for pairwise comparisons. Statistical significance was set at $p<0.05$.

\subsection{Results}

2.3.1 Taste bud innervation can be divided into TrkB-positive and TrkB-negative fibers.

Although taste bud innervation is reduced when the Bdnf gene is removed from adult mice (Meng et al., 2015), a surprising amount of innervation remains. One possible explanation is that some fibers innervating taste buds are not responsive to BDNF because they do not express TrkB receptors. Therefore, we examined whether all taste fibers express the high-affinity BDNF receptor, TrkB, by labeling taste buds with anti-P2X3 (blue) and anti-GFP (green) in TrkB ${ }^{\mathrm{GFP} /+}$ mice (Figure 1A-D). P2X3 is an ATP channel required for neuronal responses to taste stimuli (Finger et al., 2005), and its antibody labels taste fibers within taste buds. Anti-K8 was used to label taste buds (red). We found that many fibers were labeled with both anti-P2X3 and anti-GFP. However, some P2X3-positive fibers were not labeled with anti-GFP (arrows in Figure 1A-C). Therefore, some P2X3positive fibers did not express TrkB. 
The cell bodies for nerve fibers that innervate fungiform taste buds are located in the geniculate ganglion. To determine whether all geniculate ganglion neurons express TrkB, we double-labeled the geniculate ganglion from $\operatorname{TrkB}{ }^{\mathrm{GFP} /+}$ mice with anti-GFP and anti-P2X3 (Figure 1E-G) and determined the percentage of double-labeled cells. We found that $56 \pm 7 \%$ of P2X3-positive neurons also expressed GFP. Together, these data indicate that not all gustatory neurons express TrkB during adulthood. Therefore, some nerve fibers may remain in taste buds after BDNF removal because they are not responsive to BDNF.

2.3.2 BDNF was effectively and specifically removed from taste buds under control of the K14 promoter.

To further examine why taste bud innervation remains after Bdnf removal, we re-evaluated the effectiveness of Bdnf removal from taste buds in K14-CreER mice. Although previous reports indicate that all types of taste bud cells arise from K14+/K5+ basal cells (Okubo et al., 2009; Gaillard et al., 2015), a recent study shows that a few taste bud cells may migrate from connective tissue (Boggs et al., 2016). We wanted to verify that taste receptor cell types that express BDNF (Car4+) undergo gene recombination. To examine what types of taste bud cells originate from K14+ progenitor cells, we bred K14-Cre mice with stop-floxed tdTomato (Ai14) mice $(n=2)$. In these mice, the lingual epithelium and taste buds were brightly stained with tdTomato (red, Figure 2A). Moreover, all fungiform taste buds examined were completely labeled with tdTomato (Figure 2B), indicating that all taste bud cells were derived from cells that at some point expressed K14. Taste bud cells labeled with anti-carbonic anhydrase 4 (Car4, 
blue), which also expresses Bdnf (Huang et al., 2015), were also labeled with tdTomato (Figure 2C-D), indicating that they originated from $\mathrm{K} 14+$ progenitor cells. To visualize the effectiveness of K14-CreER-induced gene recombination, we bred K14-CreER mice with stop-floxed tdTomato (Ai14) mice. Ten weeks after tamoxifen administration ended ( 3 weeks), the fungiform papillae and taste buds were labeled with tdTomato (Figure $2 \mathrm{E}, \mathrm{n}=3$ ), and taste bud cells appeared to be derived from cells that underwent gene recombination (red, Figure $2 \mathrm{~F}$ ). Taste bud cells were double-labeled with anti-Car4 and tdTomato (arrow, Figure $2 \mathrm{~F}-\mathrm{H})$, indicating that taste buds cell types that expressed Bdnf underwent gene recombination.

A previous study shows that Bdnf expression was decreased in the whole epithelium after 3 weeks of tamoxifen injections in K14-CreER:Bdnf fox/- mice (Meng et al., 2015); however, Bdnf expression in taste buds was not specifically examined. One possible explanation for why innervation remains in taste buds after Bdnf gene recombination is that BDNF is more effectively removed from the epithelium than from taste buds. To assess whether Bdnf gene recombination changes Bdnf expression levels in taste buds, we isolated taste buds using LCM and performed real-time RT-PCR. We found that Bdnf was reduced to less than $1 \%$ in K14-CreER:Bdnf ${ }^{\text {oxl } /:}:$ TrkB $B^{\mathrm{GFP} /+}$ mice $(\mathrm{n}=4)$ compared with three control genotypes $\left(B d n f^{\text {fox/++}}: \operatorname{TrkB}^{\mathrm{GFP} /+}, p<0.01,(\mathrm{n}=4) ; K 14-\operatorname{CreER}: B d n f^{\mathrm{dox} /+}: \operatorname{Trk} B^{\mathrm{GFP} /+}, p<\right.$ 0.05, $(\mathrm{n}=4) ; B d n f^{\mathrm{fox} / .}: \operatorname{Trk}^{\mathrm{GFP} /+}, p<0.05,(\mathrm{n}=4)$; Figure 2I). This reduction was greater than that previously observed in the whole epithelium (Meng et al., 2015). 
Therefore, it does not appear that nerve fibers remain because of inefficient gene recombination in taste buds.

2.3.3 BDNF regulates TrkB-positive but not TrkB-negative innervation within taste buds.

After demonstrating that remaining taste bud innervation is not due to inadequate Bdnf gene removal, we speculated that TrkB-negative fibers may not depend on BDNF during adulthood. To address this issue, we quantified TrkBpositive innervation after $B d n f$ removal from taste buds by breeding mice in which Bdnf could be inducibly removed by tamoxifen with mice in which cells that express TrkB were genetically labeled ( $\mathrm{Li}$ et al., 2011). Taste fibers were labeled with anti-P2X3 (blue, most gustatory innervation) and anti-GFP (green, TrkBpositive innervation), and taste buds were labeled with anti-K8 (red). All three control genotypes $\left(B d n f^{\text {fox/+}}: \operatorname{Trk} B^{\mathrm{GFP} /+}, \quad(\mathrm{n}=4), \quad K 14-\operatorname{CreER}: B d n f^{\mathrm{ox} /+}: \operatorname{Trk} B^{\mathrm{GFP} /+}\right.$, $(\mathrm{n}=4), B d n f^{\mathrm{dox} /-}: \operatorname{TrkB}^{\mathrm{GFP} /+},(\mathrm{n}=4)$, Figure $\left.3 \mathrm{~A}-\mathrm{L}\right)$ and mice in which $B d n f$ expression was reduced (K14-CreER:Bdnf ${ }^{\text {doxl-: }}: \operatorname{TrkB}^{\mathrm{GFP} /+},(\mathrm{n}=4)$, Figure 3M-P) had P2X3- and GFP-labeled innervation within taste buds. However, taste buds appeared to have less P2X3- and GFP-labeled innervation in mice with reduced Bdnf (K14CreER: $B d n f^{\text {fox/- }}: \operatorname{Trk} B^{\mathrm{GFP} /+}$ ) compared with control genotypes. No obvious difference in taste bud size was observed across genotypes.

To quantify the effect of Bdnf gene removal on total innervation, we analyzed the volume of P2X3-positive and TrkB-positive innervation to taste buds. Ten weeks after tamoxifen administration, the volume of remaining P2X3-positive innervation differed among genotypes $\left(F_{(3,12)}=10.8, p<0.001\right)$. Specifically, 
taste buds in $K 14-C r e E R: B d n f^{\text {fox/- }}:$ Trk $B^{\mathrm{GFP} /+}$ mice showed $39 \%$ less $\mathrm{P} 2 \mathrm{X} 3$-positive innervation than the three control genotypes $\left(B d n f^{\mathrm{dox} /+}: \operatorname{TrkB}^{\mathrm{GFP} /+}, p<0.005 ; \mathrm{K} 14-\right.$

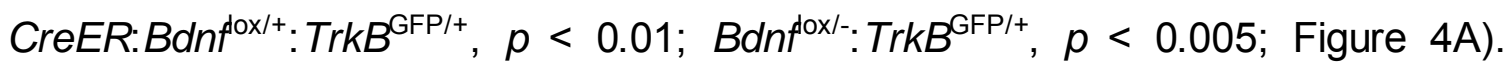
Similarly, the volume of TrkB-positive innervation also differed among genotypes $\left(\mathrm{F}_{(3,12)}=35.4, p<0.001\right) . K 14-C r e E R: B d n f^{\text {dox/ } /:}: \operatorname{Trk}^{\mathrm{GFP} /+}$ mice showed $55 \%$ less TrkB-positive innervation than the three control genotypes $\left(B d n f^{\text {dox } /+}: \operatorname{Trk} B^{\mathrm{GFP} /+}, p\right.$ $<0.001 ;$ K14-CreER:Bdnf ${ }^{\mathrm{fox} /+}: \operatorname{TrkB}^{\mathrm{GFP} /+}, p<0.001 ;$ Bdnf $^{\mathrm{dox} /-}: \operatorname{TrkB}^{\mathrm{GFP} /+}, p<0.001$; Figure 4A). There were no differences in the volume of P2X3-positive or TrkBpositive innervation among the three control genotypes, indicating that neither tamoxifen nor elimination of a single Bdnf allele altered the amount of innervation within taste buds. Furthermore, removal of the Bdnf gene from the epithelium and taste buds caused a greater loss of TrkB-positive innervation than total (i.e., P2X3-positive) innervation ( $p<0.001)$, suggesting that Bdnf gene removal primarily affects TrkB-positive fibers.

Using P2X3 as a marker for all gustatory innervation, we estimated the amount of TrkB-negative gustatory innervation by subtracting the amount of TrkB-positive innervation from P2X3-positive innervation for each taste bud. We found no difference in the volume of TrkB-negative innervation among the four genotypes $\left(F_{(3,12)}=0.74, p=0.546\right.$, Figure 4B), suggesting that TrkB-negative innervation was not affected by removal of the Bdnf gene.

Previously, taste bud volume was reduced when the Bdnf gene was removed from all tissue with a ubiquitous promoter but not when it was specifically removed from taste buds of adult mice (Meng et al., 2015). To confirm these find- 
ings, we quantified taste bud volume in $B d n f^{\text {dox/+ }}: \operatorname{Trk} B^{\mathrm{GFP} /+}(\mathrm{n}=4), \quad K 14-$ CreER:Bdnf $f^{\mathrm{dox} /+}: \operatorname{TrkB}^{\mathrm{GFP} /+}(\mathrm{n}=4), B d n^{\mathrm{fox} /-}: \operatorname{TrkB}^{\mathrm{GFP} /+}(\mathrm{n}=4)$ and K14-CreER:Bdnf ${ }^{\text {ox/- }}$ $: \operatorname{TrkB}{ }^{\mathrm{GFP} /+}(\mathrm{n}=4)$ mice. We found no genotype differences in taste bud volume $\left(F_{(3,12)}=1.54, p=0.26\right.$, Figure $\left.4 C\right)$, indicating that taste bud size is not affected when Bdnf is inducibly removed from taste buds.

In summary, we found that the reduced taste bud innervation in mice lacking Bdnf in the epithelium was due to a loss of TrkB-positive innervation and not TrkB-negative innervation. However, in addition to the TrkB-negative innervation, a surprising amount of TrkB-positive innervation remained in taste buds. Taste bud size was not affected by Bdnf gene removal or loss of innervation.

2.3.4 BDNF removal reduced expression of the $\mathrm{y}$ subunit of the $\mathrm{ENaC}$ receptor.

Finally, we investigated whether BDNF signaling has a direct effect on the presence of transduction mechanisms in adult taste buds. Deactivation of specific TrkB signaling pathways (SHC and PLCY) during development alters the expression of multiple taste transduction mechanisms in the whole tongue epithelium (Koudelka et al., 2014). However, it is not clear whether this is strictly a developmental role or whether BDNF-TrkB signaling regulates transduction mechanisms in adulthood. Therefore, we used RT-PCR to examine the expression of different taste receptors/channels that transduce taste stimuli in fungiform taste buds of K14-CreER:Bdnfox/- mice and three control genotypes. Salt taste on the front of the tongue is largely transduced by the amiloride-sensitive channel $\mathrm{ENaC}$, which has three subunits. We found that the expression of the $y$ subunit of $\mathrm{ENaC}$ (Scnn1g) was significantly decreased in K14-CreER:Bdnfox/- mice (Figure 
$5 A$ ), whereas the expression of $\beta$ and $\alpha$ subunits did not change (Figure $5 B-C$ ). We observed no changes in the other transduction mechanisms examined. Specifically, there were no differences in the expression of T1R1, T1R2, or T2R5 between $K 14-C r e E R: B d n f^{\text {dox/- }}$ mice and the three control genotypes (T1R1, $\mathrm{n}=4, \mathrm{p}$ $=0.9713 ; \mathrm{T} 1 \mathrm{R} 2, \mathrm{n}=4, \mathrm{p}=0.8796 ; \mathrm{T} 2 \mathrm{R} 5, \mathrm{n}=4, \mathrm{p}=0.2862$ ), whereas the sour taste channel PKD2L1 was consistently below the detection threshold. These findings suggest that although the impact of BDNF-TrkB signaling on taste transduction mechanisms may be largely developmental (Koudelka et al., 2014), salt taste transduction could be altered in the taste buds of adult K14-CreER:Bdnfox/mice.

\subsection{Discussion}

Taste bud cells die and turnover continuously in adulthood, and new taste bud cells must be innervated by nerve fibers (Beidler and Smallman, 1965; Perea-Martinez et al., 2013). Thus, the maintenance of innervation to taste buds in adulthood is an active process that is likely regulated by multiple factors. In the absence of BDNF, taste bud innervation is reduced by $40 \%$ (Meng et al., 2015), indicating that BDNF is required to maintain some innervation to taste buds. However, $60 \%$ of innervation remains in taste buds after Bdnf gene removal. We speculated that a subset of taste nerve fibers expressing the BDNF receptor TrkB may be lost by adulthood, thus reducing taste bud innervation, which would be consistent with previous studies demonstrating that some adult gustatory neurons do not express the TrkB receptor (Cho and Farbman, 1999; Matsumoto et al., 2001; Farbman et al., 2004a). We found that some taste nerve fibers do not 
express the TrkB receptor, and more TrkB-positive innervation than total innervation was lost from adult taste buds after inducible $B d n f$ removal. Therefore, we conclude that taste bud-derived BDNF is specifically required to maintain a subset of TrkB-positive fiber innervation to adult taste buds.

Our results confirm and extend the findings of an earlier study examining BDNF support of gustatory innervation (Meng et al., 2015). In this earlier study, BDNF expression was measured in the whole lingual epithelium, including both epithelial cells and taste bud cells, making it unclear how much of the $80 \%$ reduction in Bdnf was specific to taste buds. This is particularly relevant because it is possible that not all taste bud cell precursors express K14 (Boggs et al., 2016), which could result in Bdnf remaining in taste buds. We found no taste receptor cells that failed to undergo gene recombination in K14-Cre:tdTomato mice, and only a few taste bud cells that failed to undergo gene recombination in adult $K 14$ CreER:tdTomato mice. Moreover, Bdnf mRNA level was reduced to less than $1 \%$ in taste buds of $K 14-C r e E R: B d n f^{\text {doxl- }}$ mice compared to those of three control genotypes. This indicates that most Bdnf-expressing cells in taste buds successfully underwent gene recombination, and only a small proportion of taste bud cells continued to express Bdnf. Therefore, it is unlikely that innervation remains in the taste buds after Bdnf removal because Bdnf-induced gene recombination was not effective.

We found that some fibers were TrkB-negative and not affected by Bdnf removal. Consistently, BDNF is expressed in some adult taste receptor cells but not others (Yee et al., 2003; Huang et al., 2015). This indicates that BDNF only 
maintains a subset of the total fibers that innervate taste buds, perhaps specifically those fibers that innervate BDNF-expressing taste bud cells. Therefore, in addition to TrkB, another mechanism likely exists to support TrkB-negative innervation. One possibility is that this role is served by another growth factor. For instance, glial cell line-derived neurotrophic factor is expressed in a different subset of taste bud cells than BDNF (Takeda et al., 2004; Suzuki et al., 2007), and its receptors are expressed in the geniculate ganglion (Farbman et al., 2004a; Yamout et al., 2005). However, many other factors could also play this role/s (McLaughlin, 2000; Suzuki et al., 2005; Takeda et al., 2005; Yee et al., 2005; Germana et al., 2006; Suzuki et al., 2007; Feng et al., 2014).

Although TrkB-positive innervation is dramatically reduced by inducible Bdnf removal from the epithelium, $45 \%$ of TrkB-positive innervation remained in the taste buds. There are at least two possible explanations for this finding. First, not all BDNF-expressing cells may undergo gene recombination, thus some BDNF protein could still remain to support TrkB-positive fibers. However, given the small remaining amount of Bdnf expression, this explanation seems unlikely to account for all of the remaining TrkB innervation. Second, some TrkB-positive fibers may not express an isoform for TrkB allowing BDNF to signal; therefore BDNF may not support the maintenance of these fibers even though they express TrkB. The TrkB receptor consists of two isoforms: a full-length and a truncated TrkB receptor (Klein et al., 1989; Klein et al., 1990; Middlemas et al., 1991). Because the truncated isoform of the TrkB receptor is expressed in the geniculate ganglion (Farbman et al., 2004a; Yamout et al., 2005), it is possible 
that some TrkB-positive fibers only express this isoform. The truncated isoform signals in some instances (Yacoubian and Lo, 2000; Ohira et al., 2005; Ohira et al., 2006; Cheng et al., 2007; Islam et al., 2009) but can also function as a dominant-negative receptor that inhibits BDNF signaling (Fenner, 2012). Therefore, only a subset of TrkB-positive fibers may express the full-length receptor, and BDNF may only support this subset of innervation.

Gustatory nerve fibers provide trophic signals that influence taste receptor cell maintenance. As TrkB-positive innervation was reduced after Bdnf removal, we investigated whether this had any impact on taste buds. We found no effect on taste bud size; however, earlier studies demonstrated a developmental impact of reducing TrkB signaling on the expression of receptors/channels required for taste transduction (Koudelka et al., 2014). We found that expression of the $Y$ subunit of ENaC channel was reduced by Bdnf removal, whereas expression of other transduction mechanisms were unaffected. Because much of a rodent's ability to transduce salt taste requires the ENaC channel (Chandrashekar et al., 2010), and when all three ( $\alpha, \beta$ and $\gamma$ ) subunits of $E N a C$ are expressed together, its generated more than 100 fold amiloride-sensitive currents than $\alpha \mathrm{ENaC}$ or $\beta E N a C$ or $y E N a C$ expressed alone (Canessa et al., 1994). So salt transduction may be altered in mice with reduced $B d n f$. Our findings differ from those of earlier studies showing that disrupted TrkB-signaling resulted in an up-regulation of umami and bitter receptors and down-regulation of sour transduction mechanisms (Koudelka et al., 2014). This difference between studies is likely due to developmental stage-dependent differences in the regulation of these transduc- 
tion mechanisms by BDNF-TrkB signaling. Interestingly, sodium deprivation, which reduces salt sensitivity, also impacts BDNF expression in taste buds (Huang and Stahler, 2009), implying a regulatory relationship between BDNF and $\mathrm{ENaC}$ expression. It is unclear whether reduction of BDNF directly influences $\mathrm{YENaC}$ expression or whether this is an indirect effect via taste nerve fibers. As TrkB-positive innervation is specifically lost after Bdnf removal, TrkB-positive fibers could innervate and influence $\mathrm{Y}$-ENaC expression in taste receptor cells that transduce salt taste stimuli.

We showed that BDNF maintains innervation of a subset of taste fibers expressing the full-length TrkB receptor. However, precisely how BDNF-TrkB signaling maintains this innervation is unclear. Because a long time period is needed to observe the impact of Bdnf removal (Meng et al., 2015) on innervation, it seems unlikely that BDNF-TrkB signaling is required to maintain established connections. Instead, we propose that BDNF promotes new innervation to taste buds during taste receptor cell turn over. New BDNF-expressing taste bud cells could induce taste fiber branching and growth (Danzer et al., 2002; Horch and Katz, 2002; Dijkhuizen and Ghosh, 2005; Cheung et al., 2007; Lazo et al., 2013), recruiting innervation from full-length-expressing TrkB-positive nerve fibers. If so, this would indicate that neurons expressing the full-length TrkB receptor are a specific type or subtype of gustatory neurons. In this scenario, new taste receptor cells that normally do not express BDNF may recruit TrkB-negative fibers using an alternate mechanism. We propose that BDNF-TrkB signaling is one mecha- 
nism that coordinates innervation between specific types of taste receptor cells and specific types of neurons during taste receptor cell turnover. 
Table 1. Sequences of primer pairs and probes used for real-time RT-PCR.

Gene

Fragment

GenBack Accession \#

Sequence 5'-3'

size (bp)

Bdnf (NM_007540)

110

Forward primer TGCAGGGGCATAGACAAAAGG

Reverse primer CTTATGAATCGCCAGCCAATTCTC

Taqman probe ACTGGAACTCGCAATGCCGAACTACCCA

T2R5 (Tas2r105) (NM_020501)

Forward primer GGCTGGGAGTTTTAGGGAAC

Reverse primer AGTTGCTAAGCCGATGAGAAG

Taqman probe CACTGGTAAACTGCATGGACTGGGC

Krt8 (NM_031170)

Forward primer TCTTCTGATGTCGTGTCCAAGTG

Reverse primer GATCCTCGGACGGGTCTCTAG

Taqman probe CCACTGAAGTCCTTGCCAGCCTGAGC

GAPDH (NM_008084)

Forward primer

AATGTGTCCGTCGTGGATCTG

Reverse primer CAACCTGGTCCTCAGTGTAGC

Taqman probe CGTGCCGCCTGGAGAAACCTGCC

$\beta$-Actin (NM_007393) 
Forward primer

Reverse primer

Taqman probe

Scnn1a (NM_011324)

Forward primer

Reverse primer

Taqman probe

Scnn1b (NM_011325)

Forward primer

Reverse primer

Taqman probe

Scnn1g (NM_011326)

Forward primer

Reverse primer

Taqman probe
CTGGGACGACATGGAGAAGATC

GTCTCAAACATGATCTGGGTCATC

ACCTTCTACAATGAGCTGCGTGTGGCC

CCAAGGGTGTAGAGTTCTGTG

AGAGCTTGTAGTTGGTCACAC

TTCTCCAAGTGCAGGAAGCCGTG

CTCGAATATCACCCTGAGCAG

CCCATCCAGAAGCCAAACT

CCGTACCATTGAGGAATCTCCAGCCA

GGACCAAAGCCAGCAAATAAAC

ACCAAAGTTAGACAGGAGCATC

TCATGGAGAGCCCAGCCAACAGTAT

T1R1 (Tas1r1) (NM_031867)

Forward primer TGATAACACTGACCACGCTG

Reverse primer CCTGGTACTTATCGCTGGG

Taqman probe TGAGCCCTTTTCTGATGCCCCTG

T1R2 (Tas1r2) (NM_031873)

Forward primer AGAACCCCTTCCAAAGCATC

Reverse primer AGGCTGGCAACTCTTAGAAC

Taqman probe CCAACAACACGGTCCCCATATCCA 
Pkd2/1 (NM_181422)

Forward primer GGTATACATAGTGTTCCTCGTGG

Reverse primer TGCTGATGGTTTGGAAGGAG

Taqman probe TGTTTCTACACACCCCATCCGACTCTG 

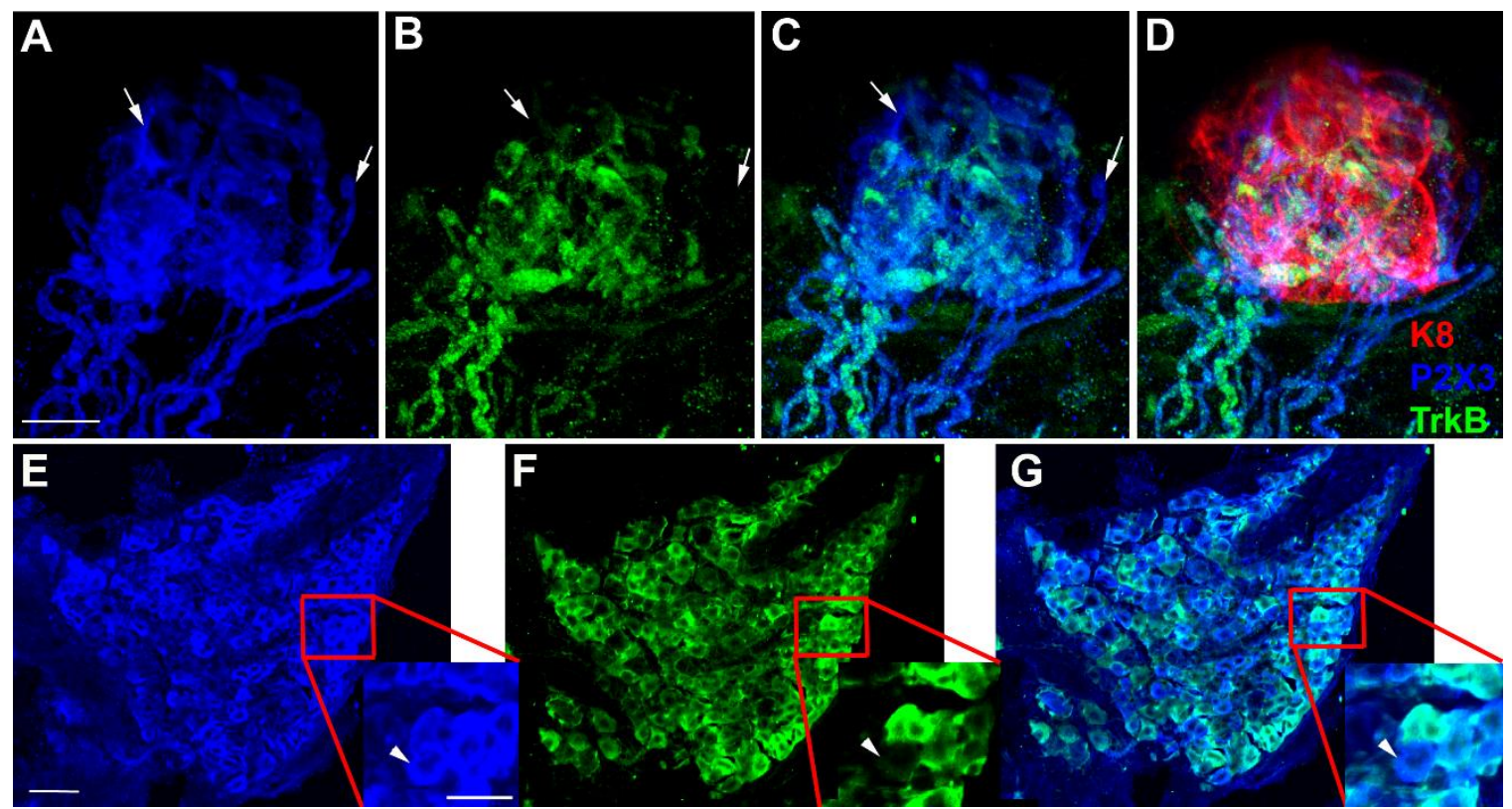

Figure 1. Not all P2X3-positive fibers are labeled with TrkB in fungiform taste buds. Representative fungiform taste bud labeled with anti-P2X3 (A, blue), antiGFP (B, green), and anti-K8 (C, red) in an adult TrkB ${ }^{\mathrm{GFP} /+}$ mouse. Several fibers labeled with P2X3 (A, arrows) were not labeled with GFP (B, arrows), which is seen more clearly when the blue and green images are merged (C). K8 staining demonstrates that these fibers were within the taste bud (D). Representative geniculate ganglion labeled with anti-P2X3 (E, blue) and anti-GFP (green, F) in a TrkB ${ }^{\mathrm{GFP} /+}$ mouse. The higher magnification inset for each ganglion image illustrates a neuron labeled with P2X3 but not GFP (arrowhead). Scale bar in A $=10$ $\mu \mathrm{m}$ (applies to A-D); scale bar in $\mathrm{E}=20 \mu \mathrm{m}$ (applies to $\mathrm{E}-\mathrm{G}$ ); scale bar in inset $=$ $10 \mu \mathrm{m}$. 

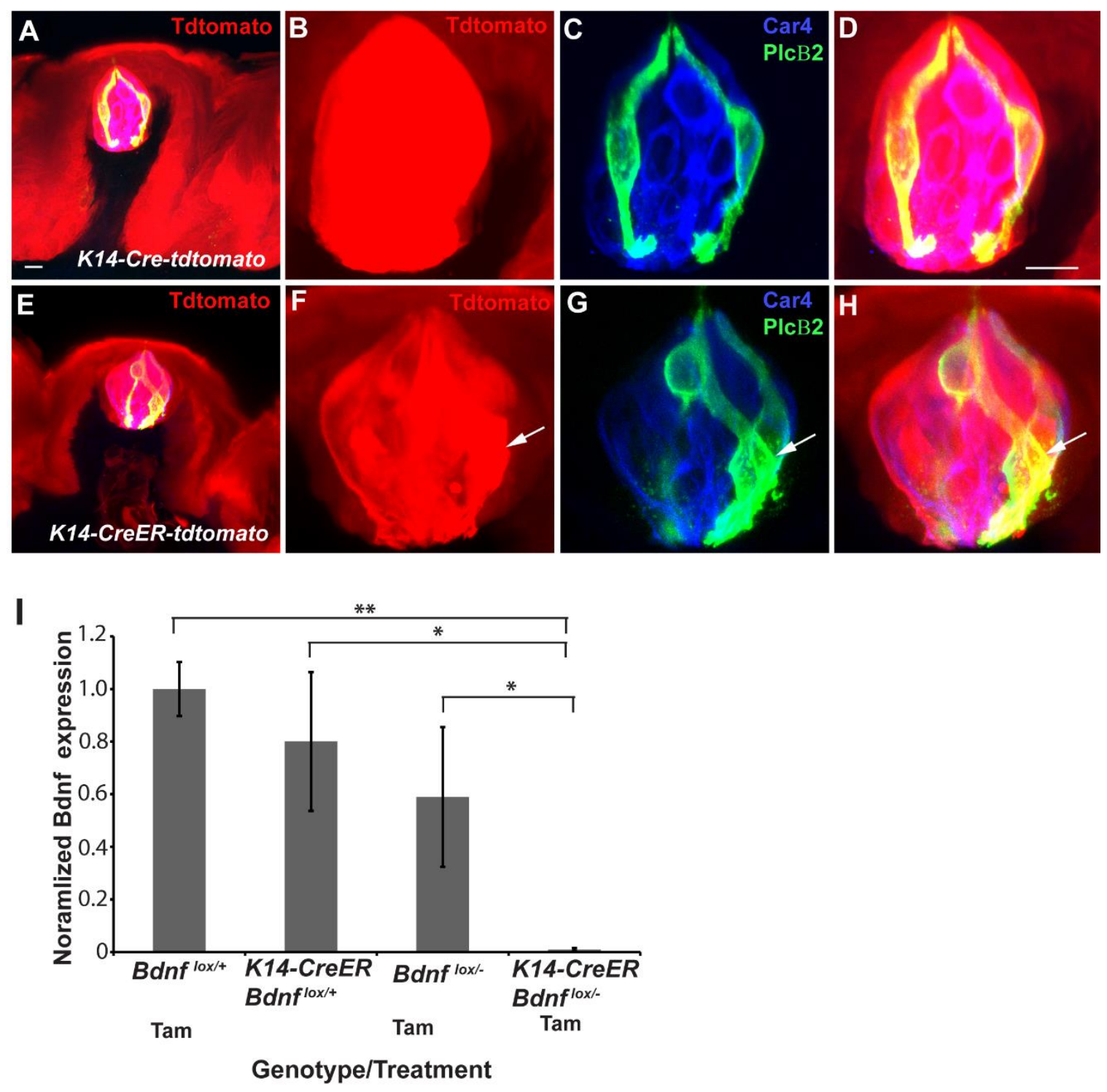

Figure 2. Bdnf gene expression in taste buds is reduced by inducible K14CreER-mediated gene recombination in lingual epithelial cells after 3 weeks of tamoxifen administration. (A-D) Representative confocal images showing fungiform taste bud staining with anti-PLCß2 (blue) and anti-Car4 (green) in an adult K14-Cre:tdTomato mouse. (A) TdTomato (red) was observed in the epithelium of fungiform papilla. (B-D) All taste bud cells were bright red, indicating that they were all derived from $\mathrm{K} 14+$ precursors. (E) Representative confocal images showing the epithelia of fungiform papillae stained with anti-K8 (blue) and anti- 
Car4 (green) in an adult K14-CreER:tdTomato mouse 10 weeks after 3 weeks of tamoxifen administration. (F-H) Most cells within the taste bud were labeled with tdTomato (red), demonstrating effective gene recombination. Many taste bud cells labeled with anti-Car4 (green) were also tdTomato-positive, indicating that they underwent gene recombination. (I) Isolated taste buds from K14CreER:Bdnf ${ }^{\text {dox/- }}$ mice expressed significantly less $B d n f$ than the three control genotypes. Bdnf expression was normalized to that in $B d n f$ ox $/+$ mice. ${ }^{*} p<0.05,{ }^{* *} p \leq$ 0.01. Scale bar in $A=10 \mu \mathrm{m}$ (applies to $A$ and $E$ ); scale bar in $D=10 \mu \mathrm{m}$ (applies to B-D and F-H). 


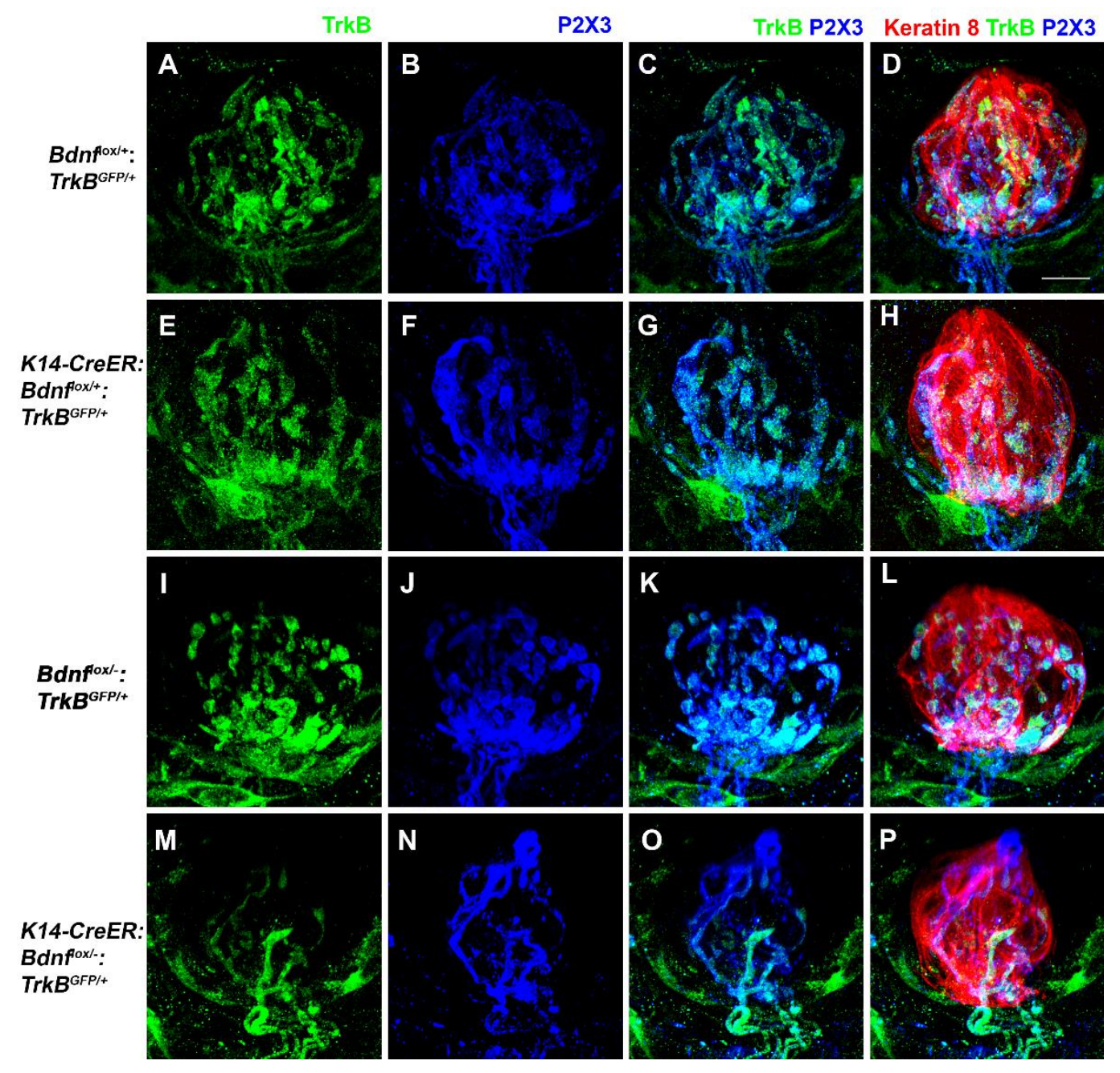

Figure 3. Fungiform taste buds appear to lose both P2X3-positive and TrkBpositive innervation when Bdnf is inducibly removed from the adult lingual epithelium. Representative confocal images showing fungiform taste buds stained with anti-GFP (green, A, E, I, and M), anti-P2X3 (blue, B, F, J, and N), and anti-K8 (red) in four different genotypes. In $B d n f^{\text {ox/++}}: \operatorname{TrkB} B^{\mathrm{GFP} /+}$ (A-D), K14CreER:Bdnf $f^{\text {ox/+t}}: \operatorname{Trk}^{\mathrm{GFP} /+}(\mathrm{E}-\mathrm{H})$, and $B d n f^{\mathrm{ox} /-}: \operatorname{TrkB}^{\mathrm{GFP} /+}(\mathrm{I}-\mathrm{L})$ control mice, taste buds had similar amounts of TrkB-positive (A, E, and I) and P2X3-positive (B, F, and $\mathrm{J}$ ) innervation 10 weeks after tamoxifen injection. However, for mice in which 
Bdnf expression was reduced (K14-CreER:Bdnf $\left.f^{\mathrm{Ox} /-}: \operatorname{Trk} B^{\mathrm{GFP} /+}, \mathrm{M}-\mathrm{P}\right)$ taste buds had less TrkB-positive (M) and P2X3-positive (N) innervation. Interestingly, at least some TrkB-positive innervation remained in taste buds even after 10 weeks of BDNF reduction. Scale bar in $\mathrm{D}=10 \mu \mathrm{m}$ (applies to all panels). 

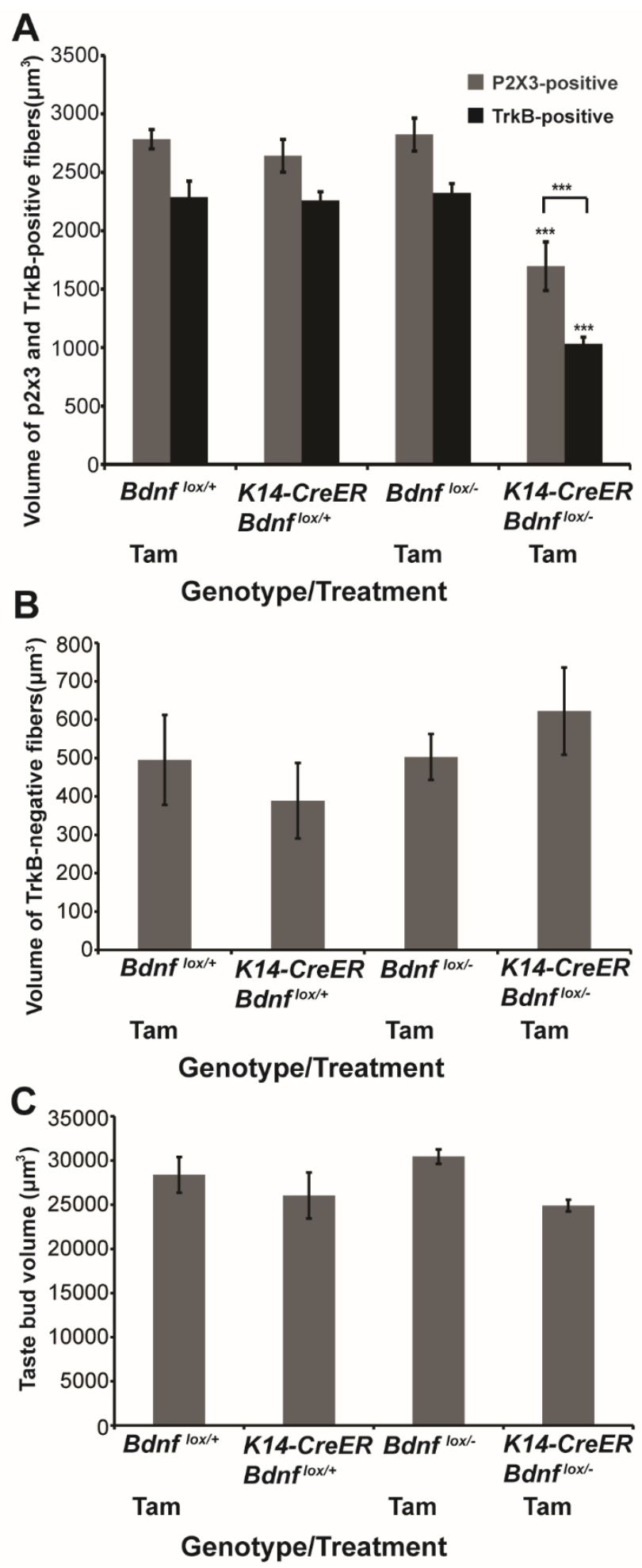

Figure 4. The total amount of innervation to taste buds is reduced due to a loss of TrkB-positive taste fibers. (A) The volume of P2X3-positive and TrkB-positive fi- 
bers within taste buds was reduced in adult mice with reduced Bdnf expression

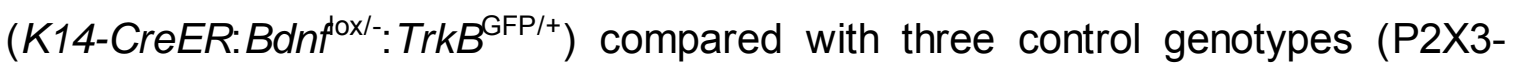
positive, Bdnf ${ }^{\mathrm{dox} /+}: \operatorname{Trk} B^{\mathrm{GFP} /+}, p<0.005 ; K 14-\operatorname{CreER}: B d n f^{\mathrm{ox} /+}: \operatorname{TrkB}^{\mathrm{GFP} /+}, p<0.01$; $B d n f^{\text {ox/-: }}:$ TrkB ${ }^{\mathrm{GFP} /+}, p<0.005$; TrkB-positive, Bdnf ${ }^{\text {dox/+ }}:$ TrkB ${ }^{\mathrm{GFP} /+}, p<0.001 ; K 14-$ CreER:Bdnf $\left.{ }^{\mathrm{dox} /+}: \operatorname{Trk}^{\mathrm{GFP} /+}, p<0.001 ; B d n f^{\mathrm{dox} /}: \operatorname{Trk}^{\mathrm{GFP} /+}, p<0.001\right)$. (B) The volume of TrkB-negative fibers was estimated by subtracting the volume of TrkBpositive fibers from the total volume of fibers/taste buds. TrkB-negative innervation was not affected by Bdnf reduction ( $p>0.05)$. (C) Taste bud volume was not affected by Bdnf reduction ( $p>0.05) .{ }^{* *} p \leq 0.01,{ }^{* * *} p \leq 0.001$. 


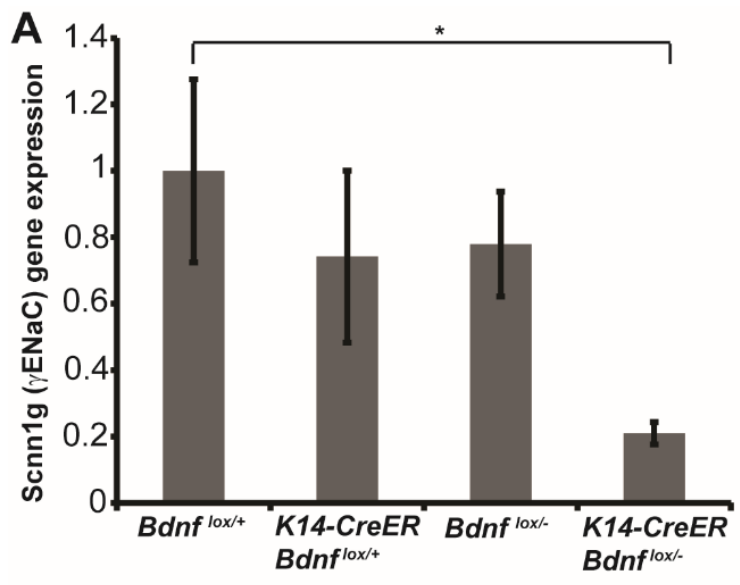

Tam Tam Tam Tam
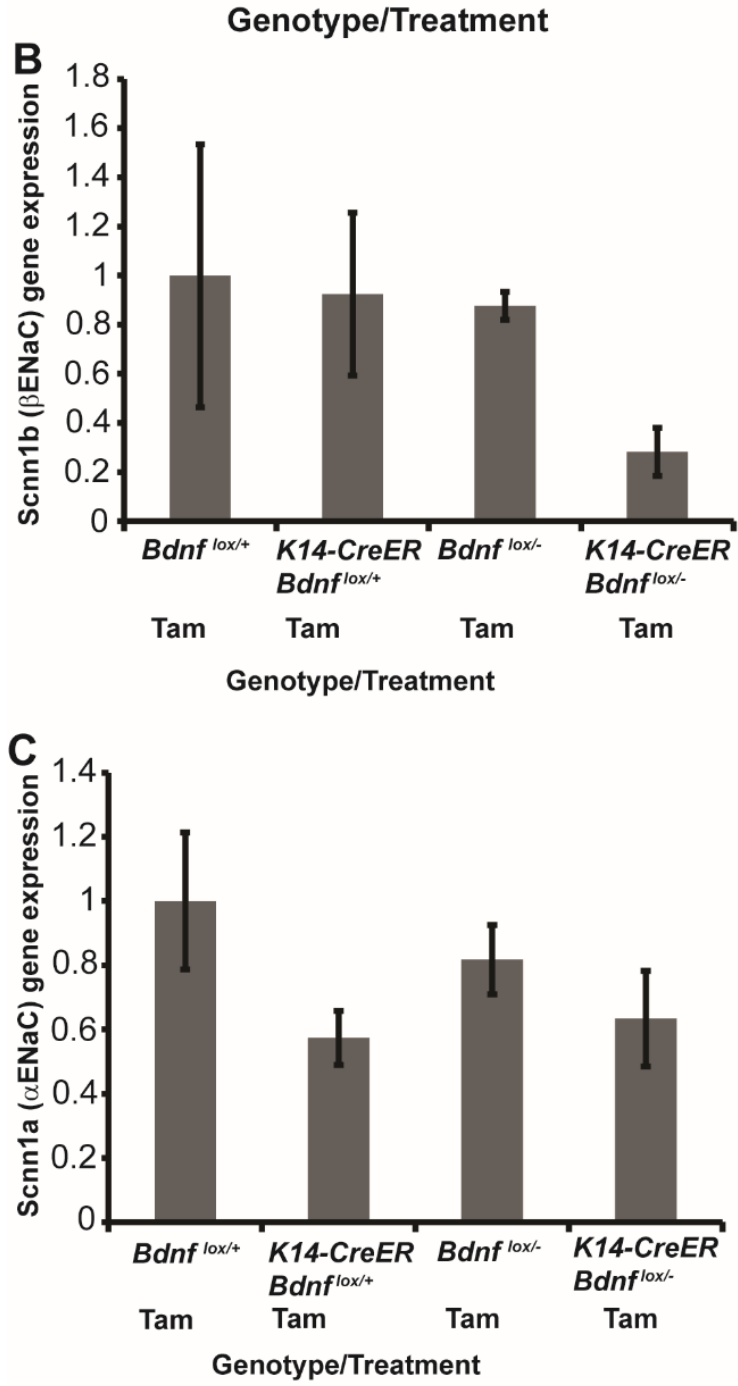
Figure 5. Inducibly removing Bdnf from the epithelium reduced expression of the Y subunit of the ENaC channel but did not affect expression of $\alpha$ and $\beta$ subunits. Normalized expression of the $\mathrm{Y}(\mathrm{A}), \beta(B)$, and $\alpha$ subunits $(C)$ of $\mathrm{ENaC}(n=4)$ in fungiform taste buds. (A) RT-PCR results show reduced expression of the $y$ subunit of ENaC in K14-CreER:Bdnfox/- mice compared with $B d n f^{\text {dox/+ }}$ mice. (B-C) RTPCR results show similar expression of $\beta$ and $\alpha$ subunits of ENaC expression across genotypes. ${ }^{*} p \leq 0.05,{ }^{* *} p \leq 0.01$. 
CHAPTER III

\section{THE FULL LENGTH TRKB RECEPTOR IS EXPRESSED IN THE GENICULATE GANGLION NEURONS, BUT NOT IN TASTE BUDS}

\subsection{Introduction}

The receptor cells within the taste bud detect various chemical stimuli and convey this information to ganglion neurons, which then carries it to the brain. The neurotrophin, brain-derived neurotrophic factor (BDNF) regulates both the targeting of innervation to the taste bud during development and maintenance of innervation with the taste bud in adulthood. (Ringstedt et al., 1999; Krimm et al., 2001; Lopez and Krimm, 2006b; Ma et al., 2009; Meng et al., 2015). BDNF continues to be expressed in a subpopulation of adult taste receptor cells (Yee et al., 2003; Huang et al., 2015) and BDNF is required to maintain normal amounts of innervation in the adult taste bud (Meng et al., 2015). These innervating fibers consist of TrkB-positive and TrkB-negative subpopulations and TrkB-positive innervation was specifically reduced when BDNF was removed from taste buds in adulthood (Chapter II). While the source of BDNF is the taste bud, it is unclear if BDNF has a direct function on the nerve fibers or could influence innervation indirectly by binding to taste bud cells, which then release another factor to influence innervation (Nosrat et al., 2012). 
BDNF accomplishes its diverse functions by binding two receptors - the high affinity tyrosine kinase receptor, TrkB, and the pan-neurotrophic receptor p75 (Klein et al., 1991; Chao, 2003; Huang and Reichardt, 2003; Kharebava et al., 2008; Nguyen et al., 2009). The TrkB receptor has multiple isoforms; a full length TrkB and a truncated TrkB receptor (Klein et al., 1990; Baxter et al., 1997; Stoilov et al., 2002; Luberg et al., 2010). The full length TrkB and TrkBT1 receptors share the same extracellular domain (ECD) and transmembrane domain (TMD); however the full length TrkB receptor contains a complex intracellular domain with a tyrosine rich catalytic region with binding sites for Shc and PLCY (Huang and Reichardt, 2001). TrkBT1 has a short intracellular domain and lacks the Shc, tyrosine kinase, and PLCy regions (Luberg et al., 2010). The bulk of BDNF function is mediated by the full length TrkB receptor which is involved in neuronal cell survival, synapse formation and plasticity, differentiation, proliferation by activating PLCY, PI3K, and Erk/MAPK pathways in different binding sites (Huang and Reichardt, 2003; Numakawa et al., 2010). The function of the Truncated (TrkBT1) receptor is not well established. It has been shown that TrkBT1 can sequester BDNF and present BDNF to the dimer of the full length TrkB receptor (Biffo et al., 1995; Eide et al., 1996; Fryer et al., 1997; McCarty and Feinstein, 1998; Alderson et al., 2000; Righi et al., 2000). The p75 receptor also binds to BDNF and is expressed in geniculate ganglion neurons, as well as in both fungiform and circumvallate taste bud cells (Fan et al., 2004; Krimm, 2006; Fei et al., 2014). 
By adulthood, BDNF is expressed in a subset of taste receptor cells (Yee et al., 2003; Huang et al., 2015), but it is unclear which cell types contain the receptors for BDNF. The taste bud is made up of taste bud cells derived from epithelia and nerve fibers. Taste bud cells can be classified into three morphologic cell types based on electron microscopy: type I, type II, and type III, by cell shape, structure and apical processes (Murray, 1993; Pumplin et al., 1997; Yee et al., 2001). Type I cells usually called "supporting cells", may function to clear neurotransmitters and ensheath other taste cells (Pumplin et al., 1997). Type II cells express G-protein coupled receptors (TAS1R and TAS2R family) and share a common intracellular signal transduction pathway which includes phospholipase C- $\beta 2$ (PLCß2). Type III cells have synapses and at least some respond to sour taste stimuli (Huang et al., 2008b) and express carbonic anhydrase 4, a glycosylphosphatidylinositol-anchored enzyme, which functions as the principal $\mathrm{CO}_{2}$ taste sensor (Chandrashekar et al., 2009). Salt taste transduction also occurs through multiple known and unknown mechanisms including an ion channel, the epithelial sodium channel (ENaC) (Chandrashekar et al., 2010), which includes three subunit- $\alpha, \beta$ and $\gamma$, which taste receptor cells express this channel is unclear (Kretz et al., 1999; Chandrashekar et al., 2010). The taste bud also contains stem cells and precursor cells which are non-polarized undifferentiated cells.

The cells on which BDNF is acting must express BDNF's receptors and which receptors are expressed in each cell type provides clues for BDNF's specific action in these cells. However, at this stage we do not know which tissues 
(taste bud cells or nerve fibers) express each of these receptors. The goal of this study is to determine which cells or/and neurons express the BDNF receptors. We found that the full length TrkB receptor is expressed in the geniculate ganglion, but not in the taste buds, and both taste buds and geniculate ganglion neurons express the TrkBT1 and p75 receptors. Furthermore, the TrkBT1 receptor is expressed in multiple types of taste bud cells. Finally, BDNF regulates the expression of the TrkBT1 receptor, but not the full length TrkB receptor in circumvallate taste buds. Thus, the conical pathway for BDNF should be through the full-length receptor on the nerve fibers, not the taste cells.

\subsection{Methods}

\subsubsection{Animals}

Adult wild-type C57BL6/J mus musculus $(\mathrm{n}=4$ ) were used in real-time polymerase chain reaction (real-time PCR) experiments to determine the expression levels of BDNF receptors in fungiform and circumvallate taste buds and the geniculate ganglion. The K14-BDNF-OE mice were used in real time RT-PCR to measure receptor expression in the circumvallate taste buds. To visualize TrkB, the GFP cassette was inserted into the first coding exon of Ntrk2 (TrkB $\left.{ }^{\mathrm{GFP} /+}\right)$. In addition, we bred TrkB ${ }^{\text {CreER/+ }}$ mice with mice expressing tdtomato (Jax\# 007914) or YFP(Jax\# 014539) to visualize the TrkBT1 receptor in the taste bud. Mice were injected with tamoxifen (T5648, Sigma-Aldrich; mixed in peanut oil, 188 $\mathrm{ng} / \mathrm{g}$ body weight) once per day for 3 days (TrkB ${ }^{\text {CreER }}:$ tdTomato or TrkB ${ }^{\text {CreER }}$ :YFP ) by oral gavage. 
3.2.2 Laser capture microdissection, RNA extraction, cDNA amplification and purification

Mice were euthanized by overdose of $2.5 \%$ tribromoethanol (Avertin, T48402, Sigma-Aldrich, St. Louis, $4 \mathrm{mg} / \mathrm{kg}$ body weight). The geniculate ganglion was dissected and transferred into a tube containing RNAlater (Ambion). Taste buds in both anterior and posterior parts of tongue were isolated with laser capture microdissection (LCM) using the protocols described previously (Huang and Krimm, 2010). Briefly, the tongue was dissected and then sectioned (10- $\mu \mathrm{m})$ and processed to visualize the taste buds. The identified taste buds were captured onto CapSure Macro LCM Caps (Molecular Devices, Sunnyvale, CA, USA). For each animal, all captured samples were stored at $-80^{\circ} \mathrm{C}$ for RNA isolation.

Total RNA was extracted from geniculate ganglia, and fungiform and circumvallate taste buds using an RNeasy micro kit according to the manufacturer's instructions (\#74004; Qiagen, Germantown, MD, USA). DNase I treatment was applied to eliminate traces of DNA during the procedure. Following isolation, the RNA quality was analyzed using a Bioanalyzer 2100 (Agilent Technologies, Santa Clara, CA, USA). The RNA Integrity Number (RIN) and 28S/18S ratio were used to estimate the RNA quality. Only RNA samples with a $260 / 280$ ratio $\geq 1.80$ and $\mathrm{RIN} \geq 8.0$ were used $\mathrm{cDNA}$ from taste buds and geniculate ganglia was synthesized from total RNA using random primers (Invitrogen, Carlsbad, CA, USA).

\subsubsection{Real-time RT-PCR}

Real-time RT-PCR was performed by ABI PRISM/7900HT Sequence detection systems (Applied Biosystems) using a TaqMan Universal PCR kit (Ap- 
plied Biosystems, Waltham, MA, USA, catalog \#4304437), and oligonucleotide primer/ probe sets, which were designed from sequences available in the GenBank Database using Beacon Designer software (Premier Biosoft International, Atlanta, GA, USA). Primers for TrkB were designed from the extracellular domain (ECD), and transmembrane domain (TMD) which was shared by the full length TrkB and TrkBT1 receptors, and so measures all isoforms. Both full length TrkB and TrkBT1 primers were designed from their unique intracellular domain. When possible, primers were chosen to span an intron to avoid genomic DNA contamination (Table 2). TaqMan probes were labeled at the 5'-end with a fluorescent reporter dye (fluorescein; FAM) and at the 3'-end with a quencher dye (carboxytetramethylrhodamine; TAMRA). Real time-PCR reactions were conducted using $10 \mu \mathrm{l}$ with $1 \mathrm{X}$ Master Mix, 720/200 nm primer/probe sets (TaqMan PCR Kit), and the same amount of target cDNA. For normalization of cDNA loading, all samples were run in parallel with the housekeeping gene, 18S ribosomal RNA, mouse glyceraldehyde 3 phosphate dehydrogenase (GAPDH) and cytokeratin 8 (K8). Each assay was carried out in triplicate. Amplification of cDNA was performed for 40 cycles of $95^{\circ} \mathrm{C}$ for $15 \mathrm{~s}$ and $60^{\circ} \mathrm{C}$ for $1 \mathrm{~min}$.

\subsubsection{Immunohistochemistry}

Mice were perfused with $4 \%$ paraformaldehyde (PFA). The anterior and posterior part of the tongue and geniculate ganglion were dissected and post fixed overnight in $4 \%$ PFA. The tissue was transferred to $30 \%$ sucrose at $4^{\circ} \mathrm{C}$ overnight, then frozen in OCT and stored at $-80^{\circ} \mathrm{C}$ until sectioned on a cryostat. To visualize TrkBT1 and total TrkB in the taste buds and geniculate ganglia, tongue 
sections $(70 \mu \mathrm{m})$ and whole mount ganglia were rinsed once in $0.1 \mathrm{M}$ phosphatebuffered saline (PB) and 4 times in PBS and then blocked with 3\% normal donkey serum in $0.1 \mathrm{M}$ PB containing $0.5 \%$ Triton $\mathrm{X}-100$. Tongue sections were incubated with the following primary antibodies for 5 days at $4^{\circ} \mathrm{C}$ : rat anti-cytokeratin8 in PBS (1:50; Developmental Studies Hybridoma Bank, Antibody Registry ID: AB_531826, Cat\#:Troma-1-s, lowa City, IA, USA), rabbit anti-TrkBT1 (1:50; Santa Cruz Biotechnology, Santa Cruz, CA, USA), goat anti-GFP (1:400; Novus, AB Registry ID: AB_10128178, Cat\#:NB100-1700, Littleton, CO, USA). Geniculate ganglia were incubated in mouse anti-ISL1 (1:100), rabbit anti-TrkBT1, goat antiGFP. Tissues were then rinsed 4 times in $\mathrm{PB}$, sections were incubated in the appropriate secondary antibodies for two days: anti-rat Alexa Fluor 555 (1:500; Jackson ImmunoResearch Laboratories, West Grove, PA, USA), anti-goat Alexa Fluor 488 (1:500; Jackson ImmunoResearch Laboratories, West Grove, PA, USA) anti-rabbit Alexa Fluor 647 (1:500; Jackson ImmunoResearch Laboratories, West Grove, PA, USA), anti-mouse Alexa Fluor 647 (1:500; Jackson ImmunoResearch Laboratories, West Grove, PA, USA), and anti-rabbit Alexa Fluor 555 (1:500; Jackson ImmunoResearch Laboratories, West Grove, PA, USA). Tissues were then rinsed 4 times in $0.1 \mathrm{M} \mathrm{PB}$, and mounted onto slides and cover-slipped using aqueous mounting medium (Fluoromount-G, SouthernBiotech, Birmingham, AL, USA). To identify which type of taste cells express the TrkBT1 receptor, the front two-thirds of the tongue containing fungiform taste buds was sectioned as described above. The sections were incubated with either: goat anti-Car4 (1:500; R\&D Systems, AF2414), and rabbit anti-Dsred (1:500; Clontech, 
Catalog \# 632496, Mountain View, CA, USA) or rabbit anti-PLCß2 (1:500; Santa Cruz Biotechnology, sc-206, Santa Cruz, CA, USA) and goat anti-GFP for 5 days at $4^{\circ} \mathrm{C}$. Then sections were incubated with secondary antibodies: anti-rabbit Alexa Fluor 555, anti-goat Alexa Fluor 488 and mounted on to slides for visualization. Optical sections of labeled taste buds were captured every $1 \mu \mathrm{m}$ using a confocal microscope (FV1200, Olympus) under a 60X objective lens with a zoom level of 3.5. Each signal was collected separately using single-wave length excitation and merged to produce a composite image. Six taste buds from the tongue were imaged from each animal for further analyses.

\subsubsection{Statistical analysis}

Data were expressed as mean \pm SEM. For real-time PCR results, the target gene expression levels were quantified by the comparative $2^{-\Delta \Delta C T}$ method (Livak and Schmittgen, 2001). The Student Newman normality test was used to examine if data were normally distributed. For mRNA levels, one-way ANOVAs were used. Once the overall significance difference was determined, Student Newman post hoc tests were used to identify significant differences in pairwise comparisons when differences were found across genotypes. Statistical significance was set at $p<0.05$.

\subsection{Results}

3.3.1 Both taste buds and geniculate ganglion expressed the TrkB and p75 receptors.

BDNF can regulate the amount of innervation in the adult taste bud (Meng et al., 2015); however, it is still unclear where the receptors for BDNF are ex- 
pressed. So we don't know on which cells BDNF could be acting directly. BDNF accomplishes its diverse functions by binding two receptors-TrkB and p75 receptors. To determine where these receptors are expressed, we first measured TrkB and p75 receptor mRNA expression using real-time RT-PCR in fungiform taste buds, circumvallate taste buds, and geniculate ganglion neurons in wild type mice. We found that the TrkB and p75 receptors are expressed in both taste buds (Figure. 6A and B) and geniculate ganglia (Figure. 6C). However, the levels of expression were different among these regions (Figure. 6A-C). The TrkB receptor is expressed at higher levels than p75 in fungiform taste buds $(p<0.05$, Figure. $6 A$ ) and geniculate ganglion ( $p<0.05$, Figure. $6 C$ ). In contrast, in the circumvallate taste buds, the TrkB receptor was expressed at approximately the same amount as the $p 75$ receptor $(p=0.055$, Figure. $6 B)$.

To confirm our real-time RT-PCR results, we labeled taste buds and geniculate ganglion from TrkB ${ }^{\mathrm{GFP} /+}$ mice with anti-GFP (green) while taste buds were visualized with anti-cytokeratin-8 (Figure. 6D-G), and neuron cell bodies with anti-Islet-1 (Figure. $6 \mathrm{H}$ and I). Consistent with the rt-PCR result, TrkB was present in taste nerve fibers in both fungiform and circumvallate taste buds (Figure. $6 \mathrm{D}$ and F), and also most of neurons in the geniculate ganglion (Figure. $6 \mathrm{H}$ ). Therefore, the TrkB and p75 receptors are expressed in the geniculate ganglion and taste buds.

3.3.2 Both the full length TrkB and TrkBT1 receptors are expressed in geniculate ganglia, while only the TrkBT1 receptor is expressed in taste buds. 
The TrkB receptor has two isoforms- the full length TrkB and the truncated receptor. BDNF activates intracellular signaling cascades through a full length TrkB receptor to induce differentiation, proliferation and survival (Numakawa et al., 2010). In addition to the full length TrkB receptor, BDNF can also function via truncated receptor isoforms. Since these different TrkB isoforms have different functions, we wanted to know whether taste buds and geniculate ganglion expressed both full length TrkB and truncated receptors. In the mouse, the primary truncated receptor is TrkBT1 (Carim-Todd et al., 2009), and only rat sequences for additional truncated receptors have been published (Armanini et al., 1995). Therefore, we measured the full length TrkB and TrkBT1 receptor mRNA expression by real-time RT-PCR in fungiform taste buds, circumvallate taste buds and geniculate ganglion neurons in the wild type mice. We found that the full length TrkB receptor mRNA is expressed in the geniculate ganglion (Figure. $7 \mathrm{C}$ ), but not in fungiform and circumvallate taste buds (Figure. 7A and B). But the TrkBT1 receptor mRNA is expressed in fungiform taste buds, circumvallate taste buds, and geniculate ganglion neurons (Figure. 7A-C).

To confirm my real-time RT-PCR results, I labeled taste buds and geniculate ganglion neurons with anti-TrkBT1 in wild type mice. In both fungiform and circumvallate taste buds, anti-TrkBT1 weakly labeled both taste bud cells (arrow in Figure. $7 \mathrm{D}$ and $\mathrm{F}$ ), and nerve fibers. In geniculate ganglion neurons, antiTrkBT1 clearly labeled neurons (arrow in Figure. $7 \mathrm{H}$ ). This finding is consistent with our real-time RT-PCR results. Therefore, the TrkBT1 receptor is expressed in both taste buds and geniculate neurons. 
3.3.3 The TrkBT1 receptor is expressed in multiple types of taste bud cells.

We found that the TrkBT1 receptor was expressed in the taste buds, but taste bud cells exist as multiple different types and we sought to determine which type of taste bud cell/s express the TrkBT1 receptor. Since anti-TrkBT1 was only weakly labeled in the taste bud cells in wild type mice we used a genetic label (TrkB-CreER:tdTomato or TrkB-CreER:YFP) to determine which taste bud cell express TrkBT1. We injected $4 \mathrm{mg}$ of tamoxifen/day for 3 days in both transgenic mouse lines, then collected the tongue on day 4 and performed immunostaining. By examining the taste bud immediately after the tamoxifen injection we insured that the taste receptor cells that underwent gene recombination were still in the taste bud and the nerve fibers expressing TrkB would not yet be labeled. There is no full length TrkB receptor expressed in the taste buds; therefore, tdTomato and GFP labeled cells only express the truncated TrkB receptors. We labeled fungiform taste buds in TrkB-CreER:tdTomato mice with anti-dsred (red) and anticarbonic anhydrase 4 (Car4, green, a marker for Type II taste receptor cells; Figure. 3A-C). Some anti-Car4 positive taste receptor cells expressed dsred (arrow in Figure. 8A), indicating that these taste receptor cells also expressed the TrkBT1 receptor. We labeled fungiform taste buds in TrkB-CreER:YFP mice, with anti-GFP (green) and anti-phospholipase C subtype $\beta 2$ (PLCß2, red; a marker for Type II taste receptor cells; Figure. 8D-F), and found that some PLCB2-positive taste cells expressed GFP (arrow in Figure. 8D), indicating that PLC 32 -positive taste cells also expressed the TrkBT1 receptor. Therefore, both Type II and Type III taste bud cells expressed TrkBT1 receptor. 
3.3.4 BDNF regulates the expression of the TrkBT1 receptor, but not the full length TrkB receptor in the circumvallate taste buds.

The full length TrkB receptor was found to be expressed in the circumvallate taste buds in mice overexpressing BDNF in the taste bud (Nosrat et al., 2012). However, we were unable to find the full length TrkB receptor in either fungiform or circumvallate taste buds of wild type mice. One possibility is that BDNF regulates expression of its own receptor, such that it is increased to detectable levels only in BDNF-overexpressing mice. To address this possibility, we examined the total TrkB, full length TrkB, TrkBT1 and p75 receptor mRNA expression in circumvallate taste buds from both BDNF-overexpressing (K14-BDNF-OE) and wild type mice using real-time RT-PCR. Surprisingly, we found the full length TrkB receptor is not expressed in either K14-BDNF-OE or wild type mice (Figure 9). However, both total TrkB $(p<0.05)$ and the TrkBT1 receptor expression $(p<0.01)$ levels were significantly increased in the circumvallate taste buds of K14-BDNFOE mice compared to wild type mice (Figure 9). Therefore, the TrkBT1 receptor in cells within and around the taste bud is regulated by BDNF levels, and the full length TrkB receptor is simply not expressed in taste buds according to our detection system, which contrary to the literature (Nosrat et al., 2012)

\subsection{Discussion}

The neurotrophin, brain-derived neurotrophic factor (BDNF) regulates TrkB-positive innervation to the adult taste bud (Chapter II). BDNF functions through its two receptors-TrkB and p75 receptor. However, it is unclear on which cells BDNF is having its actions or the receptors used by these cells. BDNF may 
have a direct effect on the nerve fibers; alternatively, BDNF could affect the nerve fibers indirectly by binding to receptors on taste bud cells who in turn influence nerve fibers. Furthermore, BDNF could have its action via any of 3 receptors, p75, full-length TrkB, and truncated TrkB. To help figure out which was the case, we determined which cells within the taste bud express the BDNF receptors. We found that the full length TrkB receptor mRNA is expressed in the geniculate ganglion, not in taste buds. Furthermore, both taste buds and geniculate ganglion neurons express the TrkBT1 and p75 receptors, and the TrkBT1 receptor is expressed in multiple types of taste bud cells. These data demonstrate that BDNF released from taste bud cells can only signal via the full length TrkB receptor on nerve fibers of geniculate ganglion and not adjacent taste cells, but BDNF could influence innervation indirectly via TrkBT1 or p75 in adjacent taste receptor cells.

Both BDNF and the truncated TrkB receptor are expressed in taste bud cells. Truncated TrkB can function as a dominant negative receptor that inhibits full length TrkB signaling (Fenner, 2012). The function of the truncated (TrkBT1) receptor is not well established. It has been shown that TrkBT1 binds to and forms heterodimers with the full length TrkB receptor to inhibit full length TrkB receptor autophosphorylation and pathway activation (Eide et al., 1996; McCarty and Feinstein, 1998; Righi et al., 2000). In addition, TrkBT1 binds and internalizes BDNF in neurons (Biffo et al., 1995), and can sequester BDNF when in abundance and re-release it when BDNF is depleted (Biffo et al., 1995; Fryer et al., 1997; Alderson et al., 2000). TrkBT1 is expressed in epithelia, and in non- 
neuronal cells of the mammary gland where it functions to prevent BDNF-TrkB signaling in sensory axons and causes a developmental loss of mammary gland innervation in males (Liu et al., 2012). BDNF is expressed in a subpopulation of adult taste receptor cells, which are Type III taste cells (Car4 + taste cells) (Yee et al., 2003; Huang et al., 2015). We found that TrkBT1 is expressed in the Type II (Plc $\beta 2+)$ and Type III (Car4+) taste receptor cells. These results indicate that in some taste cells the TrkBT1 receptor is co-expressed with BDNF, but other taste receptor cells only express TrkBT1. This suggests that BDNF release may not be specific to Type III cells, because Type II cells could sequester BDNF and rerelease it (Alderson et al., 2000). Our results also reported that there are many TrkBT1 receptors expressed on the connective tissue cells immediately surrounding the taste bud, TrkBT1 in this location may function to bind and sequester BDNF to prevent BDNF spread to regions outside the taste bud.

Both the full length TrkB receptor and the truncated receptors can regulate dendritic branching and neuron morphology in the central nervous system. However, they likely have opposite roles. For example, the TrkBT1 receptor regulates complexity of neurites of neurons in the basolateral amygdala, but not hippocampus. Specifically, in TrkBT1 mutant neurons, there is a decrease in dendritic arbor complexity and reduction in dendritic length in amygdala (Carim-Todd et al., 2009). Interestingly TrkBT1 deletion rescues the effects of BDNF haplodeficiency suggesting that it inhibits BDNF function. TrkBT1 and full length TrkB can regulate distinct modes of dendritic growth in visual cortical neurons (Yacoubian and Lo, 2000). In our study, we found that both full length TrkB and TrkBT1 receptors 
are expressed in the geniculate ganglion. Therefore, it is possible that both the full length TrkB receptor and the truncated TrkB receptor promote to regulate peripheral fiber branches in geniculate neurons, but they possibly function in different neurons or branch types or with differential timing or modes of growth.

We found that the full length TrkB receptor mRNA is not detected in circumvallate taste buds of $K 14-B D N F-O E$ mice. This result is different from an earlier study demonstrating that the full length TrkB receptor is expressed in circumvallate taste buds of mice overexpressing BDNF under the control of the $\alpha$ gustducin promoter (Nosrat et al., 2012). It's possible that our results differ from this earlier study because we used the K14 promoter to overexpress BDNF instead of an a-gustducin promoter. The K14 promoter is efficient and results in BDNF expression in the tongue that is 70 times that of normal levels (LeMaster et al., 1999), and the a-gustducin promoter can only increase the BDNF expression to 7 times (Nosrat et al., 2012). Therefore, BDNF overexpression under the control of K14 should be more than sufficient to enhance expression of the full length TrkB receptor if its expression in relationship to BDNF expression is linear. It's also possible that the BDNF regulation of full length TrkB receptor follows an inverted-U dose-response curve. If so, the lower BDNF overexpression could induce the expression of the full length TrkB receptor, while the higher BDNF overexpression may inhibit expression of the full length TrkB receptor. Another possibility is that our primer was different from Nosrat et al., 2012, although both primers can detect the full length TrkB receptor. Lastly, a-gustducin-expressing cells are Type II taste receptor cells, which unlike K14+ taste cells do not normal- 
ly express BDNF (Huang et al., 2015). Therefore, this ectopic BDNF expression could induce full-length expression in the taste bud where it does not otherwise occur. We did find that the expression of the TrkBT1 receptor mRNA was upregulated in circumvallate taste buds of $K 14-B D N F-O E$ mice compare to wild type mice. Overexpression of BDNF may stimulate taste cells to produce more TrkBT1 receptor in order to bind and sequester BDNF. This would be consistent with the idea that TrkBT1 functions to bind and sequester BDNF to prevent BDNF spread to the outside of taste bud.

In addition to the TrkB receptor, p75 is another receptor which binds to BDNF. In the taste system, the p75 receptor regulates gustatory axon branching during development and is also required for maintaining a full complement of taste buds into adulthood (Fan et al., 2004; Krimm, 2006; Fei et al., 2014). The p75 receptor is expressed in ganglion neurons in both development and adulthood (Fei et al., 2014); however previous studies differ as to whether or not p75 is expressed in taste buds (Fan et al., 2004; Krimm, 2006). In this study, we sought to resolve this discrepancy. We found that p75 receptor mRNA is expressed in fungiform and circumvallate taste buds, and geniculate ganglion neurons by real time RT-PCR. P75 receptor expression in the geniculate ganglion is consistent with a previous immunostaining finding, but the p75 receptor was not previously found in the fungiform taste buds (Krimm, 2006). This may be because expression of the p75 receptor in fungiform taste buds is below detection levels for antibody staining. In conclusion, the p75 receptor was expressed in both taste buds and geniculate ganglion neurons, and so it may function to di- 
rectly influence nerve fibers or could indirectly influence nerve fibers via taste receptor cells.

In conclusion, the full length TrkB receptor mRNA is expressed in the geniculate ganglion neurons, not in the taste buds. These findings suggesting that BDNF released from taste bud cells signal via the full length TrkB receptor on nerve fibers of geniculate ganglion and not adjacent taste cells. The TrkBT1 receptor is expressed in multiple types of taste bud cells where TrkBT1 may function to bind and sequester BDNF in the taste bud to prevent BDNF binding to the full length TrkB receptor. Consistent with this idea TrkBT1 is up-regulated by increased BDNF levels. Finally, the p75 receptor is expressed in both taste buds and geniculate ganglion neurons which may bind the BDNF ligand to mediate geniculate ganglion axon branching in adulthood. 
Table 2. Sequences of primer pairs and probes used for real-time RT-PCR

Gene

Fragment

GenBack Accession \# Sequence 5'-3'

size (bp)

Total TrkB (NM_001025074)

Forward primer ACCTGCAGATACCCAATTGTG

Reverse primer GAAACCAAATTCCCAACGTCC

Taqman probe TGACCCACTCCCCACCTTGTACTG

P75 (AF105292)

74

Forward primer $\quad$ GGGTGATGGCAACCTCTACAGT

Reverse primer TGTCACCATTGAGCAGCTTCTC

Taqman Probe CCTGCCCCTGACCAAGCGTGAGGA

Full length TrkB (NM_001025074) 86

Forward primer $\quad$ AAGGACTTTCATCGGGAAGCTG

Reverse primer TCGCCCTCCACACAGACAC

Taqman Probe CCAACCTCCAGCACGAGCACATTGTCAA

TrkBT1 (NM_008745.3)

Forward primer

Reverse primer

Taqman Probe
CTATTTCCTTGTCCTGGTCTCG

AGTGTGGGTTTGGGAGTTG

TCACTGGCTACCCTGAAGTGTGAGTC 
Krt8 (NM_031170)

Forward primer

Reverse primer

Taqman Probe

GAPDH (NM_008084)

Forward primer

Reverse primer

Taqman Probe

$\beta$-Actin (NM_007393)

Forward primer

Reverse primer

Taqman Probe
TCTTCTGATGTCGTGTCCAAGTG

GATCCTCGGACGGGTCTCTAG

CCACTGAAGTCCTTGCCAGCCTGAGC

130

AATGTGTCCGTCGTGGATCTG

CAACCTGGTCCTCAGTGTAGC

CGTGCCGCCTGGAGAAACCTGCC

144

CTGGGACGACATGGAGAAGATC

GTCTCAAACATGATCTGGGTCATC

ACCTTCTACAATGAGCTGCGTGTGGCC 

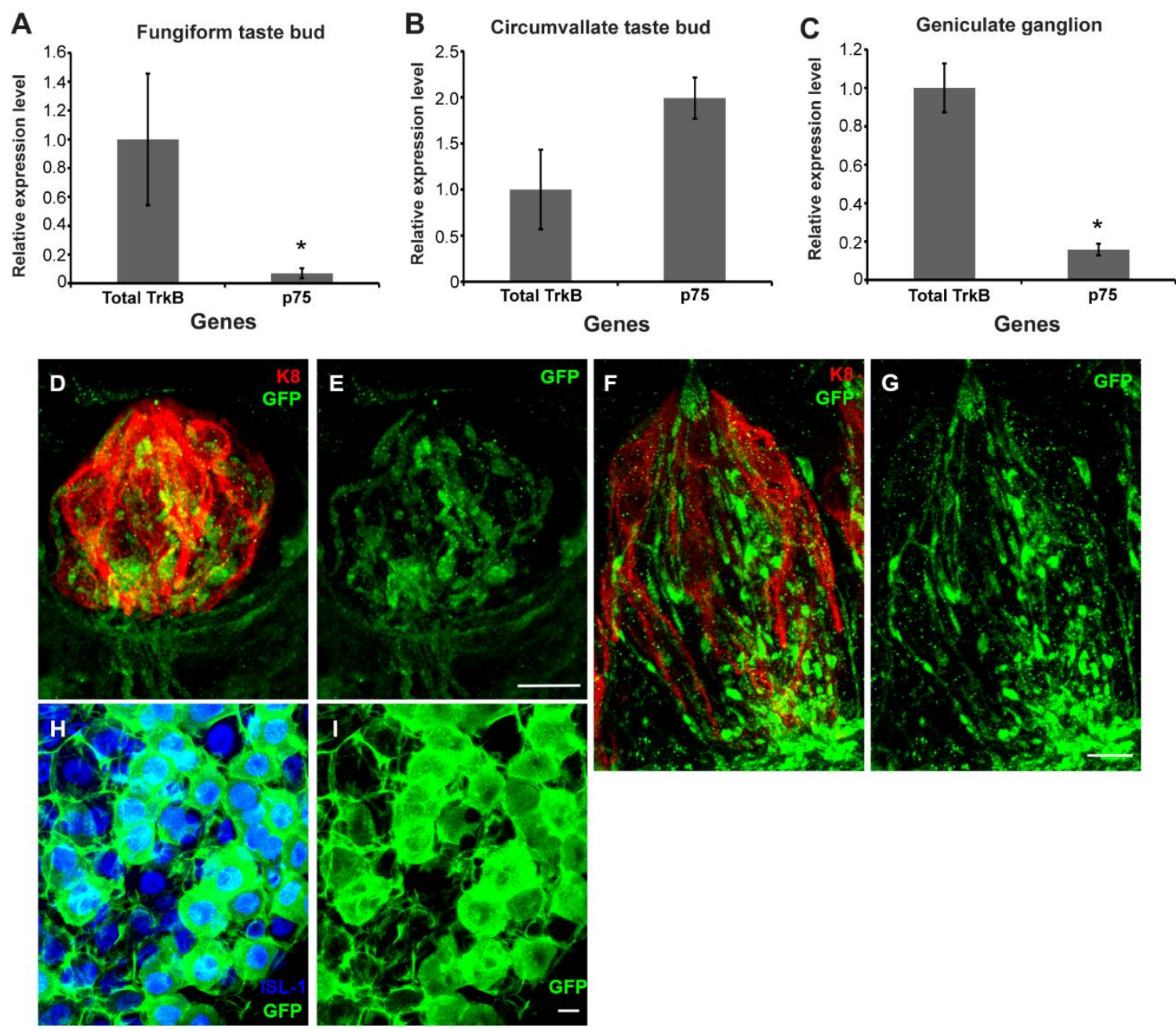

Figure 6 . The TrkB and p75 receptors are expressed in the geniculate ganglion and taste buds. Relative expression of the TrkB and p75 receptors are measured by Real time RT-PCR in the fungiform taste buds (A), circumvallate taste buds (B) and geniculate ganglion neurons (C) in wild type mice. The expression of the TrkB receptor was significantly higher than the p75 receptor in the fungiform taste buds and geniculate ganglion neurons $(p<0.05)$, but was not different in the circumvallate taste buds $(p=0.055)$. A fungiform taste bud $(E, F)$, and circumvallate taste bud $(F, G)$ were labeled with anti-GFP (green; $E, G$ ) and anticytokeratin 8 (K8, red; D, F), and a geniculate ganglion (I) was labeled with anti- 
GFP and anti-Islet-1 $\left(\mathrm{H}\right.$, blue) in an adult TrkB ${ }^{\mathrm{GFP} /+}$ mouse. The nerve fibers in the taste buds ( $E$ and $G$ ) and geniculate ganglion neurons (I) were strongly labeled with GFP. The scale bars in E $=10 \mu \mathrm{m}$ and apply to D-I. 

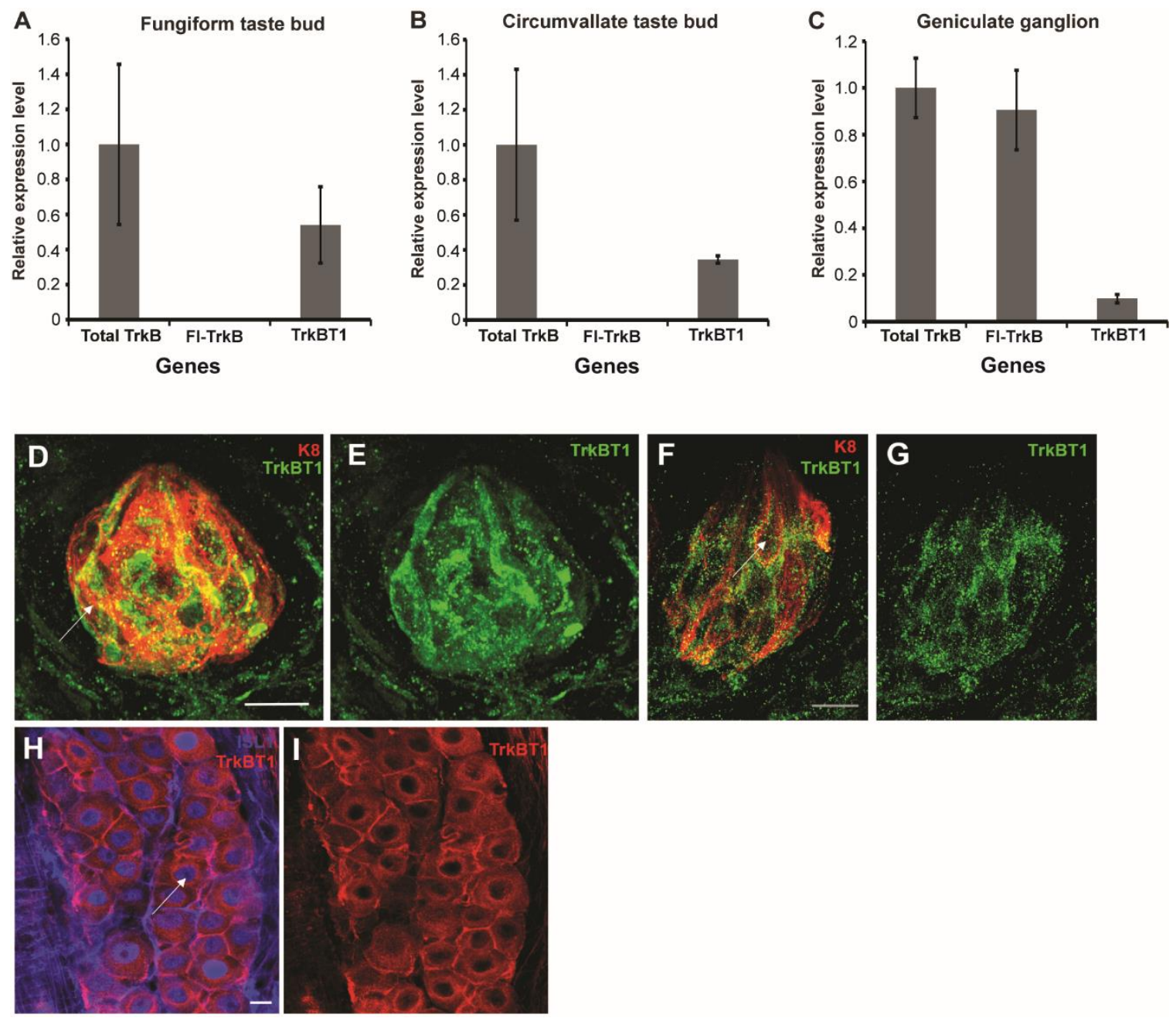

Figure 7. Geniculate ganglia express both full length TrkB and TrkBT1 receptors, while taste buds only expressed the TrkBT1 receptor. Relative expression of the full length TrkB and TrkBT1 receptors are measured by Real time RT-PCR in fungiform taste buds (A), circumvallate taste buds (B) and geniculate ganglion neurons (C) in wild-type mice. A fungiform taste bud (D, E) and circumvallate taste bud $(F, G)$ labeled with anti-TrkBT1 (E, G, green) and anti-cytokeratin 8 (D, $\mathrm{F}, \mathrm{K} 8$, red) in an adult wild type mouse. Geniculate ganglion neurons are labeled with anti-TrkBT1 (I, red) and anti-Islet-1 $\left(\mathrm{H}\right.$, blue) from TrkB ${ }^{\mathrm{GFP} /+}$ mouse. AntiTrkBT1 (arrow in A, C) weakly labeled taste cells in both fungiform and circum- 
vallate taste buds. Anti-TrkBT1 (arrow in E) clearly labeled geniculate ganglion neurons. The scale bars in $\mathrm{D}=10 \mu \mathrm{m}$ and applies to $\mathrm{D}-\mathrm{I}$. 

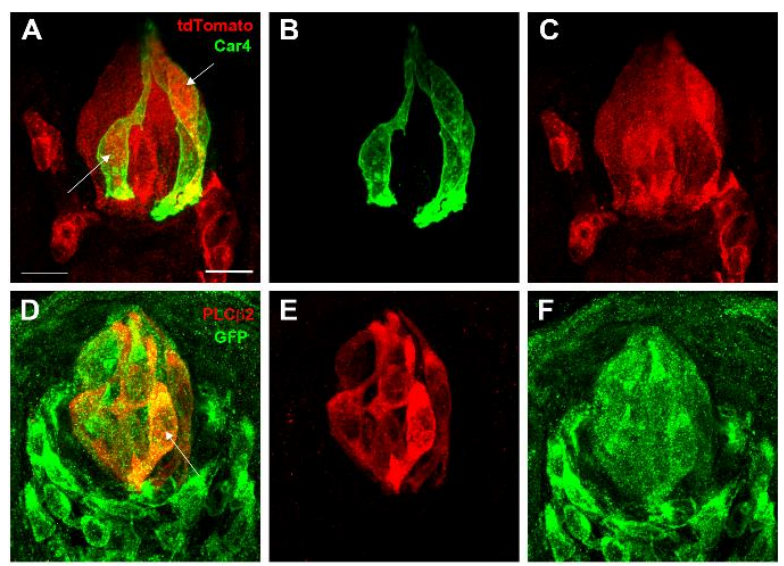

Figure 8. The TrkBT1 receptor is expressed in both Car4- and PLCß2-positive taste bud cells. A fungiform taste bud (A-C) is labeled with anti-Car4 (B, green) and anti-Dsred $(\mathrm{C}$, red) in an adult TrkB-CreER:tdTomato mouse. Arrows in A show Car4 cells labeled with Dsred (TrkBT1). A fungiform taste bud (D-F) is labeled with anti- PLCB2 (E, red) and anti-GFP ( $F$, green) in an adult TrkBCreER:YFP mice. An arrow in D shows PLC $\beta 2$ labeled cells are also labeled with YFP (TrkBT1). Thus, both Car4-positive and PLCß2-positive taste receptor cells express TrkBT1. The scale bars in A $=10 \mu \mathrm{m}$ and apply to all. 


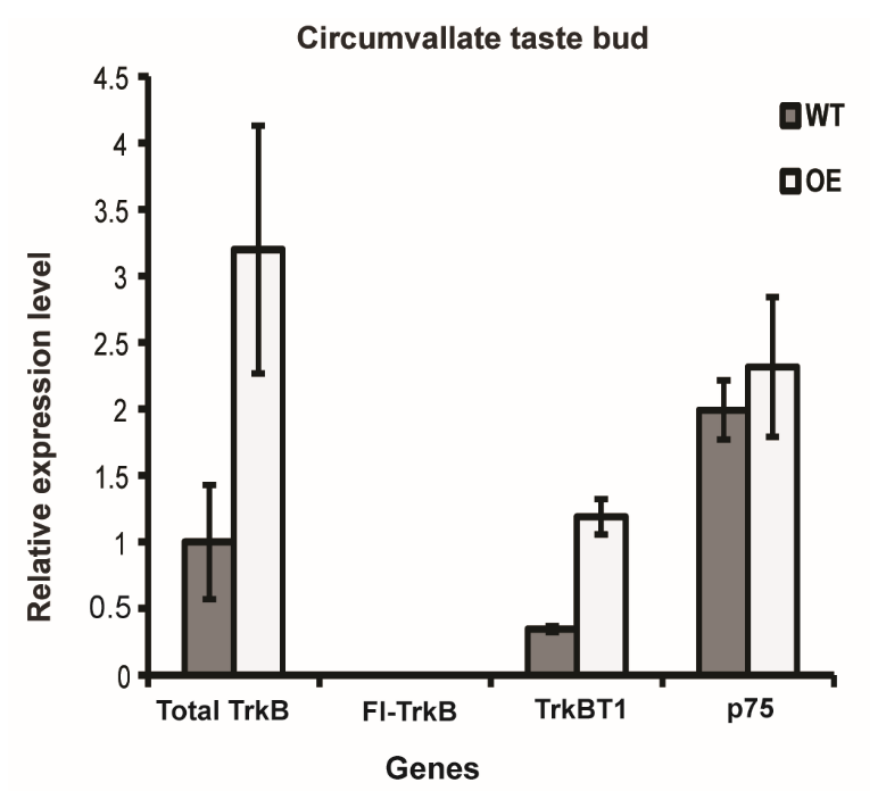

Figure 9. BDNF regulates the expression of TrkBT1, but not the full length receptor in the circumvallate taste buds. Relative expression of TrkB (total), the full length TrkB receptor, TrkBT1 and the p75 receptor in the circumvallate taste buds from both wild type and BDNF-overexpressing mice. The full length TrkB receptor was not expressed in the circumvallate taste buds of BDNFoverexpressing mice, but circumvallate taste buds did express TrkBT1 and the p75 receptor. The expression of total TrkB (the full length and truncated receptors combined) and TrkBT1 in the BDNF-overexpressing mice was significantly higher (Total TrkB, $p<0.05$; TrkBT1, $p<0.01$ ) than wild type mice, but the expression of p75 receptor was not different between wild type and BDNFoverexpressing mice. 
CHAPTER IV

\section{BLOCKING TRKB-SIGNALING DECREASES BRANCHES WITHIIN THE TASTE BUD WITHIN TWO WEEKS}

\subsection{Introduction}

In the tongue, taste buds in the fungiform papillae are innervated by geniculate ganglion neurons via chorda tympani nerve, which transmits information to the brain. During development the neurotrophin, brain-derived neurotrophic factor (BDNF), regulates the initial innervation to newly formed taste buds (Ringstedt et al., 1999; Krimm et al., 2001; Lopez and Krimm, 2006b; Ma et al., 2009). BDNF continues to be expressed in subpopulation of taste receptor cells in adulthood (Yee et al., 2003; Huang et al., 2015), where it continues to maintain taste bud innervation in adulthood (Meng et al., 2015) (Chapter II). Specifically, $55 \%$ of the TrkB-positive innervation within the taste bud was lost when Bdnf was specifically removed from taste buds and epithelium for 10 weeks in adulthood (Chapter II). The main function of BDNF is mediated by the full length TrkB receptor. The full length TrkB receptor is expressed in the geniculate ganglion neurons, but not in the taste buds (Chapter III). Therefore, if BDNF maintains innervation through the full length TrkB receptor, BDNF's action is directly on nerve fibers. 
Taste receptor cells have a limited lifespan and continuously turn over throughout life (Beidler and Smallman, 1965; Perea-Martinez et al., 2013). Therefore, maintenance of innervation to taste bud is an active process, which may depend on BDNF. TrkB-positive innervation is reduced 10 weeks following Bdnf gene recombination in taste buds and epithelium (Chapter II). However, many taste receptor cells are replaced within 2 weeks (Beidler and Smallman, 1965; Perea-Martinez et al., 2013), which means some taste receptor cells may have been replaced several times by 10 weeks. Therefore, it is unclear whether BDNF supports taste bud innervation with timing consistent with BDNF support of new taste receptor cells.

The current study had two goals. First to determine if BDNF signaling affects the taste innervation via full the length TrkB receptor. Second, to determine whether blocking TrkB signaling can impact innervation to taste bud with timing consistent with regulation of innervation during receptor cell turnover. Because BDNF-TrkB signaling regulates branching during central nervous system development and adulthood (Martinez et al., 1998; Gorski et al., 2003; Chakravarthy et al., 2006; Liu et al., 2007; Bergami et al., 2008; Wang et al., 2015), we wanted to use an approach that would permit the measure of specific branching characteristics in the taste bud. Therefore, we combined a chemical genetic approach for blocking TrkB signaling with a sparse cell labeling approach in which only a subset of TrkB-positive nerve fibers were labeled allowing branches of individual fibers to be examined. We found that blocking TrkB-signaling resulted in a reduc- 
tion of the number of labeled fibers innervating the taste bud and also reduced branching of fibers within the taste bud.

\subsection{Methods}

\subsubsection{Animals}

To block TrkB-signaling we used mice in which the TrkB allele harbors a single point mutation by changing phenylalanine $(F)$ to alanine $(A)$ within the ATP binding pocket of kinase subdomain $\mathrm{V}\left(\operatorname{TrkB}^{\mathrm{F} 616 A}\right)$, this modified TrkB gene is also flanked by LoxP sequences (Chen et al., 2005). The substitution of phenylalanine $(F)$ with an alanine $(A)$ in adjacent introns does not affect BDNF-dependent TrkB signaling, but does render the mutant TrkB receptor susceptible to inhibition by 1NM-PP1 (Chen et al., 2005). In order to visualize TrkB-positive nerve fibers, mice with-tdTomato and -YFP conditional alleles were bred with mouse lines containing an inducible Cre-recombinase driven by the TrkB promoter (TrkBCreER; \#027214, Jackson Laboratory), the resulting offspring (TrkB CreER: YFP/tdTomato) had the STOP cassette deleted in Cre-expressing cells; resulting in expression of either tdTomato or YFP or both. Experimental and control mice were generated by crossing male (TrkB ${ }^{F 616 A /+} ;$ YFP) with female (TrkB $B^{C r e E /+}$; tdTomato) mice. Thus, one set of experimental mice had a point mutation on one TrkB allele, allowing TrkB signaling to be blocked with 1NM-PP1 (TrkB ${ }^{\text {CreER/F616A }}$ : YFP/tdTomato). The other set of experimental mice also had a point mutation on

one TrkB allele, while without 1NM-PP1 injection (TrkB ${ }^{\text {CreER/F616A }}$ : YFP/tdTomato without 1NM-PP1). Two control genotypes were used for different purposes of comparison. TrkB ${ }^{C r e E R / t}$ : YFP/tdTomato without 1NM-PP1 are compared with 
TrkB ${ }^{C r e E R / t}$ : YFP/tdTomato with 1NM-PP1 to determine if $1 \mathrm{NM}-\mathrm{PP} 1$ has any nonspecific effects on TrkB-positive innervation. TrkB ${ }^{\mathrm{CreER/+}}$ : YFP/tdTomato without 1NM-PP1 are compared with TrkB ${ }^{\text {CreER/F616A }}$ YFP/tdTomato without 1NM-PP1 to determine if Tamoxifen has any effects on TrkB gene recombination in subset of TrkB-positive fibers.

\subsubsection{Tamoxifen and 1NM-PP1 administration}

Mice were injected with tamoxifen (T5648, Sigma-Aldrich, St. Louis, MO; mixed in peanut oil, $188 \mathrm{ng} / \mathrm{g}$ body weight) once per day for 5 days by oral gavage beginning at day P35 Then two genotypes (TrkB ${ }^{\text {CreER/F616A }}$ : YFP/tdTomato and Trk-

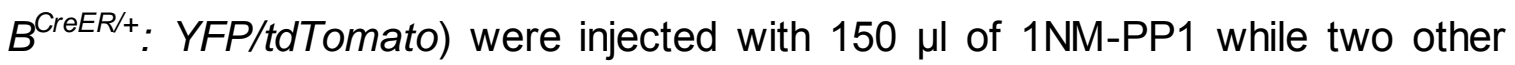
genotypes (TrkB ${ }^{C r e E R / F 616 A}:$ YFP/tdTomato and TrkB ${ }^{C r e E R / t}$ : YFP/tdTomato) were injected with vehicle. 1NM-PP1 was mixed by dissolving $50 \mathrm{mg}$ into $1508 \mu \mathrm{l}$ of DMSO to make a $100 \mathrm{mM}$ stock solution. For injections $12 \mu \mathrm{l}$ of the 1 NMPP1 stock solution (1NMPP1 injections) or DMSO (vehicle injections) was diluted into $138 \mu \mathrm{l}$ of injection solution ( $0.9 \% \mathrm{NaCl}$ and $2.5 \%$ Tween-20) (Johnson et al., 2008). All the mice were euthanized after two weeks of 1NM-PP1 or vehicle injections for anatomical analysis.

\subsubsection{Immunohistochemistry}

Mice were euthanized by an overdose of Avertin ( $4 \mathrm{mg} / \mathrm{kg}$ body weight), transcardially perfused with $4 \%$ paraformaldehyde (PFA), and post-fixed in PFA for 2 hours or immersion-fixed in 4\% PFA overnight. The anterior part of the tongue was dissected and post-fixed overnight in 4\% PFA. The tissue was transferred to $30 \%$ sucrose at $4^{\circ} \mathrm{C}$ overnight, frozen in OCT, and stored at $-80^{\circ} \mathrm{C}$ until 
used. To visualize taste buds and TrkB innervation, in thick floating sections, tongues were sectioned at $70 \mu \mathrm{m}$, and the sections were collected in $0.1 \mathrm{M}$ phosphate-buffered saline (PBS) and rinsed four times in PBS. Cryostat sections were blocked with $3 \%$ normal donkey serum in $0.1 \mathrm{M}$ PBS containing $0.5 \%$ Triton X100. The tissue was incubated with the following primary antibodies for 5 days at $4^{\circ} \mathrm{C}$ : rat anti-K8 in PBS (1:50; Developmental Studies Hybridoma Bank, AB Registry ID: AB_531826, cat\#: Troma-1-s, lowa City, IA), goat anti-GFP (1:400; Novus, AB Registry ID: AB_10128178, cat\#: NB100-1700, Littleton, CO), rabbit anti-Dsred (1:500; Clontech, Catalog \# 632496, Mountain View, CA, USA). After incubation in primary antibodies and four rinses in PBS, sections were incubated in the following secondary antibodies for 2 days: anti-rat Alexa Fluor 647 (1:500; Jackson ImmunoResearch Laboratories, West Grove, PA), anti-goat Alexa Fluor 488 (1:500; Jackson ImmunoResearch Laboratories), or anti-rabbit Alexa Fluor 555 (1:500; Jackson ImmunoResearch Laboratories). The tissue was then washed four times in 0.1M PBS, mounted onto slides, and cover-slipped using aqueous mounting medium (Fluoromount-G, SouthernBiotech, Birmingham, AL). To visualize whole taste buds and quantify branching characteristics, we performed whole mount staining of the entire lingual epithelium. The epithelium including taste buds was excised from the tongue muscle. This was accomplished by first removing most of muscle from underneath of the tongue with scissors. The tongue epithelium with attached lamina propria frozen in OCT and the lamina propria was reduced in thickness by sectioning on the cryostat. The remaining 
tongue epithelium was then processed for whole mount immunohistochemistry using the same protocol as described above.

4.2.4 Quantification of the number of taste buds innervated by labeled TrkBpositive fibers.

The numbers of taste buds innervated by red, green and yellow labeled TrkB-positive fibers were counted in thick sections of the tongue using a Leica DMLB microscope. Specifically, in addition to determining if a taste bud is innervated or uninnervated by TrkB-positive fibers, innervated taste buds were classified into those innervated by fibers of only color (red, green, or yellow -only) vs taste buds innervated by fibers with more than one color. The probability of an individual taste bud having fibers of multiple colors would be reduced as the number of fibers innervating each taste bud is reduced.

4.2.5 Quantification of TrkB-positive fiber branching within the taste bud.

Taste buds from the tip of the tongue were imaged by an Olympus Fluoview FV1200 Laser scanning confocal microscope. Optical images were captured every $0.47 \mu \mathrm{m}$ with a $60 \times$ objective at a zoom level of 3.5 from the front one-third of the fungiform field (i.e., tongue tip). For each image, all three channels were taken separately using single-wavelength excitation and merged to produce a composite image. The first six taste buds identified containing TrkBpositive fibers per mouse tongue were used for quantification. These taste buds were all taken from the tip of the tongue where taste bud density is high. All the taste bud images were deconvolved using Deconvolution Software (AutoQuant X, Media Cybernetics, MD, USA). Each labeled fiber was traced from where it 
entered the taste bud (defined by keratin 8 labeling) using Neurolucida 360 software (MBF Bioscience, Williston, Vermont, USA). The number of fibers entering the taste bud, fiber length, number of branch points, and branch ends were measured.

\subsubsection{Statistical analysis}

Results are expressed as mean \pm standard error of the mean (SEM). Oneway analysis of variance (ANOVA) was used to test for differences between genotypes for the percentage of taste buds that are innervated by labeled TrkBpositive fibers, the percentage of taste buds are innervated by labeled fibers of two or more colors, total fiber length, total number of fibers, total branch ends, total branch points, percentage of fibers have secondary or higher branches, percentage of fibers have tertiary or higher branches, mean length of total branch fibers, mean length of primary branch fibers and mean length of secondary or higher order branch fibers. Two-way analysis of variance (ANOVA) was used to compare differences in the patterns within the histogram for branch length a twoway analysis of variance (ANOVA) was used to compare the values at each interval across genotypes, a significant difference in the interaction effect indicates differences in the pattern of these distributions. After significant overall ANOVAs, Student-Newman-Keuls post-hoc tests were used for pairwise comparisons. Statistical significance was set at $p<0.05$.

\subsection{Results}


4.3.1 Fewer taste buds are innervated by labeled TrkB-positive fibers when TrkBsignaling is blocked by $1 \mathrm{NM}-\mathrm{PP} 1$.

TrkB-positive innervation to the taste bud is reduced when the Bdnf gene is inducibly removed from the tongue epithelium and taste bud for 10 weeks in adult mice (Chapter II). Nerve fibers express the full length TrkB receptor, while taste buds do not (Chapter III). Since many taste receptor cells have been replaced by new cells within two weeks (Beidler and Smallman, 1965; PereaMartinez et al., 2013), I hypothesized that an effect could be seen in two weeks if BDNF-TrkB-signaling does regulate innervation to new taste receptor cells. We had two questions. First, we wanted to know if BDNF functions through the full length TrkB receptor to affect innervation to the taste bud. If so, this would mean the action of BDNF is directly on nerve fibers. Second, we wanted to know if the BDNF-TrkB signaling functions with a timing consistent with support of innervation to new taste receptor cells. To answer these questions, we blocked TrkBsignaling using a chemical genetic approach where the TrkB gene was removed in a subset of neurons via gene recombination and then the remaining TrkB could be blocked with 1NMPP1 (TrkB ${ }^{\text {CreER/F616A: YFP/tdTomato). These mice }}$ were compared to mice of the same genotype that underwent TrkB gene recombination, but TrkB signaling was not blocked and a control genotype (TrkB ${ }^{\mathrm{CreER/+}}$ : YFP/tdTomato) both with and with 1NM-PP1. We also wanted to use a more sensitive method for quantifying innervation to the taste bud. Therefore, we used inducible genetic labeling to randomly label most TrkB-positive fibers with two markers - tdTomato and GFP. Because gene recombination is random this re- 
sulted in red (tdtomato-only), green (GFP-only) and yellow (tdtomato plus GFP) fibers. Taste buds were labeled with anti-cytokeratin-8 (Blue) (Figure10, A-P). Most of taste buds from control genotypes (TrkB ${ }^{\mathrm{CreER} / t}$ : YFP/tdTomato without 1NM-PP1 is shown) are innervated by red, green, and yellow labeled TrkBpositive fibers (Figure 10, A-D). When all three colors are present this indicated that the taste bud is innervated by 3 or more different neurons. In mice in which TrkB signaling was blocked (TrkB ${ }^{C r e E R / F 616 A}$ : YFP/tdTomato) with 1NM-PP1, some of taste buds are uninnervated by TrkB-labeled fibers (Figure 10, E-H); other taste buds were innervated by only one color of TrkB-labeled fibers (Figure 10, IL). Unlike controls, some taste buds were innervated by one color of TrkBlabeled fibers, but appeared to have reduced TrkB-labeled innervation (Figure 10, M-P). Because the truncated TrkB receptor is expressed in lingual epithelium, some perigemmel cells were also labeled (arrows in the Figure 10).

To examine the effect of blocking TrkB signaling on TrkB-positive innervation within taste buds, we counted the percentage of taste buds that were innervated by TrkB-labeled fibers and taste buds are innervated by TrkB-labeled fibers of more than one different color, indicating that the taste bud is innervated by two or more TrkB-labeled neurons. Two weeks after 1NM-PP1 administration, the percentage of taste buds innervated by labeled TrkB-positive fibers was different across genotypes $\left(F_{(3,11)}=27.290, p<0.001\right)$. Specifically, when TrkB signaling was blocked (TrkB ${ }^{C r e E R / F 616 A}$ : YFP/tdTomato mice) with 1NM-PP1, the percentage of taste buds innervated by TrkB-positive fibers was decreased to $68 \%$ compared with two control genotypes (TrkB ${ }^{C r e E R / t}$ : YFP/tdTomato without 1NM-PP1, 
$\mathrm{p}<0.001 ;$ TrkB ${ }^{\text {CreER/t }}:$ YFP/tdTomato with 1NM-PP1, $<<0.001$, Figure 11) and with sparse TrkB gene recombination alone (TrkB ${ }^{\text {CreER/F616A }}$ YFP/tdTomato without 1NM-PP1, $p<0.001$, Figure 11). There was no difference in percentage of taste buds innervated by labeled TrkB-positive fibers among the other three genotypes $\left(\right.$ TrkB $^{\text {CreER/t}}$ : YFP/tdTomato without $1 \mathrm{NM}-\mathrm{PP} 1, \operatorname{TrkB}^{\mathrm{CreER} / t}$ : YFP/tdTomato with 1NM-PP1, TrkB ${ }^{C r e E R / F 616 A}:$ YFP/tdTomato without 1NM-PP1), which was around $98 \%$ of taste bud. This indicates that neither the 1NM-PP1 nor the floxed TrkB allele changed the number of TrkB-positive fibers innervating the taste bud. The percentage of taste buds innervated by multiple colors of labeled TrkB-positive fibers was also different across genotypes $\left(F_{(3,11)}=118.588, p<0.001\right)$. Specifically, when TrkB-signaling was blocked (TrkB ${ }^{\text {CreER/F616A }}$ YFP/tdTomato) with 1NMPP1 fewer taste buds were innervated by labeled TrkB-positive fibers of more than one color compared with each of three genotypes (TrkB ${ }^{C r e E R / t}$ : YFP/tdTomato without 1NM-PP1, p<0.001; TrkB ${ }^{\mathrm{CreER} /+}$ : YFP/tdTomato with 1NMPP1, $p<0.001, T r k B^{C r e E R / F 616 A}$ : YFP/tdTomato without 1NM-PP1, $p<0.001$, Figure 11). There was no difference in the percentage of taste buds that were innervated by TrkB-positive fibers labeled by more than one color among the three other genotypes (around $72 \%$ ). These data indicate that neither 1NM-PP1 nor a partial removal of TrkB changed the percentage of taste buds that were innervated by labeled TrkB-positive fibers of more than one color. As the number of labeled TrkB-positive neurons innervating the taste bud increases, the probability of have more than one color of labeled fiber also increases. Therefore, this is an indirect measure of the number of TrkB-positive neurons innervating the taste bud. 
These data suggest that the number of TrkB-positive neurons innervating the taste bud was reduced by blocking TrkB signaling.

4.3.2 Blocking TrkB signaling reduced both the number of separate TrkB-positive fibers entering and branch points within the taste bud.

We wondered whether blocking TrkB-signaling would have an effect on the number of branches made by TrkB-positive fibers within taste buds. BDNF plays an important role in regulating the growth and branching of cortical and hippocampal neurons (McAllister et al., 1995; Niblock et al., 2000; Horch and Katz, 2002; Dijkhuizen and Ghosh, 2005; Cheung et al., 2007; Lazo et al., 2013). Mutant mice with an inducible deletion of TrkB receptors exhibit a significant reduction of dendritic arborization in cortical neurons (Xu et al., 2000). However, it is not clear whether BDNF-TrkB signaling could regulate the branching of taste neurons. To answer this question, we quantified the branching characteristics of TrkB-positive innervation within the taste bud of two experiment genotypes (Trk$B^{\text {CreER/F616A }}:$ YFP/tdTomato mice with 1NM-PP1, TrkB ${ }^{\text {CreER/F616A. YFP/tdTomato }}$ without 1NM-PP1) and two control genotypes (TrkB ${ }^{C r e E R /+}$ : YFP/tdTomato without 1NM-PP1, TrkB ${ }^{\text {CreER/t}: ~ Y F P / t d T o m a t o ~ w i t h ~ 1 N M-P P 1) . ~ B e c a u s e ~ g e n e ~ r e c o m b i n a-~}$ tion is random and incomplete at lower doses of tamoxifen, tamoxifen injections resulted in TrkB-positive fibers that were labeled, red-only, green-only and both red and green (yellow). Using this type of visualization allowed individual fibers to be followed in the taste buds. Because gene recombination is random and some fibers were red-only, some green-only and others were both red and green. 
Therefore, it was possible to trace each TrkB-positive fiber from the bottom of taste bud using Neurolucida 360 software (Figure 12).

To quantify the different characteristics of TrkB-positive innervation, we analyzed the total fiber length, number of independent fibers entering the taste bud, total branch ends, and total branch points within the taste bud. The total length of TrkB-positive fibers within taste bud was different across the genotypes $\left(F_{(3,11)}=13.270, p<0.01\right)$. Specifically, taste buds from mice in which TrkBsignaling was blocked TrkB-signaling (TrkB ${ }^{C r e E R / F 616 A}$ : YFP/tdTomato with 1NMPP1) had a significant reduction in total fiber length compared with two control genotypes (TrkB ${ }^{\mathrm{CreER} / t}$ : YFP/tdTomato without 1NM-PP1, p<0.01; TrkB ${ }^{\mathrm{CreER/+}}$ : YFP/tdTomato with 1NM-PP1, $p<0.01$; Figure 13A) and mice that underwent gene recombination without blocking with 1NM-PP1 (TrkB ${ }^{\text {CreER/F616A }}$ : YFP/tdTomato, $\mathrm{p}<0.01$; Figure 13A). There was no difference in total TrkBpositive fiber length among the other three genotypes, which indicates that neither 1NM-PP1 nor the point mutation on the TrkB allele altered total fiber length. The total number of fibers entering the taste bud was also different across the genotypes $\left(F_{(3,11)}=6.911, p<0.05\right)$. Specifically, taste buds of mice in which TrkBsignaling was blocked (TrkB ${ }^{C r e E R / F 616 A}:$ YFP/tdTomato with 1NM-PP1) had a significant decrease in the total number of fibers compared with the two control genotypes (TrkB ${ }^{C r e E R /+}$ : YFP/tdTomato without 1NM-PP1, p<0.05; TrkB ${ }^{C r e E R /+}$ : YFP/tdTomato with 1NM-PP1, p<0.05; Figure 13B). However, there was no difference with mice of the same genotype in which TrkB was not blocked ( TrkB ${ }^{\text {Cre- }}$ ER/F616A: YFP/tdTomato without 1NM-PP1, $\mathrm{p}=0.149)$. This means that mice un- 
derwent TrkB gene recombination also had fewer fibers entering the taste bud. There was no difference in total number of fibers in the two control genotypes, which means 1NM-PP1 had no effect on the total number of fibers within taste bud.

In order to examine branching we measured the total branch points and branch ends within the taste bud. The total branch ends and total branch points within taste buds were also different across the genotypes (total branch ends, $F_{(3,11)}=16.78, p<0.001$; total branch points, $\left.F_{(3,11)}=34.02, p<0.001\right)$. Specifically, branching was reduced in mice in which TrkB-signaling was blocked (TrkB ${ }^{\text {Cre- }}$ ER/F616A: YFP/tdTomato with 1NM-PP1) mice compared with the other three genotypes (total branch ends, TrkB ${ }^{C r e E R /+}$ : YFP/tdTomato without 1NM-PP1, p<0.001; TrkB ${ }^{\text {CreER/t }}$ : YFP/tdTomato with 1NM-PP1, p<0.01; TrkB ${ }^{\text {CreER/F616A. }}$ YFP/tdTomato without 1NM-PP1, $\mathrm{p}<0.05$. total branch points, TrkB ${ }^{C r e E R / t}$ : YFP/tdTomato without 1NM-PP1, p<0.001; TrkB ${ }^{\mathrm{CreER} /+}$ : YFP/tdTomato with 1NM-PP1, p<0.001; TrkB ${ }^{\text {Cre- }}$ ER/F616A: YFP/tdTomato without 1NM-PP1, $p<0.01$; Figure 13 C-D). However, in mice that underwent TrkB gene recombination such that the TrkB gene was removed in some, but probably not most neurons (TrkB ${ }^{\text {CreER/F616A. YFP/tdTomato }}$ without 1NM-PP1), both total branch ends and total branch points were decreased compare to one of the control groups (TrkB ${ }^{C r e E R /+}$ : YFP/tdTomato without 1NM-PP1, total branch ends, $p<0.05$. total branch points, $p<0.05$ ), but not the other (TrkB ${ }^{C r e E R /+}$ : YFP/tdTomato with 1NM-PP1 mice; total branch ends, $p=0.101$. total branch points, $p=0.131$ ). There were no obvious differences between the two controls genotypes, indicating that 1NM-PP1 in the absence of the 
point mutation has no impact on branching. These data indicate that partial removal of the TrkB gene is sufficient to reduce the number of branch ends and branch points within the taste bud, and this effect is enhanced by blocking TrkBsignaling.

We wanted to know if branch ends were lost because the numbers of fibers entering the taste bud were reduced, or if remaining fibers also lose branch ends. To address this question, we measured the percentage of fibers that have secondary or higher order branches and percentage of fibers have tertiary or higher branches within taste buds. We identified each branch from its entry into the taste bud to the first branch point as the primary branch, the first branch point to second branch point as a secondary branch, etc. The percentage of fibers that have secondary or higher branches and percentage of fibers have tertiary or higher branches are significantly reduced after blocking TrkB-signaling (TrkB ${ }^{C r e-}$ ER/F616A: YFP/tdTomato with 1NM-PP1 mice) compared with the other three genotypes (percentage of fibers have secondary or higher branches: $T r k B^{C r e E R /+}$ : YFP/tdTomato without 1NM-PP1, p<0.001; TrkB ${ }^{\text {CreER/t }}$ : YFP/tdTomato with 1NMPP1, $\mathrm{p}<0.001 ;$ TrkB ${ }^{\text {CreER/F616A }}$ YFP/tdTomato without 1NM-PP1, $\mathrm{p}<0.001$. percentage of fibers have tertiary or higher branches: TrkB ${ }^{C r e E R /+}$ : YFP/tdTomato without 1NM-PP1, $\mathrm{p}<0.001 ;$ TrkB $^{\mathrm{CreER} /+}$ : YFP/tdTomato with 1NM-PP1, $\mathrm{p}<0.001$;

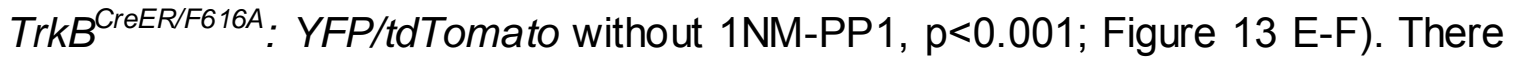
were also no difference between the two control genotypes (TrkB ${ }^{C r e E R / t}$ : YFP/tdTomato without 1NM-PP1, TrkB ${ }^{\text {CreER/t}}:$ YFP/tdTomato with 1NM-PP1) and one that underwent limited TrkB gene recombination (TrkB ${ }^{\text {CreER/F616A. }}$ 
YFP/tdTomato without 1NM-PP1), which indicates that neither tamoxifen nor a point mutation on TrkB allele has an effect on the percentage of fibers with higher order branches. These data suggest that the remaining fibers have fewer branches when TrkB signaling is blocked.

In summary, we found that blocking TrkB signaling can cause a reduction in the total fiber length, total number of fibers, total branch ends, total branch points and percentage of fibers with higher order branches. These data indicate that innervation to the taste bud is reduced both because the number of separate fiber branches entering the taste bud is reduced and some higher order branches on the fiber branches remaining in the taste bud are lost.

4.3.3 Primary branches become longer due to a loss of higher order branches when TrkB signaling is blocked.

We wanted to know whether branch length was impacted by blocking BDNF-TrkB signaling. To address this question, we first analyzed the mean length of all fiber branches within the taste bud. We found that there are no significant differences between mice in which TrkB-signaling is blocked (TrkB ${ }^{\text {Cre- }}$ ER/F616A: YFP/tdTomato with 1NM-PP1) compared with the other three genotypes $\left(F_{(3,11)}=3.278, p=0.08\right)$ (Figure 14A). When branch length was plotted on a histogram, there was no significant differences between the experiment and control genotypes $\left(F_{(30,88)}=0.898, p=0.62\right) \quad(F i g u r e$ 14B). These data suggest that branches are lost equally across the different lengths.

If a fiber entering the taste bud consists of a single primary and two secondary branches, and one secondary branch is lost, the remaining of primary fi- 
ber will become longer. Therefore, it seemed likely that although there was no difference in mean fiber length, some branches become longer while others become shorter. This would result in the same average branch length across genotypes. To examine this possibility, we measured the mean length of primary and higher order branch fibers separately and found that the mean length of primary branches is not different between mice in which TrkB-signaling was blocked for

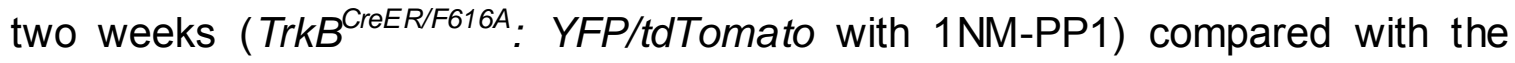
other three genotypes $\left(F_{(3,11)}=0.353, p=0.788\right)$ (Figure 14C). However, when branch length is plotted on a histogram, there were fewer short primary branches and more medium sized within the taste buds of mice with reduced TrkBsignaling (TrkB ${ }^{\text {CreER/F616A }}$ : YFP/tdTomato with 1NM-PP) compared with the other three genotypes $\left(F_{(30,88)}=1.615, p<0.05\right)$ (Figure 14D). Specifically, the primary branch fibers were shifted from shorter lengths to longer lengths compared with other three genotypes.

For the higher order branch fibers, we found that the mean lengths of secondary or higher order branches were significantly decreased after two weeks of blocking TrkB-signaling (TrkB ${ }^{\text {CreER/F616A }}$ : YFP/tdTomato with 1NM-PP1) compared with other three genotypes $\left(F_{(3,11)}=6.172, p<0.05\right)$ (Figure $\left.14 E\right)$. However, this decrease was roughly the same across the different lengths of these fibers $\left(F_{(30,88)}=0.916, p=0.60\right)$ (Figure 14F). Specifically, there is no difference on the frequency of short (0-15 um), medium (15-30 um) secondary or higher order branch fibers among those four genotypes. However, there was a loss of the longest branches in that the frequency of long secondary or higher order branch- 
es (>30 um) was decreased in the TrkB ${ }^{\text {CreER/F616A }}$ : YFP/tdTomato with 1NM-PP1 mice compared with other three genotypes. Taken together, these data indicate that when TrkB signaling is blocked, some short primary branches become longer because of a loss of higher or branches, while higher order branches decrease in length.

\subsection{Discussion}

Taste receptor cells turnover continuously and most of them have around a 2 week lifespan (Beidler and Smallman, 1965; Perea-Martinez et al., 2013). When new taste receptor cells enter the taste bud, they must be innervated by taste fibers. One possible factor regulating this continuous plasticity is the neurotrophin, BDNF. Consistent with this possibility, $40 \%$ of taste innervation and $55 \%$ of TrkB-positive innervation are lost from the taste bud when BDNF is inducibly removed for 10 weeks (Meng et al., 2015) (Chapter II). If BDNF does has this role its action in maintaining innervation to the taste bud would occur on nerve fibers. Consistent with a direct action on nerve fibers, I found that the full length TrkB receptor was expressed on the nerve fibers, and not in the taste buds (Chapter III). However, BDNF still could have its function directly on taste cells via other BDNF receptors (p75 and TrkBT1) which are expressed in the taste bud (Chapter III). To determine if the action of BDNF is via the full length TrkB receptor we blocked BDNF-TrkB signaling through the full length TrkB receptor. We found that fewer taste buds were innervated by TrkB-positive fibers. In addition, innervated taste buds had reduced innervation primarily due to reduced branch- 
ing of fibers in the taste bud. We conclude that the action of BDNF occurs directly on nerve fibers,

Taste bud innervation is lost when BDNF is inducibly removed for 10 weeks (Meng et al., 2015) (Chapter II). So it seems likely that BDNF functions to maintain innervation to mature taste cells or recruit innervation to new taste receptor cells. However, many taste receptor cells are replaced within two weeks (Beidler and Smallman, 1965; Perea-Martinez et al., 2013), and in previous studies it took 70 days to observe an effect following BDNF removal; this timing is inconsistent with this hypothesis. Because it is unclear when the BDNF is reduced to levels where it is likely to have an effect, it is difficult to know when BDNF removal is first acting on taste bud innervation. To resolve this problem, we used chemical 1NM-PP1 to block TrkB-signaling for two weeks. We found that blocking TrkB-signaling reduces taste bud innervation within this time period, which is consistent with BDNF having a role regulating innervation to new taste receptor cells.

Previous studies found that the volume of TrkB-positive innervation was reduced when BDNF was inducibly removed (Chapter II). In this study, all TrkBpositive fibers are labeled in a single color, and the TrkB-positive fibers are densely packed within taste buds, such that single fibers cannot be analyzed. Thus, it is not possible to follow fibers individually as they course through the taste bud. Because of this limitation, this measure was likely less sensitive than examining single fibers required a larger difference to observe an effect. In addition, no information was provided concerning what aspect of innervation had 
been altered. In this study, we combined sparse genetic labeling in multiple colors to allow us to follow individual branches as they course through the taste bud. This technique provided a more sensitive measurement which allowed us to quantify branching characteristics of individual TrkB-positive fibers. Using this new measurement, we found that the number of fibers entering taste buds, the total fiber length and the number of total branch fibers were significantly decreased when BDNF is inducibly removed. This finding indicates that this new technique provides a much more detailed analysis of branching characteristics of TrkB-positive fibers, which could not be achieved with volume measurements.

Although TrkB innervation is reduced when TrkB signaling is blocked for 2 weeks, TrkB-positive fibers are not completely lost. One possible explanation for this finding is because the chemical 1 NM-PP1 blocked the TrkB $^{\mathrm{F} 616 \mathrm{~A}}$ autophosphorylation and signaling on full length TrkB receptor, not the truncated isoform (Chen et al., 2005). It is possible that some of TrkB-positive fibers only express the truncated isoform, but not full length TrkB receptor. This is consistent with our previous finding that some geniculate ganglion neurons express both the full length and truncated isoforms and some only express the truncated isoforms (Chapter III). A second possibility is that two weeks is not a sufficient time to see a full effect and that longer time periods on blocking TrkB-signaling would result in continued loss of some of this innervation These ideas are not mutually exclusive and likely both are at play.

The decreased innervation seen to the taste bud in this study can all be explained by a loss of branching at different levels. Reduction of branch points 
outside the taste bud reduces the number of branches entering the taste bud and we also see a loss of branching within the taste bud. Consistently, BDNF-TrkBsignaling regulates dendritic and/or axonal branching in cortical, hippocampal during development (Martinez et al., 1998; Liu et al., 2007) and in adulthood (Gorski et al., 2003; Chakravarthy et al., 2006; Bergami et al., 2008; Wang et al., 2015). Many downstream signaling mediators of the BDNF/TrkB pathway are involved in the control of dendritic branching, such as mTOR, PI3-kinase and MAPK (Dijkhuizen and Ghosh, 2005; Jaworski et al., 2005; Kumar et al., 2005; Jeanneteau et al., 2010), which indicates that deactivation of BDNF/TrkB signaling alters axon and dendritic branching. In conclusion, BDNF/TrkB signaling regulates the branching of peripheral gustatory fibers within the taste bud.

There was no difference in branch length when all the branches were considered. However, if a single terminal branch is lost from a bifurcating fiber within the bud this could result in a longer fiber. Therefore, we predicted that blocking TrkB signaling might differentially effect branch length depending on branch order. When we just considered the length of the fiber branch entering the taste bud, before it branches the first time (primary branches) we found that there were fewer short primary branches and more medium to long branches. This is likely due to the loss the some higher order branches. Meanwhile, higher order branch length shifted such that there were fewer longer branches relative to shorter ones when TrkB-signaling was blocked. This occurred either because longer secondary branches were more likely to be lost or because longer branches became 
shorter or both. This finding indicates that BDNF-TrkB signaling is important for maintaining both the number and length of second order branches within the bud.

Compared to previous findings that 55\% TrkB-positive innervation are removed when BDNF is inducibly removed for 10 weeks (Chapter II), our results show a surprisingly large effect on TrkB-positive innervation by blocking TrkB signaling within 2 weeks. While these effects are impossible to compare directly because only a portion of the innervation in this study was labeled and all taste buds had some innervation remaining, the effect was still much larger than we predicted. One possible explanation is that removing BDNF from taste buds and epithelium leads to removal of both BDNF/TrkB signaling and BDNF/p75 signaling, but blocking TrkB signaling only remove BDNF/TrkB signaling while not BDNF/p75 signaling. According to previous studies, when neurotrophins bind to p75 receptor, it causes axon degeneration in both developmental sympathetic neurons and adult septal cholinergic neurons (Singh et al., 2008; Park et al., 2010). It's possible that pro-BDNF/p75 signaling also cause axon degeneration in adult geniculate ganglion neurons. This maybe the reason why blocking TrkB signaling within 2 weeks had larger effect than could be predicted from the effects of 10 weeks of BDNF removal.

Taken together my data are consistent with the following role for BDNF/TrkB-signaling maintenance of innervation during adulthood. When the old taste receptor cell die, the fiber branches innervating this receptor cell likely retract. When the new taste receptors enter into the taste bud, BDNF/TrkB signaling may promote formation of a new branch from some of TrkB-positive fibers 
and support fiber growth and targeting to newly differentiated taste receptor cells. The remaining TrkB-positive fibers which are not affected by BDNF/TrkB signaling, may support the innervation of other taste cells through a different mechanism, and could be inhibited by BDNF through p75. 

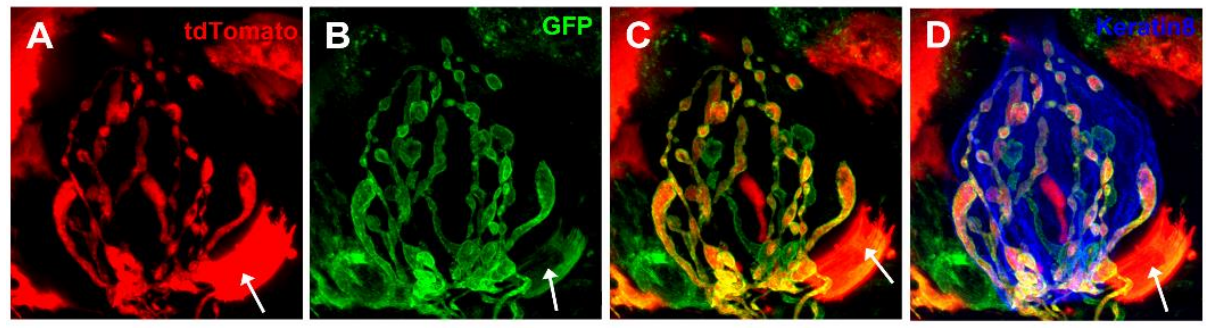

TrkB ${ }^{\text {CreER/F616A }}$ YFP/TD with 1NM-PP1
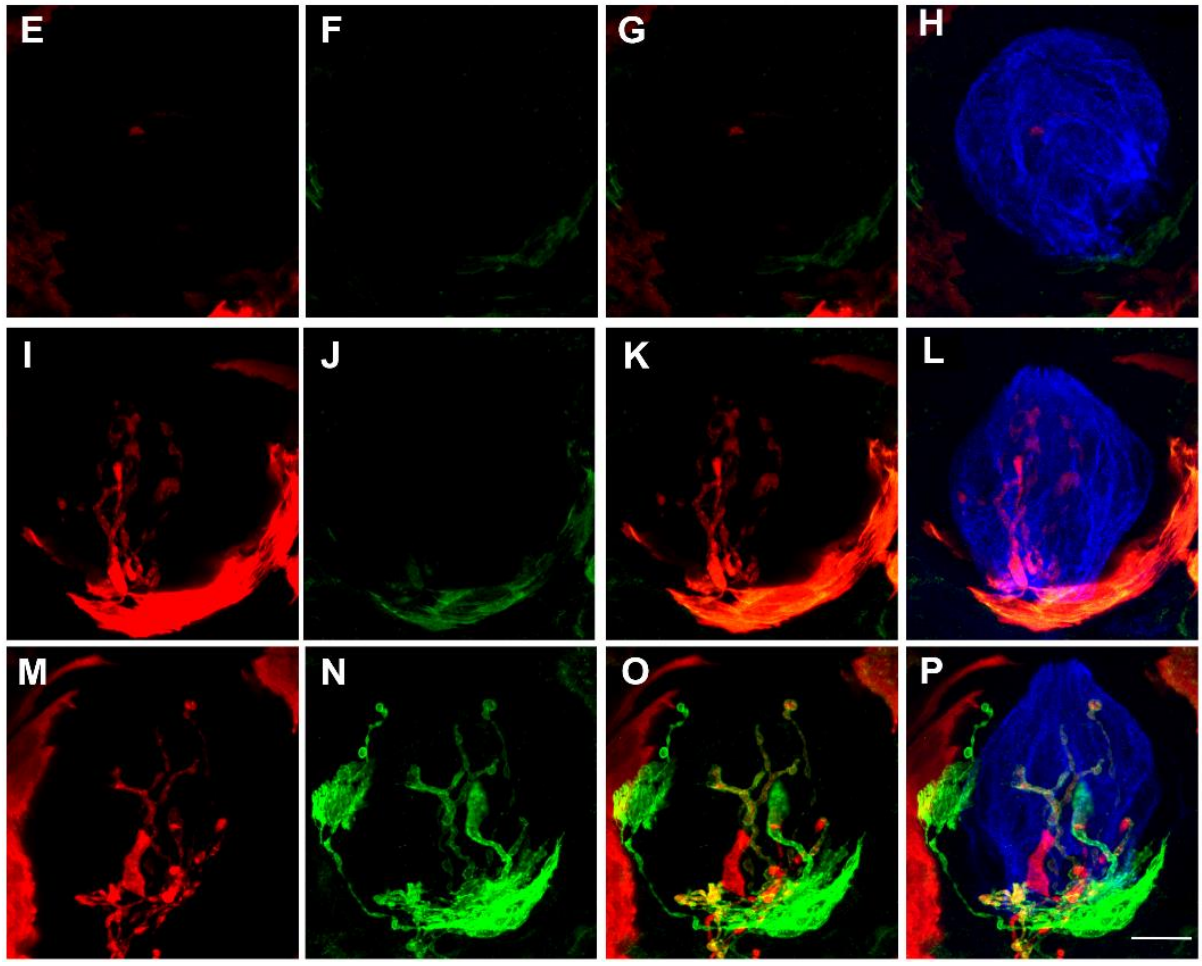

Figure 10. Fungiform taste buds appear to have less TrkB-positive or no TrkBpositive innervation when TrkB signaling is blocked by 1NM-PP1. Confocal images show fungiform taste bud staining with anti-GFP (green), anti-tdTomato (Red) and anti-cytokeratin 8 (keratin 8, blue) in one control and one experimental genotype/treatment group of mice. In the control animal TrkB $B^{\mathrm{CreER} / t}$ : YFP/tdTomato without 1NM-PP1 (A-D), taste buds were typically innervated by three different colors of TrkB-positive fibers- red (A), green (B) and yellow (C) (red and green). However, for mice in which TrkB signaling is blocked (TrkB ${ }^{\text {Cre- }}$ 
ER/F616A : YFP/tdTomato with 1NM-PP1), some of taste buds are uninnervated (E$H$ ), some of taste buds are innervated by one color of fibers (red; I-L) and some of taste buds are innervated fibers of all 3 colors $(M-P)$, and yet still appeared to have less labeled innervation. The scale bar in $D=10 \mu \mathrm{m}$ and applies to all. 


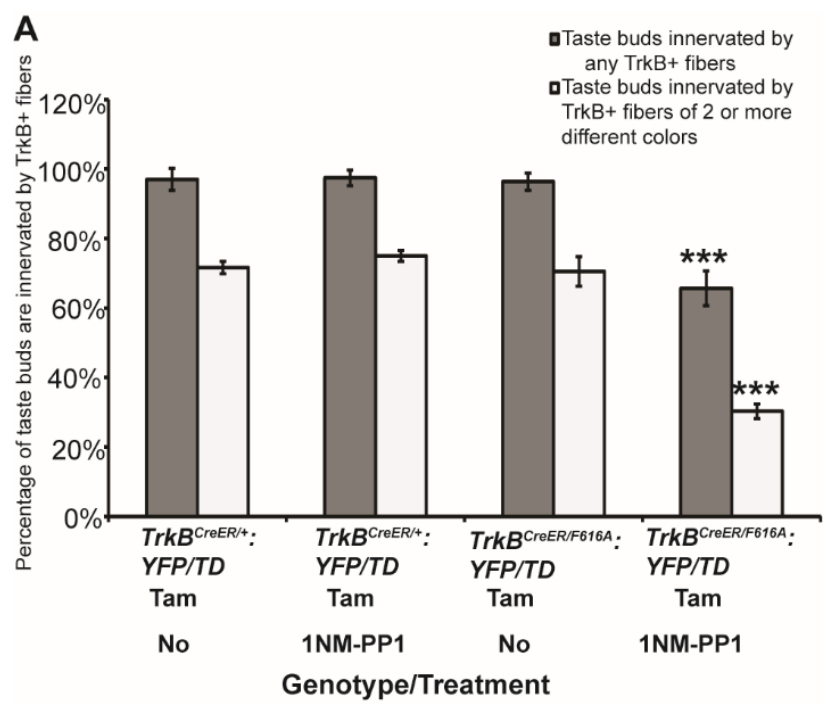

Figure 11. TrkB-positive innervation to the taste bud decreases when TrkB signaling is blocked. The percentage of taste buds that are innervated by TrkBpositive fibers (gray bar) and more than one color of TrkB-positive fibers (white bar) were quantified in TrkB ${ }^{\text {CreER/+}}:$ YFP/tdTomato without $1 \mathrm{NM}-\mathrm{PP} 1$, TrkB ${ }^{\text {Cre- }}$ ${ }^{E R /+}:$ YFP/tdTomato with 1NM-PP1, TrkB ${ }^{\text {CreER/F616A }}$ YFP/tdTomato without 1NMPP1 and TrkB ${ }^{\text {CreER/F616A }}$ YFP/tdTomato with 1NM-PP1 mice. Fewer taste buds are innervated by TrkB-positive fibers in mice where TrkB-signaling is blocked (TrkB ${ }^{C r e E R / F 616 A}$ :YFP/tdTomato with 1NM-PP1) compared with the other three groups $\left(\operatorname{TrkB}^{\mathrm{CreER} / \mathrm{t}}:\right.$ YFP/tdTomato without $1 \mathrm{NM}-\mathrm{PP} 1, \quad \mathrm{p}<0.01 ; \quad$ TrkB ${ }^{\text {Cre- }}$ ${ }^{E R /+}:$ YFP/tdTomato with 1NM-PP1, p<0.01; TrkB ${ }^{\text {CreER/F616A }}$ :YFP/tdTomato without 1NM-PP1 $\mathrm{p}<0.01$ ). Also, the percentage of taste buds innervated labeled TrkBpositive fibers of two or more colors was reduced with blocking TrkB-signaling (TrkB ${ }^{\text {CreER/F616A }}$ YFP/tdTomato with 1NM-PP1) compared with the other 3 genotypes $\quad\left(\right.$ TrkB $^{\text {CreER/t }}:$ YFP/tdTomato without $1 \mathrm{NM}-\mathrm{PP} 1, \mathrm{p}<0.01 ; \quad$ TrkB ${ }^{\text {Cre- }}$

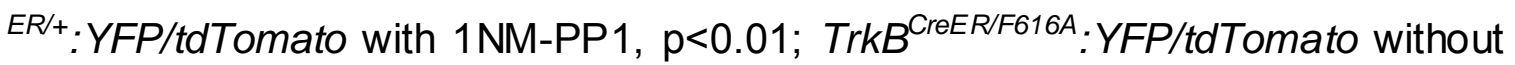
1NM-PP1 $p<0.01)$. Because the probability that a taste bud will be innervated by 
different colored fibers increases as the number of independent neurons innervating the taste bud increases, this means that fewer labeled TrkB neurons innervate each taste bud. 
TrkB $^{\text {CreER/+ }}$ YFP/TD without 1NM-PP1
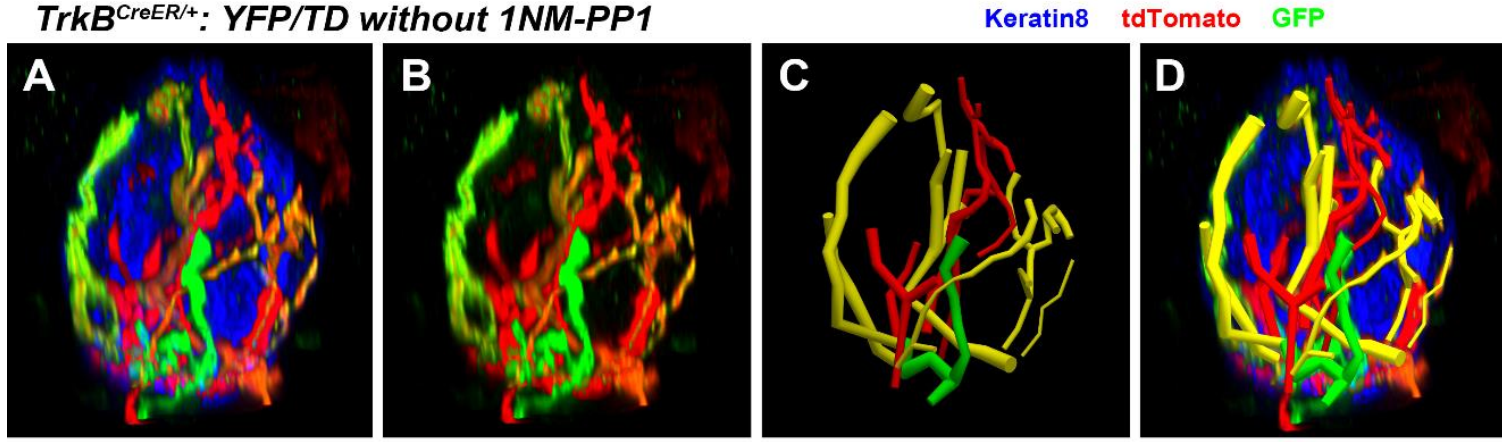

TrkB ${ }^{\text {CreER/F616A }}$ YFP/TD with 1NM-PP1
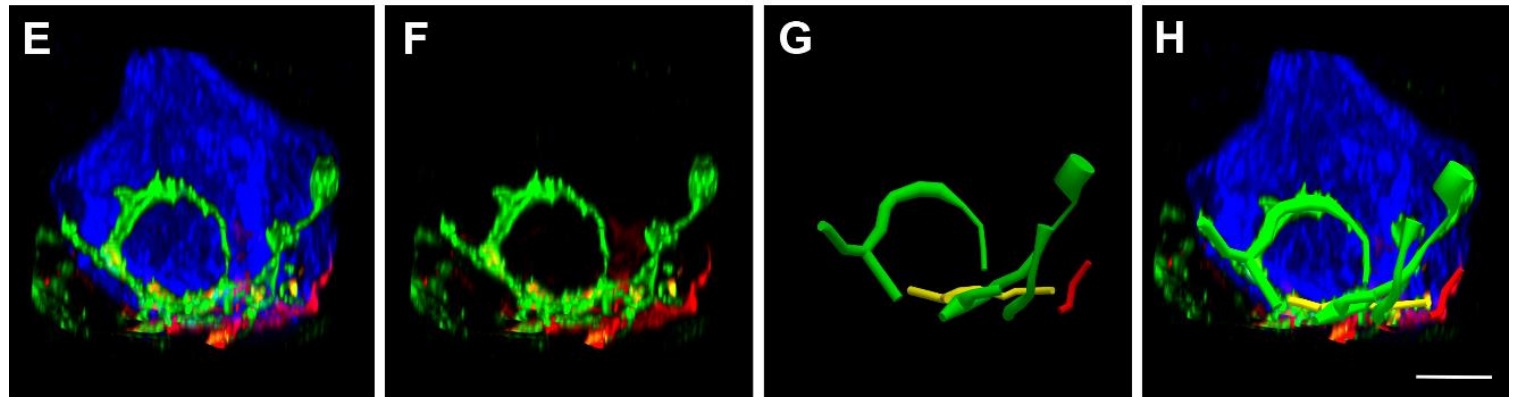

Figure 12. Quantification of TrkB-positive fiber branching within taste buds. Images show a keratin 8 labeled taste bud (blue; A) and the labeled TrkB-positive fibers (red, green yellow) innervating it (blue A, E). Neurolucida was used to draw each fiber within the taste bud from where it entered to the top of the bud. C Taste fibers are frequently flat, while the diameter of drawn fibers is a uniform thickness in each direction. For this reason fiber or innervation volume cannot be measured using this approach, but branch lengths and branch points cand be measured.. The images illustrate one taste bud from a control genotype (TrkB ${ }^{\text {Cre- }}$ ER/t: YFP/tdTomato without 1NM-PP1 (A-D)) and one from a mouse in which TrkB-signaling had been blocked (TrkB ${ }^{C r e E R / F 616 A}$ : YFP/tdTomato with 1NM-PP1 mice $(E-H))$. Each color fiber branch entering the taste bud was traced by a different color line. The scale bar in $D=10 \mu \mathrm{m}$ and applies to all. 
A
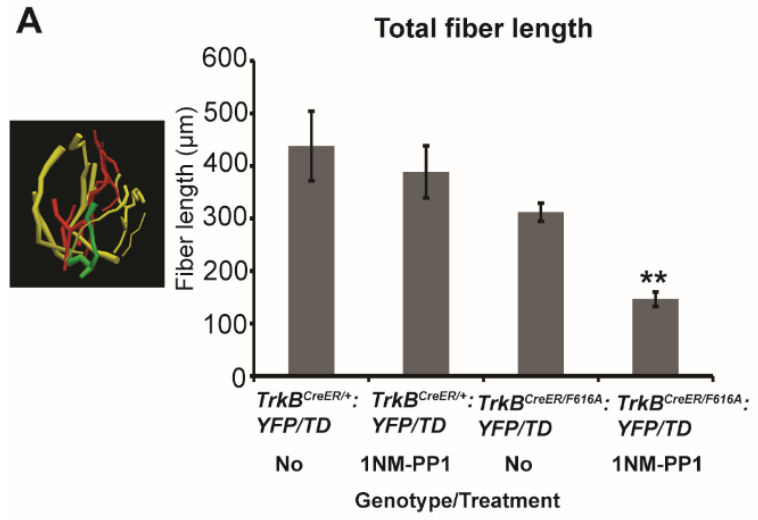

C

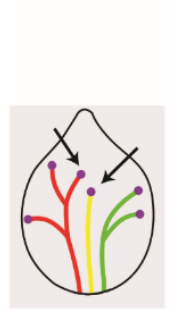

Total branch ends

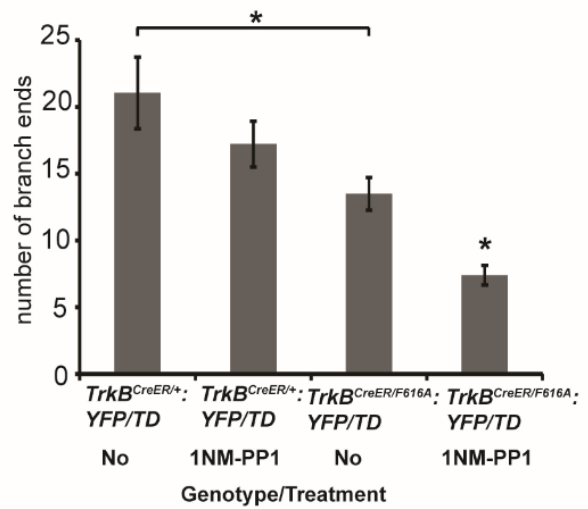

E

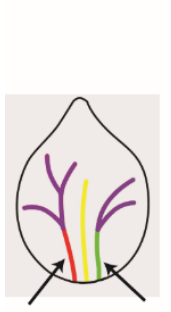

B

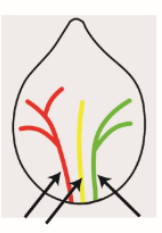

D

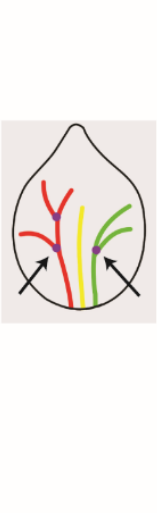

$F$

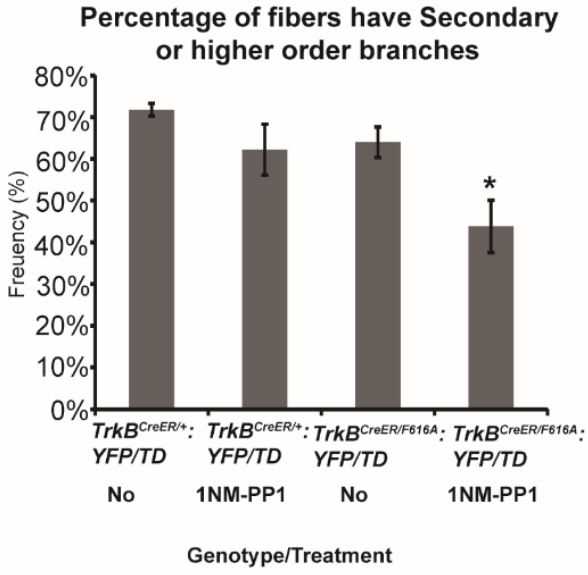

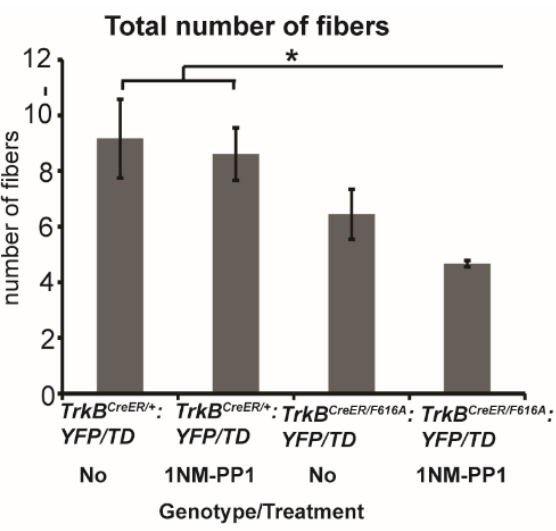

Total branch points

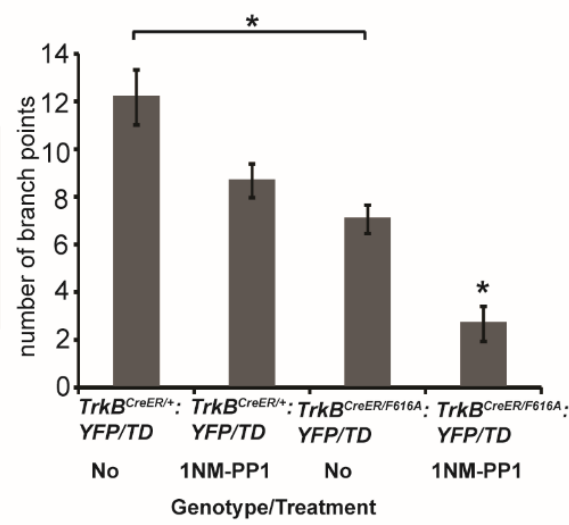

Percentage of fibers have tertiary or higher order branches

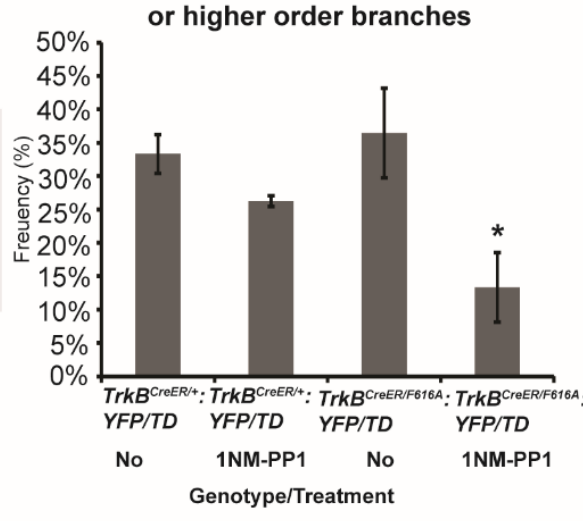

Figure 13. Innervation is lost in the taste bud with reduction of TrkB-signaling due to a loss of fiber branches. Quantification of total fiber length $(A)$, total number of fibers (B), branch ends (C), branch points (D), the percentage of fibers that have secondary or more branches $(E)$ and the percentage of fibers have tertiary or

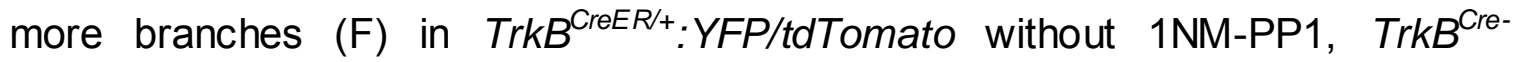


${ }^{E R /+}:$ YFP/tdTomato with 1NM-PP1, TrkB ${ }^{C r e E R / F 616 A}:$ YFP/tdTomato without 1NMPP1 and TrkB ${ }^{C r e E R / F 616 A}:$ YFP/tdTomato with 1NM-PP1 mice. A, Measurement of the total TrkB fiber length within taste buds. The total TrkB fiber length was significantly reduced when TrkB-signaling was blocked (TrkB ${ }^{\text {CreER/F616A }}$ :YFP/tdTomato with 1NM-PP1). B, The total number of separate fiber branches entering a taste bud were significantly decreased when TrkB-signaling was blocked (TrkB ${ }^{\text {Cre- }}$ ER/F616A: YFP/tdTomato with 1NM-PP1) compared with two control groups, but there was no difference the other experimental group (TrkB ${ }^{\text {Cre- }}$ ER/F616A:YFP/tdTomato without 1NM-PP1). The total number of branch ends within taste buds (C) and total number of branch points within taste buds (D). Both number of branch ends (C) and branch points (D) were significantly decreased when TrkB-signaling was blocked (TrkB ${ }^{\text {CreER/F616A }}$ YFPP/tdTomato with 1NM-PP1) compared with other three genotypes. Another experiment group (TrkB ${ }^{\text {Cre- }}$ ER/F616A:YFP/tdTomato without 1NM-PP1) had a significant reduction on both number of branch ends and branch points compared $\operatorname{TrkB}^{\mathrm{CreER/+}}$ :YFP/tdTomato without 1NM-PP1 mice, but no difference with TrkB ${ }^{\mathrm{CreER} / t}$ : YFP/tdTomato with 1NM-PP1 mice. Quantification of the percentage of fibers that have secondary or more branches within taste buds $(\mathrm{E})$ and the percentage of fibers have tertiary or more branches within taste buds $(F)$. Both percentages were significantly reduced when TrkB-signaling was blocked (TrkB $B^{C r E E R / F 616 A}$ :YFP/tdTomato with 1NM-PP1) compared with other three genotypes. The arrows in the cartoons show that the different characteristics of fibers are quantified. ${ }^{*} p \leq 0.05,{ }^{* *} p \leq 0.0$ 

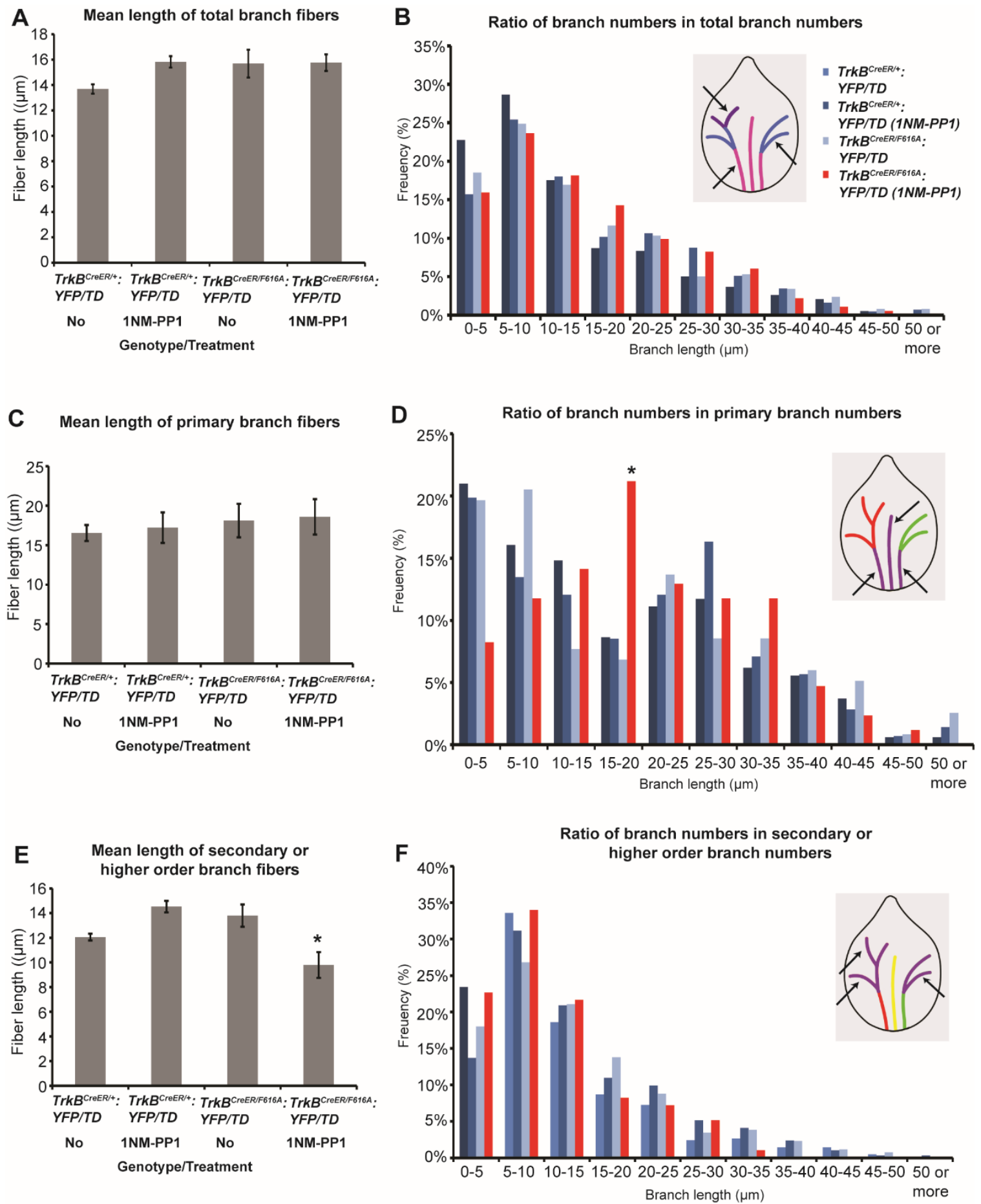

Figure 14. The longest secondary and tertiary branches were lost disproportionately when TrkB-signaling is blocked. A, Quantification of the mean length of each fiber branch within taste buds. Blocking TrkB signaling did not alter the 
mean lengthof all braches when clumped together. B, Histogram of frequency distribution of total branch fibers based on length. The distribution of the different branch lengths were unaffected by blocking TrkB-signaling. C, Quantification of the mean length of primary branches within taste buds. There was no difference in the mean length of primary branches between TrkB ${ }^{C r e E R / F 616 A}$ : YFP/tdTomato with 1NM-PP1 mice and other three genotypes. D, Histogram illustrating the frequency distribution of primary fiber branch lengths. Many shorter primary branch fibers become longer in the TrkB ${ }^{\text {CreER/F616A }}$ YFP/tdTomato with 1NM-PP1 mice compared to the other three genotypes. E, Quantification of the mean length of secondary or higher order branch fibers within taste buds. The mean length of secondary or higher order branch fibers are significantly reduced in the TrkB ${ }^{\text {Cre- }}$ ER/F616A: YFP/tdTomato with 1NM-PP1 mice compared to other three genotypes. F, Histogram of frequency distribution of secondary or higher order branch fibers based on length. There is no difference in the overall distribution of the various

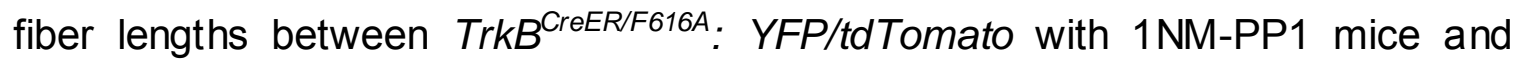
other three genotypes. The reduction in the mean appears to be due to loss of

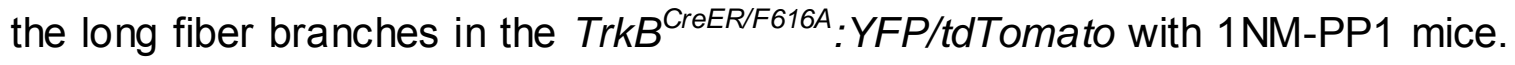
The arrows in the cartoons show that the different characteristics of branch fibers are quantified. ${ }^{*} p \leq 0.05,{ }^{* *} p \leq 0.01$. 


\section{CHAPTER V}

\section{SUMMARY AND DISCUSSION}

Taste bud cells turn over continuously in adulthood (Beidler and Smallman, 1965; Perea-Martinez et al., 2013), and new taste bud cells must be reinnervated by nerve fibers. Forty percent of the innervation is reduced when BDNF is removed from the taste buds and epithelium (Meng et al., 2015), while $60 \%$ remains. It is unclear if the remaining taste bud innervation is due to insufficient BDNF removal or lack of BDNF dependence in the remaining fibers. My findings indicate that Bdnf expression was efficiently removed from taste buds using the K14 promoter ruling out insufficient BDNF removal. I found that taste fibers consist of TrkB-positive and TrkB-negative populations. Taste bud-derived BDNF supported a large subset of TrkB-expressing nerve fibers and not TrkBnegative nerve fibers. Since TrkB-negative taste fibers are not affected by BDNF removal, they may be supported by some other factor/s. Not all TrkB-positive innervation is lost after BDNF removal, so it is also likely that these fibers do not express an isoform for TrkB allowing BDNF to signal. Together these findings point to two types of innervation, TrkB-negative that does not respond to BDNF removal, and some of TrkB-positive that is lost with BDNF removal, while some does not. One possibility is that these different fibers innervate different 
types of taste receptor cells. Consistently, BDNF is expressed in some adult taste receptor cells but not others (Yee et al., 2003; Huang et al., 2015). This may indicate that BDNF maintains a subset of TrkB-positive fibers that innervate BDNF-expressing taste bud cells. Interestingly these BDNF-expressing taste cells co-express Car4 (marker of sour taste cells), SNAP 25 (marker of taste receptor cells with synapses), but also aENaC (transduction mechanisms for salt). BDNF removal reduces $\mathrm{YENaC}$ expression in the taste bud. It is not clear if this is a direct effect of BDNF or an indirect of nerve fiber loss. However, it is possible that the nerve fibers are lost from the subset of taste receptor cells that transduce salt and sour and this influences gene expression in those taste cells. Together these findings suggest that BDNF functions to support taste innervation to specific cell types.

BDNF maintains TrkB-positive innervation to the adult taste bud. However, it is unclear whether BDNF has a direct function on the nerve fibers or could influence innervation indirectly by binding to taste bud cells, which then release another factor to influence innervation (Nosrat et al., 2012). The cells on which BDNF is acting must express BDNF's receptors. I found that the full length TrkB receptor is expressed in the geniculate ganglion, not in taste buds, and that BDNF maintains TrkB fibers by functioning through the full length receptor. Therefore, the primary function of BDNF occurs on nerve fibers, not taste buds. Alternatively, both taste buds and geniculate ganglion neurons express the TrkBT1 receptor, and the TrkBT1 receptor is expressed immediately surrounding the taste bud and is also up-regulated when BDNF is over expressed. These da- 
ta indicate that TrkBT1 functions to bind and sequester BDNF in the taste bud to prevent BDNF binding to full length TrkB receptor. In conclusion, my findings demonstrate that conical BDNF signaling via the full length TrkB receptor occurs at nerve fibers, and that TrkBT1 sequesters BDNF limiting its location and availability to nerve fibers.

BDNF could function to maintain innervation to mature taste cells or it could function to recruit innervation to new taste cells, or both. Given that during development BDNF regulates many of the same processes (i.e. target innervation, nerve fiber growth, fiber branching) that would be required for the innervation of new taste receptor cells, it seems reasonable that this may be the case. However, it took 70 days for an effect to be measured following removal of BDNF. Given that many taste receptor cells are replaced within two weeks, this timing is inconsistent with the idea that BDNF is required for innervation of new taste receptor cells. However, it is difficult to know the precise timing of BDNF removal and measurements of innervation were crude requiring a large effect before differences between groups could be measured. I resolved these issues by blocking TrkB signaling directly and measuring the effects of this blockade on nerve fiber branching within the taste bud. I found that fewer taste buds are innervated by labeled TrkB-positive fibers, the numbers of branches entering the taste bud were reduced, and other fibers lose higher order branches, while some remaining higher order branches also become shorter after blocking TrkB signaling. This data may suggest that TrkB signaling mediates terminal branch arborization of geniculate ganglion axons. In summary, my findings indicate that BDNF 
from the taste bud maintains innervation by acting directly through the full length TrkB receptor. Blocking TrkB-signaling reduces taste bud innervation within two weeks; this timing is consistent with TrkB regulation of innervation to new taste receptor cells. Taste innervation is lost due to a reduction in branching.

Overall, my data are consistent with the following role for BDNF-TrkB function in the taste bud. When an old BDNF-expressing receptor cell dies, the TrkB-positive fibers innervating this cell retracts from the taste bud, and branches within the taste bud are lost. When a new BDNF-expressing receptor cell enters into the taste bud, BDNF/TrkB signaling may stimulate TrkB-positive nerve fibers to produce a new branch which grows into and within the taste bud and likely branches several times within the taste bud (Figure 15). TrkBT1 receptor in BDNF-expressing receptor cell may sequester BDNF to prevent it from diffusing away from the new uninnervated cell and influencing innervation at a distance. The p75 receptor binding to pro-BDNF may function to inhibit growth of other fibers preventing aberrant growth of the incorrect nerve fibers into the taste bud. The innervation of taste cells that do not express BDNF may be supported by TrkB-negative fibers through a different mechanism or in some cases TrkBT1 could sequester BDNF and rerelease it to encourage innervation by TrkB-positive fibers.

In the future studies, it would be interesting to figure out which type of taste receptor cells are connected by TrkB-positive fibers and how the fibers form a new connection with new taste receptor cells. First, to figure out when blocking TrkB signaling first has an effect on innervation. I will examine TrkB-positive fi- 
bers after blocking TrkB signaling for different times ( 2 days, 4 days, 1 weeks, 4 weeks and 2 months). This should give me an idea when TrkB-positive innervation first effected and also how long is required for the maximal effect to occur. Then I will examine whether blocking TrkB signaling affects specific taste function by doing a behavior test and nerve recording. Finally, I plan to study which taste receptor cells are connected by TrkB-positive fibers by doing immunostaining on whole mount taste buds. 

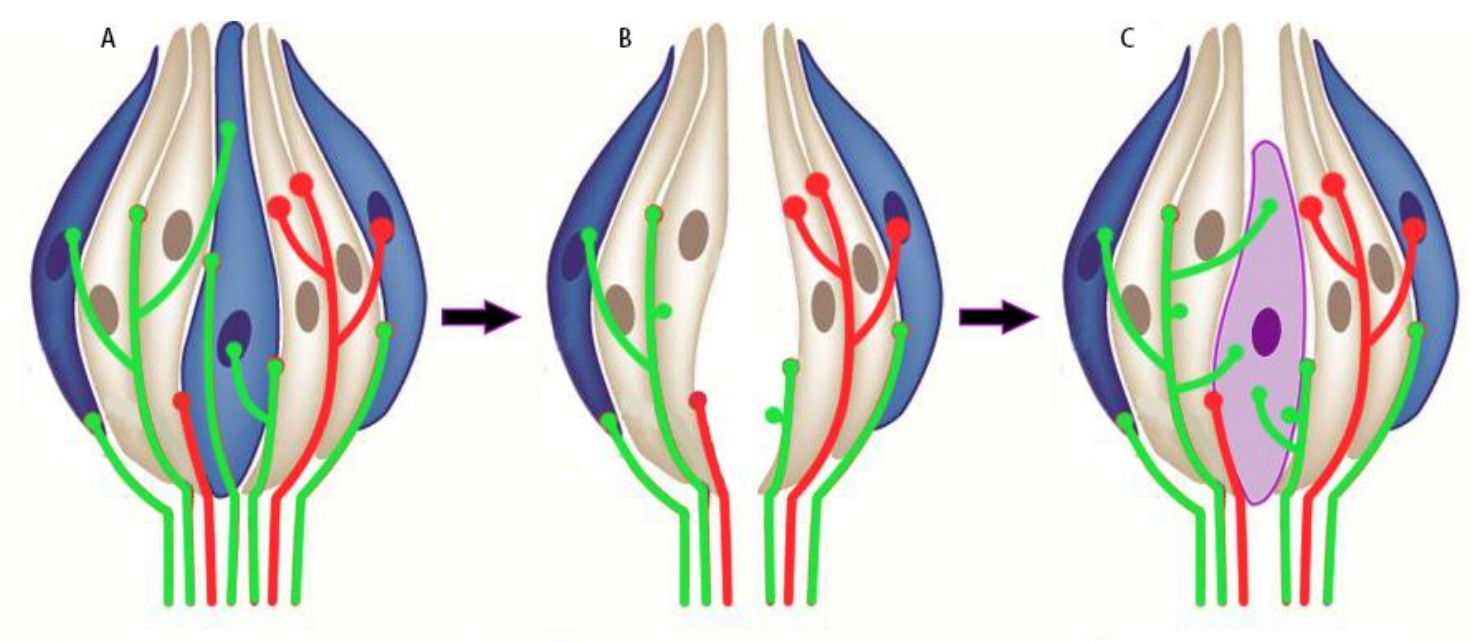

BDNF expressing taste cell

BDNF expressing taste cell

New taste cell

Figure 15. A model illustrating how we think BDNF-TrkB signaling functions in the adult taste system. Old BDNF expressing taste cell (blue cell in A) are innervated by TrkB-positive fibers (Green in A). As old BDNF expressing taste cell die, some branches of TrkB-positive fibers are retracted back to the branch point of fibers (B). When a new BDNF-expressing cell (purple cell in C) enters the taste bud, it releases BDNF which binds to the full-length receptor on nerve fibers. This promotes branch formation and growth of a new fiber branch into the taste bud that can then innervate this taste receptor cell. 


\section{REFERENCES}

Adler E, Hoon MA, Mueller KL, Chandrashekar J, Ryba NJ, Zuker CS (2000) A novel family of mammalian taste receptors. Cell 100:693-702.

Alderson RF, Curtis R, Alterman AL, Lindsay RM, DiStefano PS (2000) Truncated TrkB mediates the endocytosis and release of BDNF and neurotrophin $-4 / 5$ by rat astrocytes and schwann cells in vitro. Brain research 871:210-222.

Alsina B, Vu T, Cohen-Cory S (2001) Visualizing synapse formation in arborizing optic axons in vivo: dynamics and modulation by BDNF. Nature neuroscience 4:1093-1101.

Altman J, Bayer SA (1982) Development of the cranial nerve ganglia and related nuclei in the rat. Advances in anatomy, embryology, and cell biology 74:1-90.

Armanini MP, McMahon SB, Sutherland J, Shelton DL, Phillips HS (1995) Truncated and catalytic isoforms of trkB are co-expressed in neurons of rat and mouse CNS. The European journal of neuroscience 7:1403-1409.

Bamji SX, Majdan M, Pozniak CD, Belliveau DJ, Aloyz R, Kohn J, Causing CG, Miller FD (1998) The p75 neurotrophin receptor mediates neuronal apoptosis and is essential for naturally occurring sympathetic neuron death. The Journal of cell biology 140:911-923.

Baquet ZC, Gorski JA, Jones KR (2004) Early striatal dendrite deficits followed by neuron loss with advanced age in the absence of anterograde cortical brain-derived neurotrophic factor. The Journal of neuroscience : the official journal of the Society for Neuroscience 24:4250-4258.

Bartel DL, Sullivan SL, Lavoie EG, Sevigny J, Finger TE (2006) Nucleoside triphosphate diphosphohydrolase-2 is the ecto-ATPase of type I cells in taste buds. The Journal of comparative neurology 497:1-12.

Baxter GT, Radeke MJ, Kuo RC, Makrides V, Hinkle B, Hoang R, Medina-Selby A, Coit D, Valenzuela P, Feinstein SC (1997) Signal transduction mediated by the truncated trkB receptor isoforms, trkB.T1 and trkB.T2. The Journal of neuroscience : the official journal of the Society for Neuroscience 17:2683-2690.

Beidler LM, Smallman RL (1965) Renewal of cells within taste buds. The Journal of cell biology 27:263-272.

Bentley CA, Lee KF (2000) p75 is important for axon growth and schwann cell migration during development. The Journal of neuroscience : the official journal of the Society for Neuroscience 20:7706-7715.

Bergami M, Rimondini R, Santi S, Blum R, Gotz M, Canossa M (2008) Deletion of TrkB in adult progenitors alters newborn neuron integration into hippocampal circuits and increases anxiety-like behavior. Proceedings of the National Academy of Sciences of the United States of America 105:15570-15575.

Biffo S, Offenhauser N, Carter BD, Barde YA (1995) Selective binding and internalisation by truncated receptors restrict the availability of BDNF during development. Development 121:2461-2470.

Boggs K, Venkatesan N, Mederacke I, Komatsu Y, Stice S, Schwabe RF, Mistretta CM, Mishina Y, Liu HX (2016) Contribution of Underlying Connective Tissue Cells to Taste Buds in Mouse 
Tongue and Soft Palate. PloS one 11:e0146475.

Canessa CM, Schild L, Buell G, Thorens B, Gautschi I, Horisberger JD, Rossier BC (1994) Amiloride sensitive epithelial $\mathrm{Na}+$ channel is made of three homologous subunits. Nature 367:463467.

Carim-Todd L, Bath KG, Fulgenzi G, Yanpallewar S, Jing D, Barrick CA, Becker J, Buckley H, Dorsey SG, Lee FS, Tessarollo L (2009) Endogenous truncated TrkB.T1 receptor regulates neuronal complexity and TrkB kinase receptor function in vivo. The Journal of neuroscience : the official journal of the Society for Neuroscience 29:678-685.

Carleton A, Accolla R, Simon SA (2010) Coding in the mammalian gustatory system. Trends in neurosciences 33:326-334.

Carr VM, Sollars SI, Farbman Al (2005) Neuronal cell death and population dynamics in the developing rat geniculate ganglion. Neuroscience 134:1301-1308.

Casademunt E, Carter BD, Benzel I, Frade JM, Dechant G, Barde YA (1999) The zinc finger protein NRIF interacts with the neurotrophin receptor $\mathrm{p} 75$ (NTR) and participates in programmed cell death. The EMBO journal 18:6050-6061.

Chakravarthy S, Saiepo ur MH, Bence M, Perry S, Hartman R, Couey JJ, Mansvelder HD, Levelt CN (2006) Postsynaptic TrkB signaling has distinct roles in spine maintenance in adult visual cortex and hippocampus. Proceedings of the National Academy of Sciences of the United States of America 103:1071-1076.

Chandrashekar J, Yarmolinsky D, von Buchholtz L, Oka Y, Sly W, Ryba NJ, Zuker CS (2009) The taste of carbonation. Science 326:443-445.

Chandrashekar J, Kuhn C, Oka Y, Yarmolinsky DA, Hummler E, Ryba NJ, Zuker CS (2010) The cells and peripheral representation of sodium taste in mice. Nature 464:297-301.

Chao MV (2003) Neurotrophins and their receptors: a convergence point for many signalling pathways. Nature reviews Neuroscience 4:299-309.

Chen X, Ye H, Kuruvilla R, Ramanan N, Scangos KW, Zhang C, Johnson NM, England PM, Shokat KM, Ginty DD (2005) A chemical-genetic approach to studying neurotrophin signaling. Neuron 46:13-21.

Cheng A, Coksaygan T, Tang H, Khatri R, Balice-Gordon RJ, Rao MS, Mattson MP (2007) Truncated tyrosine kinase $B$ brain-derived neurotrophic factor receptor directs cortical neural stem cells to a glial cell fate by a novel signaling mechanism. Journal of neurochemistry 100:1515-1530.

Cheung ZH, Chin WH, Chen Y, Ng YP, Ip NY (2007) Cdk5 is involved in BDNF-stimulated dendritic growth in hippocampal neurons. PLoS biology 5:e63.

Cho TT, Farbman Al (1999) Neurotrophin receptors in the geniculate ganglion. Brain research Molecular brain research 68:1-13.

Clapp TR, Yang R, Stoick CL, Kinnamon SC, Kinnamon JC (2004) Morphologic characterization of rat taste receptor cells that express components of the phospholipase $\mathrm{C}$ signaling pathway. The Journal of comparative neurology 468:311-321.

Cohen-Cory S, Fraser SE (1995) Effects of brain-derived neurotrophic factor on optic axon branching and remodelling in vivo. Nature 378:192-196.

Conger AD, Wells MA (1969) Radiation and aging effect on taste structure and function. Radiation research 37:31-49.

Danzer SC, Crooks KR, Lo DC, McNamara JO (2002) Increased expression of brain-derived neurotrophic factor induces formation of basal dendrites and axonal branching in dentate granule cells in hippocampal explant cultures. The Journal of neuroscience : the official journal of the Society for Neuroscience 22:9754-9763.

Delay RJ, Kinnamon JC, Roper SD (1986) Ultrastructure of mouse vallate taste buds: II. Cell types 
and cell lineage. The Journal of comparative neurology 253:242-252.

Dijkhuizen PA, Ghosh A (2005) BDNF regulates primary dendrite formation in cortical neurons via the PI3-kinase and MAP kinase signaling pathways. Journal of neurobiology 62:278-288.

Dorsey SG, Renn CL, Carim-Todd L, Barrick CA, Bambrick L, Krueger BK, Ward CW, Tessarollo L (2006) In vivo restoration of physiological levels of truncated TrkB.T1 receptor rescues neuronal cell death in a trisomic mouse model. Neuron 51:21-28.

Dotson CD, Roper SD, Spector AC (2005) PLCbeta2-independent behavioral avoidance of prototypical bitter-tasting ligands. Chem Senses 30:593-600.

Dvoryanchikov G, Huang YA, Barro-Soria R, Chaudhari N, Roper SD (2011) GABA, its receptors, and GABAergic inhibition in mouse taste buds. The Journal of neuroscience : the official journal of the Society for Neuroscience 31:5782-5791.

Eide FF, Vining ER, Eide BL, Zang K, Wang XY, Reichardt LF (1996) Naturally occurring truncated trkB receptors have dominant inhibitory effects on brain-derived neurotrophic factor signaling. The Journal of neuroscience : the official journal of the Society for Neuroscience 16:3123-3129.

Fan L, Girnius S, Oakley B (2004) Support of trigeminal sensory neurons by nonneuronal p75 neurotrophin receptors. Brain research Developmental brain research 150:23-39.

Farbman Al (1965) Fine Structure of the Taste Bud. Journal of ultrastructure research 12:328350.

Farbman Al (1980) Renewal of taste bud cells in rat circumvallate pa pillae. Cell and tissue kinetics 13:349-357.

Farbman Al, Mbiene JP (1991) Early development and innervation of taste bud-bearing papillae on the rat tongue. The Journal of comparative neurology 304:172-186.

Farbman Al, Guagliardo N, Sollars SI, Hill DL (2004a) Each sensory nerve arising from the geniculate ganglion expresses a unique fingerprint of neurotrophin and neurotrophin receptor genes. Journal of neuroscience research 78:659-667.

Farbman Al, Brann JH, Rozenblat A, Rochlin MW, Weiler E, Bhattacharyya M (2004b) Developmental expression of neurotrophin receptor genes in rat geniculate ganglion neurons. Journal of neurocytology 33:331-343.

Fei D, Krimm RF (2013) Taste neurons consist of both a large TrkB-receptor-dependent and a small TrkB-receptor-independent subpopulation. PloS one 8:e83460.

Fei D, Huang T, Krimm RF (2014) The neurotrophin receptor p75 regulates gustatory axon branching and promotes innervation of the tongue during development. Neural development 9:15.

Feng P, Chai J, Zhou M, Simon N, Huang L, Wang H (2014) Interleukin-10 is produced by a specific subset of taste receptor cells and critical for maintaining structural integrity of mouse taste buds. The Journal of neuroscience : the official journal of the Society for Neuroscience 34:2689-2701.

Fenner BM (2012) Truncated TrkB: beyond a dominant negative receptor. Cytokine \& growth factor reviews 23:15-24.

Finger TE (2005) Cell types and lineages in taste buds. Chem Senses 30 Suppl 1:i54-55.

Finger TE, Danilova V, Barrows J, Bartel DL, Vigers AJ, Stone L, Hellekant G, Kinnamon SC (2005) ATP signaling is crucial for communication from taste buds to gustatory nerves. Science 310:1495-1499.

Frade JM, Barde YA (1998) Nerve growth factor: two receptors, multiple functions. BioEssays : news and reviews in molecular, cellular and developmental biology 20:137-145.

Friedman WJ (2000) Neurotrophins induce death of hippocampal neurons via the $\mathrm{p} 75$ receptor. The Journal of neuroscience : the official journal of the Society for Neuroscience 
20:6340-6346.

Fritzsch B, Sarai PA, Barbacid M, Silos-Santiago I (1997) Mice with a targeted disruption of the neurotrophin receptor trkB lose their gustatory ganglion cells early but do develop taste buds. International journal of developmental neuroscience : the official journal of the International Society for Developmental Neuroscience 15:563-576.

Fryer RH, Kaplan DR, Kromer LF (1997) Truncated trkB receptors on nonneuronal cells inhibit BDNF-induced neurite outgrowth in vitro. Experimental neurology 148:616-627.

Gaillard D, Xu M, Liu F, Millar SE, Barlow LA (2015) beta-Catenin Signaling Biases Multipotent Lingual Epithelial Progenitors to Differentiate and Acquire Specific Taste Cell Fates. PLoS genetics 11:e1005208.

Galati DF, Hiester BG, Jones KR (2016) Computer Simulations Support a Morphological Contribution to BDNF Enhancement of Action Potential Generation. Front Cell Neurosci 10:209.

Germana A, Montalbano G, de Carlos F, Levanti MB, Abbate F, Vega JA, Ciriaco E (2006) Epidermal growth factor (EGF) expression in lateral line system and in taste buds of adult zebrafish (Brachidanio rerio). Neurosci Lett 397:210-213.

Gorski JA, Zeiler SR, Tamowski S, Jones KR (2003) Brain-derived neurotrophic factor is required for the maintenance of cortical dendrites. The Journal of neuroscience : the official journal of the Society for Neuroscience 23:6856-6865.

Hill DL (2004) Neural plasticity in the gustatory system. Nutrition reviews 62:S208-217; discussion S224-241.

Hoon MA, Adler E, Lindemeier J, Battey JF, Ryba NJ, Zuker CS (1999) Putative mammalian taste receptors: a class of taste-specific GPCRs with distinct topographic selectivity. Cell 96:541-551.

Horch HW, Katz LC (2002) BDNF release from single cells elicits local dendritic growth in nearby neurons. Nature neuroscience 5:1177-1184.

Horch HW, Kruttgen A, Portbury SD, Katz LC (1999) Destabilization of cortical dendrites and spines by BDNF. Neuron 23:353-364.

Horio N, Yoshida R, Yasumatsu K, Yanagawa Y, Ishimaru Y, Matsunami H, Nino miya Y (2011) Sour taste responses in mice lacking PKD channels. PloS one 6:e20007.

Hoshino N, Vatterott P, Egwiekhor A, Rochlin MW (2010) Brain-derived neurotrophic factor attracts geniculate ganglion neurites during embryonic targeting. Developmental neuroscience 32:184-196.

Hu B, Nikolakopoulou AM, Cohen-Cory S (2005) BDNF stabilizes synapses and maintains the structural complexity of optic axons in vivo. Development 132:4285-4298.

Huang AL, Chen X, Hoon MA, Chandrashekar J, Guo W, Trankner D, Ryba NJ, Zuker CS (2006) The cells and logic for mammalian sour taste detection. Nature 442:934-938.

Huang EJ, Reichardt LF (2001) Neurotrophins: roles in neuronal development and function. Annual review of neuroscience 24:677-736.

Huang EJ, Reichardt LF (2003) Trk receptors: roles in neuronal signal transduction. Annual review of biochemistry 72:609-642.

Huang T, Stahler $F$ (2009) Effects of dietary $\mathrm{Na}$ + deprivation on epithelial $\mathrm{Na}+$ channel $(\mathrm{ENaC})$, BDNF, and TrkB mRNA expression in the rat tongue. BMC neuroscience 10:19.

Huang T, Krimm RF (2010) Developmental expression of Bdnf, Ntf4/5, and TrkB in the mouse peripheral taste system. Developmental dynamics : an official publication of the American Association of Anatomists 239:2637-2646.

Huang T, Krimm RF (2014) BDNF and NT4 play interchangeable roles in gustatory development. Developmental biology 386:308-320. 
Huang T, Ma L, Krimm RF (2015) Postnatal reduction of BDNF regulates the developmental remodeling of taste bud innervation. Dev Biol 405:225-236.

Huang YA, Maruya ma Y, Roper SD (2008a) Norepinephrine is coreleased with serotonin in mouse taste buds. The Journal of neuroscience : the official journal of the Society for Neuroscience 28:13088-13093.

Huang YA, Pereira E, Roper SD (2011) Acid stimulation (sour taste) elicits GABA and serotonin release from mouse taste cells. PloS one 6:e25471.

Huang YA, Maruyama Y, Stimac R, Roper SD (2008b) Presynaptic (Type III) cells in mouse taste buds sense sour (acid) taste. The Journal of physiology 586:2903-2912.

Huang YJ, Maruyama Y, Dvoryanchikov G, Pereira E, Chaudhari N, Roper SD (2007) The role of pannexin 1 hemichannels in ATP release and cell-cell communication in mouse taste buds. Proceedings of the National Academy of Sciences of the United States of America 104:6436-6441.

Ishida Y, Ugawa S, Ueda T, Yamada T, Shibata Y, Hondoh A, Inoue K, Yu Y, Shimada S (2009) $\mathrm{P} 2 \mathrm{X}(2)$ - and $\mathrm{P} 2 \mathrm{X}(3)$-positive fibers in fungiform papillae originate from the chorda tympani but not the trigeminal nerve in rats and mice. The Journal of comparative neurology 514:131-144.

Ishimaru Y, Ina da H, Kubota M, Zhuang H, Tominaga M, Matsunami H (2006) Transient receptor potential family members PKD1L3 and PKD2L1 form a candidate sour taste receptor. Proceedings of the National Academy of Sciences of the United States of America 103:12569-12574.

Islam O, Loo TX, Heese K (2009) Brain-derived neurotrophic factor (BDNF) has proliferative effects on neural stem cells through the truncated TRK-B receptor, MAP kinase, AKT, and STAT-3 signaling pathways. Current neurovascular research 6:42-53.

Jaworski J, Spangler S, Seeburg DP, Hoogenraad CC, Sheng M (2005) Control of dendritic arborization by the phosphoinositide-3'-kinase-Akt-mammalian target of rapamycin pathway. The Journal of neuroscience : the official journal of the Society for Neuroscience 25:11300-11312.

Jeanneteau F, Deinhardt K, Miyoshi G, Bennett AM, Chao MV (2010) The MAP kinase phosphatase MKP-1 regulates BDNF-induced axon branching. Nature neuroscience 13:1373-1379.

Johnson AW, Chen X, Crombag HS, Zhang C, Smith DR, Shokat KM, Gallagher M, Holland PC, Ginty DD (2008) The brain-derived neurotrophic factor receptor TrkB is critical for the acquisition but not expression of conditioned incentive value. The European journal of neuroscience 28:997-1002.

Kharebava G, Makonchuk D, Kalita KB, Zheng JJ, Hetman M (2008) Requirement of 3phosphoinositide-dependent protein kinase-1 for BDNF-mediated neuronal survival. The Journal of neuroscience : the official journal of the Society for Neuroscience 28:1140911420.

Kinnamon JC, Taylor BJ, Delay RJ, Roper SD (1985) Ultrastructure of mouse vallate taste buds. I. Taste cells and their associated synapses. The Journal of comparative neurology 235:4860.

Klein R, Parada LF, Coulier F, Barbacid M (1989) trkB, a novel tyrosine protein kinase receptor expressed during mouse neural development. The EMBO journal 8:3701-3709.

Klein R, Conway D, Parada LF, Barbacid M (1990) The trkB tyrosine protein kinase gene codes for a second neurogenic receptor that lacks the catalytic kinase domain. Cell 61:647-656.

Klein R, Nanduri V, Jing SA, Lamballe F, Tapley P, Bryant S, Cordon-Cardo C, Jones KR, Reichardt LF, Barbacid M (1991) The trkB tyrosine protein kinase is a receptor for brain-derived 
neurotrophic factor and neurotrophin-3. Cell 66:395-403.

Koudelka J, Horn JM, Vatanashevanopakorn C, Minichiello L (2014) Genetic dissection of TrkB activated signalling pathways required for specific aspects of the taste system. Neural development 9:21.

Kretz O, Barbry P, Bock R, Lindemann B (1999) Differential expression of RNA and protein of the three pore-forming subunits of the amiloride-sensitive epithelial sodium channel in taste buds of the rat. The journal of histochemistry and cytochemistry : official journal of the Histochemistry Society 47:51-64.

Krimm RF (2006) Mice lacking the p75 receptor fail to acquire a normal complement of taste buds and geniculate ganglion neurons by adulthood. The anatomical record Part A, Discoveries in molecular, cellular, and evolutionary biology 288:1294-1302.

Krimm RF (2007) Factors that regulate embryonic gustatory development. BMC neuroscience 8 Suppl 3:S4.

Krimm RF, Miller KK, Kitzman PH, Davis BM, Albers KM (2001) Epithelial overexpression of BDNF or NT4 disrupts targeting of taste neurons that innervate the anterior tongue. Developmental biology 232:508-521.

Krylova O, Herreros J, Cleverley KE, Ehler E, Henriquez JP, Hughes SM, Salinas PC (2002) WNT -3, expressed by motoneurons, regulates terminal arborization of neurotrophin-3responsive spinal sensory neurons. Neuron 35:1043-1056.

Kumar V, Zhang MX, Swank MW, Kunz J, Wu GY (2005) Regulation of dendritic morphogenesis by Ras-PI3K-Akt-mTOR and Ras-MAPK signaling pathways. The Journal of neuroscience : the official journal of the Society for Neuroscience 25:11288-11299.

Larson ED, Vandenbeuch A, Voigt A, Meyerhof W, Kinnamon SC, Finger TE (2015) The Role of 5HT3 Receptors in Signaling from Taste Buds to Nerves. The Journal of neuroscience : the official journal of the Society for Neuroscience 35:15984-15995.

Lazo OM, Gonzalez A, Ascano M, Kuruvilla R, Couve A, Bronfman FC (2013) BDNF regulates Rab11-mediated recycling endosome dynamics to induce dendritic branching. The Journal of neuroscience : the official journal of the Society for Neuroscience 33:61126122.

Lee KF, Bachman K, Landis S, Jaenisch R (1994) Dependence on p75 for innervation of some sympathetic targets. Science 263:1447-1449.

LeMaster AM, Krimm RF, Davis BM, Noel T, Forbes ME, Johnson JE, Albers KM (1999) Overexpression of brain-derived neurotrophic factor enhances sensory innervation and selectively increases neuron number. The Journal of neuroscience : the official journal of the Society for Neuroscience 19:5919-5931.

Li L, Rutlin M, Abraira VE, Cassidy C, Kus L, Gong S, Jankowski MP, Luo W, Heint z N, Koerber HR, Woodbury CJ, Ginty DD (2011) The functional organization of cutaneous low-threshold mechanosensory neurons. Cell 147:1615-1627.

Li X, Staszewski L, Xu H, Durick K, Zoller M, Adler E (2002) Human receptors for sweet and umami taste. Proceedings of the National Academy of Sciences of the United States of America 99:4692-4696.

Liepinsh E, llag LL, Otting G, Ibanez CF (1997) NMR structure of the death domain of the p75 neurotrophin receptor. The EMBO journal 16:4999-5005.

Liu X, Grishanin RN, Tolwani RJ, Renteria RC, Xu B, Reichardt LF, Copenhagen DR (2007) Brainderived neurotrophic factor and TrkB modulate visual experience-dependent refinement of neuronal pathways in retina. The Journal of neuroscience : the official journal of the Society for Neuroscience 27:7256-7267.

Liu Y, Rutlin M, Huang S, Barrick CA, Wang F, Jones KR, Tessarollo L, Ginty DD (2012) Sexually 
dimorphic BDNF signaling directs sensory innervation of the mammary gland. Science 338:1357-1360.

Livak KJ, Schmittgen TD (2001) Analysis of relative gene expression data using real-time quantitative PCR and the 2(-Delta Delta C(T)) Method. Methods 25:402-408.

Lom B, Cohen-Cory S (1999) Brain-derived neurotrophic factor differentially regulates retinal ganglion cell dendritic and axonal arborization in vivo. The Journal of neuroscience : the official journal of the Society for Neuroscience 19:9928-9938.

Lopez GF, Krimm RF (2006a) Refinement of innervation accuracy following initial targeting of peripheral gustatory fibers. Journal of neurobiology 66:1033-1043.

Lopez GF, Krimm RF (2006b) Epithelial overexpression of BDNF and NT4 produces distinct gustatory axon morphologies that disrupt initial targeting. Developmental biology 292:457-468.

Luberg K, Wong J, Weickert CS, Timmusk T (2010) Human TrkB gene: novel alternative transcripts, protein isoforms and expression pattern in the prefrontal cerebral cortex during postnatal development. Journal of neurochemistry 113:952-964.

Ma L, Tessier-Lavigne M (2007) Dual branch-promoting and branch-repelling actions of Slit/Robo signaling on peripheral and central branches of developing sensory axons. The Journal of neuroscience : the official journal of the Society for Neuroscience 27:6843-6851.

Ma L, Lopez GF, Krimm RF (2009) Epithelial-derived brain-derived neurotrophic factor is required for gustatory neuron targeting during a critical developmental period. The Journal of neuroscience : the official journal of the Society for Neuroscience 29:3354-3364.

Ma Z, Saung WT, Foskett JK (2017) Action Potentials and Ion Conductances in Wild-type and CALHM1-knockout Type II Taste Cells. Journal of neurophysiology:jn 0083502016.

MacColl G, Bouloux P, Quinton R (2002) Kallmann syndrome: adhesion, afferents, and anosmia. Neuron 34:675-678.

Martinez A, Alcantara S, Borrell V, Del Rio JA, Blasi J, Otal R, Campos N, Boronat A, Barbacid M, Silos-Santiago I, Soriano E (1998) TrkB and TrkC signaling are required for maturation and synaptogenesis of hippocampal connections. The Journal of neuroscience : the official journal of the Society for Neuroscience 18:7336-7350.

Matsumoto I, Emori Y, Ninomiya Y, Abe K (2001) A comparative study of three cranial sensory ganglia projecting into the oral cavity: in situ hybridization analyses of neurotrophin receptors and thermosensitive cation channels. Brain research Molecular brain research 93:105-112.

Mbiene JP, Mistretta CM (1997) Initial innervation of embryonic rat tongue and developing taste papillae: nerves follow distinctive and spatially restricted pathways. Acta anatomica 160:139-158.

McAllister AK, Lo DC, Katz LC (1995) Neurotrophins regulate dendritic growth in developing visual cortex. Neuron 15:791-803.

McCarty JH, Feinstein SC (1998) Activation loop tyrosines contribute varying roles to TrkB autophosphorylation and signal transduction. Oncogene 16:1691-1700.

McGraw CM, Samaco RC, Zoghbi HY (2011) Adult neural function requires MeCP2. Science 333:186.

McLaughlin SK (2000) Erb and c-Kit receptors have distinctive patterns of expression in adult and developing taste papillae and taste buds. J Neurosci 20:5679-5688.

Medler KF, Margolskee RF, Kinnamon SC (2003) Electrophysiological characterization of voltage gated currents in defined taste cell types of mice. The Journal of neuroscience : the official journal of the Society for Neuroscience 23:2608-2617.

Meng L, Ohman-Gault L, Ma L, Krimm RF (2015) Taste Bud-Derived BDNF Is Required to Maintain 
Normal Amounts of Innervation to Adult Taste Buds. eNeuro 2.

Middlemas DS, Lindberg RA, Hunter T (1991) trkB, a neural receptor protein-tyrosine kinase: evidence for a full-length and two truncated receptors. Molecular and cellular biology 11:143-153.

Minichiello L (2009) TrkB signalling pathways in LTP and learning. Nature reviews Neuroscience 10:850-860.

Mistretta CM, Goosens KA, Farinas I, Reichardt LF (1999) Alterations in size, number, and morphology of gustatory papillae and taste buds in BDNF null mutant mice demonstrate neural dependence of developing taste organs. The Journal of comparative neurology 409:13-24.

Miyoshi MA, Abe K, Emori Y (2001) IP(3) receptor type 3 and PLCbeta2 are co-expressed with taste receptors T1R and T2R in rat taste bud cells. Chem Senses 26:259-265.

Murata Y, Yasuo T, Yoshida R, Obata K, Yanagawa Y, Margolskee RF, Ninomiya Y (2010) Action potential-enhanced ATP release from taste cells through hemichannels. Journal of neurophysiology 104:896-901.

Murray RG (1993) Cellular relations in mouse circumvallate taste buds. Microscopy research and technique 26:209-224.

Murray RG, Murray A (1967) Fine structure of taste buds of rabbit foliate papillae. Journal of ultrastructure research 19:327-353.

Murray RG, Murray A, Fujimoto S (1969) Fine structure of gustatory cells in rabbit taste buds. Journal of ultrastructure research 27:444-461.

Nagahama S, Kurihara K (1985) Norepinephrine as a possible transmitter involved in synaptic transmission in frog taste organs and $\mathrm{Ca}$ dependence of its release. The Journal of general physiology 85:431-442.

Nagai T, Delay RJ, Welton J, Roper SD (1998) Uptake and release of neurotrans mitter candidates, $[3 \mathrm{H}]$ serotonin, $[3 \mathrm{H}]$ glutamate, and [3H]gamma-aminobutyric acid, in taste buds of the mudpuppy, Necturus maculosus. The Journal of comparative neurology 392:199-208.

Nelson GM, Finger TE (1993) Immunolocalization of different forms of neural cell adhesion molecule (NCAM) in rat taste buds. The Journal of comparative neurology 336:507-516.

Nguyen N, Lee SB, Lee YS, Lee KH, Ahn JY (2009) Neuroprotection by NGF and BDNF against neurotoxin-exerted apoptotic death in neural stem cells are mediated through Trk receptors, activating PI3-kinase and MAPK pathways. Neurochemical research 34:942951.

Niblock MM, Brunso-Bechtold JK, Riddle DR (2000) Insulin-like growth factor I stimulates dendritic growth in primary somatosensory cortex. The Journal of neuroscience : the official journal of the Society for Neuroscience 20:4165-4176.

Nosrat CA, Olson L (1995) Brain-derived neurotrophic factor mRNA is expressed in the developing taste bud-bearing tongue papillae of rat. The Journal of comparative neurology 360:698-704.

Nosrat CA, Ebendal T, Olson L (1996) Differential expression of brain-derived neurotrophic factor and neurotrophin 3 mRNA in lingual papillae and taste buds indicates roles in gustatory and somatosensory innervation. The Journal of comparative neurology 376:587-602.

Nosrat CA, Blomlof J, ElShamy WM, Ernfors P, Olson L (1997) Lingual deficits in BDNF and NT3 mutant mice leading to gustatory and somatosensory disturbances, respectively. Development 124:1333-1342.

Nosrat IV, Margolskee RF, Nosrat CA (2012) Targeted taste cell-specific overexpression of brainderived neurotrophic factor in adult taste buds elevates phosphorylated TrkB protein levels in taste cells, increases taste bud size, and promotes gustatory innervation. J Biol 
Chem 287:16791-16800.

Numakawa T, Suzuki S, Kumamaru E, Adachi N, Richards M, Kunugi H (2010) BDNF function and intracellular signaling in neurons. Histology and histopathology 25:237-258.

Ohira K, Homma KJ, Hirai H, Nakamura S, Hayashi M (2006) TrkB-T1 regulates the RhoA signaling and actin cytoskeleton in glioma cells. Biochemical and biophysical research communications 342:867-874.

Ohira K, Kumanogoh H, Sahara Y, Homma KJ, Hirai H, Nakamura S, Hayashi M (2005) A truncated tropomyosin-related kinase $B$ receptor, $T 1$, regulates glial cell morphology via Rho GDP dissociation inhibitor 1 . The Journal of neuroscience : the official journal of the Society for Neuroscience 25:1343-1353.

Okubo T, Clark C, Hogan BL (2009) Cell lineage mapping of taste bud cells and keratinocytes in the mouse tongue and soft palate. Stem cells 27:442-450.

Ozdinler PH, Macklis JD (2006) IGF-I specifically enhances axon outgrowth of corticospinal motor neurons. Nature neuroscience 9:1371-1381.

Park KJ, Grosso CA, Aubert I, Kaplan DR, Miller FD (2010) p75NTR-dependent, myelin-mediated axonal degeneration regulates neural connectivity in the adult brain. Nature neuroscience 13:559-566.

Patel AV, Krimm RF (2010) BDNF is required for the survival of differentiated geniculate ganglion neurons. Developmental biology 340:419-429.

Patel AV, Krimm RF (2012) Neurotrophin-4 regulates the survival of gustatory neurons earlier in development using a different mechanism than brain-derived neurotrophic factor. Developmental biology 365:50-60.

Patel AV, Huang T, Krimm RF (2010) Lingual and palatal gustatory afferents each depend on both BDNF and NT-4, but the dependence is greater for lingual than palatal afferents. The Journal of comparative neurology 518:3290-3301.

Perea-Martinez I, Nagai T, Chaudhari N (2013) Functional cell types in taste buds have distinct longevities. PLoS One 8:e53399.

Pumplin DW, Yu C, Smith DV (1997) Light and dark cells of rat vallate taste buds are morphologically distinct cell types. The Journal of comparative neurology 378:389-410.

Righi M, Tongiorgi E, Cattaneo A (2000) Brain-derived neurotrophic factor (BDNF) induces dendritic targeting of BDNF and tyrosine kinase $B$ mRNAs in hippocampal neurons through a phosphatidylinositol-3 kinase-dependent pathway. The Journal of neuroscience : the official journal of the Society for Neuroscience 20:3165-3174.

Ringstedt T, Ibanez CF, Nosrat CA (1999) Role of brain-derived neurotrophic factor in target invasion in the gustatory system. The Journal of neuroscience : the official journal of the Society for Neuroscience 19:3507-3518.

Rose CR, Blum R, Pichler B, Lepier A, Kafitz KW, Konnerth A (2003) Truncated TrkB-T1 mediates neurotrophin-evoked calcium signalling in glia cells. Nature 426:74-78.

Ruzankina Y, Pinzon-Guzman C, Asare A, Ong T, Pontano L, Cotsarelis G, Zediak VP, Velez M, Bhandoola A, Brown EJ (2007) Deletion of the developmentally essential gene ATR in adult mice leads to age-related phenotypes and stem cell loss. Cell stem cell 1:113-126.

Shigemura N, Iwata S, Yasumatsu K, Ohkuri T, Horio N, Sanematsu K, Yoshida R, Margolskee RF, Ninomiya $Y$ (2013) Angiotensin II modulates salty and sweet taste sensitivities. The Journal of neuroscience : the official journal of the Society for Neuroscience 33:62676277.

Singh KK, Park KJ, Hong EJ, Kramer BM, Greenberg ME, Kaplan DR, Miller FD (2008) Developmental axon pruning mediated by BDNF-p75NTR-dependent axon degeneration. Nature neuroscience 11:649-658. 
Sollars SI (2005) Chorda tympani nerve transection at different developmental ages produces differential effects on taste bud volume and papillae morphology in the rat. Journal of neurobiology 64:310-320.

Sollars SI, Bernstein IL (2000) Neonatal chorda tympani transection permanently disrupts fungiform taste bud and papilla structure in the rat. Physiology \& behavior 69:439-444.

Sommerfeld MT, Schweigreiter R, Barde YA, Hoppe E (2000) Down-regulation of the neurotrophin receptor TrkB following ligand binding. Evidence for an involvement of the proteasome and differential regulation of TrkA and TrkB. The Journal of biological chemistry 275:8982-8990.

Starostik MR, Rebello MR, Cotter KA, Kulik A, Medler KF (2010) Expression of GABAergic receptors in mouse taste receptor cells. PloS one 5:e13639.

Steinbeck JA, Methner A (2005) Translational downregulation of the noncatalytic growth factor receptor TrkB.T1 by ischemic preconditioning of primary neurons. Gene expression 12:99-106.

Stoilov P, Castren E, Stamm S (2002) Analysis of the human TrkB gene genomic organization reveals novel TrkB isoforms, unusual gene length, and splicing mechanism. Biochemical and biophysical research communications 290:1054-1065.

Suzuki Y, Mizoguchi I, Uchida N (2007) Detection of neurotrophic factors in taste buds by laser capture microdissection, immunohistochemistry, and in situ hybridization. Archives of histology and cytology 70:117-126.

Suzuki Y, Takeda M, Sakakura Y, Suzuki N (2005) Distinct expression pattern of insulin-like growth factor family in rodent taste buds. J Comp Neurol 482:74-84.

Takeda M (1976) An electron microscopic study on the innervation in the taste buds of the mouse circumvallate papillae. Archivum histologicum Japonicum $=$ Nihon soshikigaku kiroku 39:257-269.

Takeda M, Hoshino T (1975) Fine structure of taste buds in the rat. Archivum histologicum Japonicum = Nihon soshikigaku kiroku 37:395-413.

Takeda M, Suzuki Y, Obara N, Tsunekawa H (2005) Immunohistochemical detection of neurotrophin-3 and -4 , and their receptors in mouse taste bud cells. Arch Histol Cytol 68:393-403.

Takeda M, Suzuki Y, Obara N, Uchida N, Kawakoshi K (2004) Expression of GDNF and GFR alpha 1 in mouse taste bud cells. The Journal of comparative neurology 479:94-102.

Takei N, Kawamura M, Hara K, Yonezawa K, Nawa H (2001) Brain-derived neurotrophic factor enhances neuronal translation by activating multiple initiation processes: comparison with the effects of insulin. The Journal of biological chemistry 276:42818-42825.

Takemoto-Kimura S, Ageta-Ishihara N, Nonaka M, Adachi-Morishima A, Mano T, Okamura M, Fujii H, Fuse T, Hoshino M, Suzuki S, Kojima M, Mishina M, Okuno H, Bito H (2007) Regulation of dendritogenesis via a lipid-raft-associated $\mathrm{Ca} 2+$ /calmodulin-dependent protein kinase CLICK-III/CaMKIgamma. Neuron 54:755-770.

Taruno A, Matsumoto I, Ma Z, Marambaud P, Foskett JK (2013a) How do taste cells lacking synapses mediate neurotransmission? CALHM1, a voltage-gated ATP channel. BioEssays : news and reviews in molecular, cellular and developmental biology 35:1111-1118.

Taruno A, Vingtdeux V, Ohmoto M, Ma Z, Dvoryanchikov G, Li A, Adrien L, Zhao H, Leung S, Abernethy M, Koppel J, Davies P, Civan MM, Chaudhari N, Matsumoto I, Hellekant G, Tordoff MG, Marambaud P, Foskett JK (2013b) CALHM1 ion channel mediates purinergic neurotransmission of sweet, bitter and umami tastes. Nature 495:223-226.

Vasioukhin V, Degenstein L, Wise B, Fuchs E (1999) The magical touch: genome targeting in epidermal stem cells induced by tamoxifen application to mouse skin. Proceedings of the 
National Academy of Sciences of the United States of America 96:8551-8556.

Vilbig R, Cosmano J, Giger R, Rochlin MW (2004) Distinct roles for Sema3A, Sema3F, and an unidentified trophic factor in controlling the advance of geniculate axons to gustatory lingual epithelium. Journal of neurocytology 33:591-606.

Walsh GS, Krol KM, Crutcher KA, Kawaja MD (1999) Enhanced neurotrophin-induced axon growth in myelinated portions of the CNS in mice lacking the p75 neurotrophin receptor. The Journal of neuroscience : the official journal of the Society for Neuroscience 19:4155-4168.

Wang L, Chang X, She L, Xu D, Huang W, Poo MM (2015) Autocrine action of BDNF on dendrite development of adult-born hippocampal neurons. The Journal of neuroscience : the official journal of the Society for Neuroscience 35:8384-8393.

Waterhouse EG, Xu B (2009) New insights into the role of brain-derived neurotrophic factor in synaptic plasticity. Molecular and cellular neurosciences 42:81-89.

Xu B, Zang K, Ruff NL, Zhang YA, McConnell SK, Stryker MP, Reichardt LF (2000) Cortical degeneration in the absence of neurotrophin signaling: dendritic retraction and neuronal loss after removal of the receptor TrkB. Neuron 26:233-245.

Yacoubian TA, Lo DC (2000) Truncated and full-length TrkB receptors regulate distinct modes of dendritic growth. Nature neuroscience 3:342-349.

Yamashita T, Tucker KL, Barde YA (1999) Neurotrophin binding to the p75 receptor modulates Rho activity and axonal outgrowth. Neuron 24:585-593.

Yamout A, Spec A, Cosmano J, Kashyap M, Rochlin MW (2005) Neurotrophic factor receptor expression and in vitro nerve growth of geniculate ganglion neurons that supply divergent nerves. Developmental neuroscience 27:288-298.

Yan Y, Eipper BA, Mains RE (2016) Kalirin is required for BDNF-TrkB stimulated neurite outgrowth and branching. Neuropharmacology 107:227-238.

Yang R, Crowley HH, Rock ME, Kinnamon JC (2000) Taste cells with synapses in rat circumvallate papillae display SNAP-25-like immunoreactivity. The Journal of comparative neurology 424:205-215.

Yates PA, Roskies AL, McLaughlin T, O'Leary DD (2001) Topographic-specific axon branching controlled by ephrin-As is the critical event in retinotectal map development. The Journal of neuroscience : the official journal of the Society for Neuroscience 21:85488563.

Yee C, Bartel DL, Finger TE (2005) Effects of glossopharyngeal nerve section on the expression of neurotrophins and their receptors in lingual taste buds of adult mice. J Comp Neurol 490:371-390.

Yee CL, Jones KR, Finger TE (2003) Brain-derived neurotrophic factor is present in adult mouse taste cells with synapses. J Comp Neurol 459:15-24.

Yee CL, Yang R, Bottger B, Finger TE, Kinnamon JC (2001) "Type III" cells of rat taste buds: immunohistochemical and ultrastructural studies of neuron-specific enolase, protein gene product 9.5, and serotonin. The Journal of comparative neurology 440:97-108.

Yoshimura T, Kawano Y, Arimura N, Kawabata S, Kikuchi A, Kaibuchi K (2005) GSK-3beta regulates phosphorylation of CRMP-2 and neuronal polarity. Cell 120:137-149.

Zhang C, Brandemihl A, Lau D, Lawton A, Oakley B (1997) BDNF is required for the normal development of taste neurons in vivo. Neuroreport 8:1013-1017.

Zhang Y, Hoon MA, Chandrashekar J, Mueller KL, Cook B, Wu D, Zuker CS, Ryba NJ (2003) Coding of sweet, bitter, and umami tastes: different receptor cells sharing similar signaling pathways. Cell 112:293-301.

Zhao GQ, Zhang Y, Hoon MA, Chandrashekar J, Erlenbach I, Ryba NJ, Zuker CS (2003) The 
receptors for mammalian sweet and umami taste. Cell 115:255-266. 


\author{
CURRICULUM VITAE \\ Tao Tang \\ Department of Anatomy and Neurobiology \\ School of Medicine, University of Louisville \\ Louisville, KY40202
}

\title{
EDUCATION BACKGROUND
}

Aug. 2014 - Current: University of Louisville, Louisville, KY. Ph.D candidate

Aug. 2011 - Aug. 2014: University of Louisville, Louisville, KY. M.S.

Sep. 2006 - Jul. 2010: East China University of Technology, B.M.

Research Experience:

Jan. 2012-present Graduate student in Dr Robin Krimm's lab, Department of ASNB, University of Louisville

Aug. 2011-Jan. 2012 Graduate student in Dr Niger Cooper's lab, Department of ASNB, University of Louisville

PUBLICATIONS:

Biggs B.T, Tang T, Krimm R.F. (2016). Insulin-Like Growth Factors Are Expressed in the Taste System, but Do Not Maintain Adult Taste Buds. PLoS One. 2016 Feb 22;11(2).

CONFERENCE PRESENTATIONS

Tao Tang and Robin F Krimm. The Full Length TrkB Receptor is Expressed in Gustatory Neurons, while Taste Buds Only Express the Truncated (TrkBT1) Re 
ceptor. Poster presentation delivered at the Association of Chemoreception Sciences Meeting, Bonita Springs, Florida, April 2015

Tao Tang and Robin F Krimm. Blocking TrkB-signaling decreases branches with the taste bud within two weeks. Poster presentation delivered at the Association of Chemoreception Sciences Meeting, Bonita Springs, Florida, April 2016 